\title{
Utilização de Redes de Petri para Avaliação de
} Sistemas Computacionais

\author{
Silmara Aparecida Nonato
}

USP - São Carlos

Janeiro de 1999 


\title{
Utilização de Redes de Petri para Avaliação de Sistemas Computacionais
}

\section{Silmara Aparecida Nonato}

\author{
Orientação: \\ Prof $^{\text {a. Dra }}$. Regina Helena Carlucci Santana
}

Dissertação apresentada ao Instituto de Ciências Matemáticas e de Computação - USP, como parte dos requisitos para a obtenção do título de Mestre em Ciências - Área de Ciências de Computação e Matemática Computacional.

USP- São Carlos

Janeiro de 1999 
"Quando você elimina o impossível, o que sobra por mais incrivel que pareça só pode ser a verdade." (Arthur Conan Doyle ) 


\section{Dedicatória}

Aos meus pais, por fazer parte não só de um sonho meu, mas também deles. 


\section{AGREDECIMENTOS}

Agradeço a Deus por me proporcionar tudo o que tenho e sou.

Ao meus pais Maria e Antonio pelo apoio, incentivo, amor e por tudo aquilo que os pais fazem por seus filhos e com certeza eles fizeram por mim.

Aos meus irmão Karla e Fábio, aos meus cunhados Luismar e Vanessa, a pequena Bruna pela compreensão e carinho.

À Prof. Regina e ao Prof. Marcos pela orientação, paciência e por tudo aquilo que eles me ensinaram.

Ao pessoal do LaSDPC: Célia, Sarita, Aletéia, Adriana, Karlinka, Márcio, Renato, Regiane, Rita, Flávio, Helder, Renata, Roberta pela amizade, esclarecimento de algumas dúvidas, e auxílio nos trabalhos.

Ao meus amigos: Paulo, Simone, Felipe, Ana Elisa, Sandra, Luciano, Rudinei, Garga, Fabiano, Jaque, Marcia, Karina, Juliana, Alessandra, Ernesto, Luis Carlos, Cris, pela grande amizade, momentos de alegria e descontração além é claro das festas e viagens agradáveis.

Às minhas grandes amigas Andréia e Mirla por me ajudarem nos momentos mais difíceis.

Aos meus alunos pelos questionamentos que ajudaram a enriquecer o meu conhecimento.

A todos que contribuíram direta e indiretamente para a realização desse trabalho.

Ao CNPq pelo apoio financeiro. 


\section{RESUMO}

Este trabalho apresenta um estudo sobre as modificações necessárias no ASiA (Ambiente de Simulação Automático) para viabilizar a utilização de Redes de Petri para a representação de modelos. Esse estudo inicia-se com uma comparação entre Redes de Filas e Redes de Petri. utilizadas como técnicas para modelagem de sistemas computacionais, visando a avaliação desses sistemas através de simulação. O estudo da viabilidade analisa diversos aspectos tais como: possibilidade de utilização da linguagem SMPL; avaliação das modificações necessárias no Editor Gráfico; alterações necessárias no Gerador de Aplicações e no Gabarito utilizado pelo ASiA. 


\section{ABSTRACT}

This work presents a study in respect to the modifications required in ASiA (Automatic Simulation Environment) to make possible the utilization of Petri Nets in models representation. The first step of this study is a comparison between Queue Nets and Petri Nets, when they are used as a techinique for computer system modeling, aiming the avaluation okf these systems using simulation. The viability study considers differents aspects, such as: the usage of SMPL in the simulation of systems represeted through Petri Nets; evaluation of the changes in the ASiA Graphic Editor, Aplication Generator and in the stencil used for the ASiA. 


\section{SUMÁRIO}

1. INTRODUÇÃo

2. MODELAGEM E SIMULAÇÃO............................................................................. 5

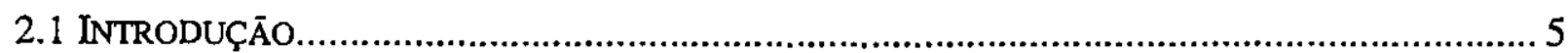

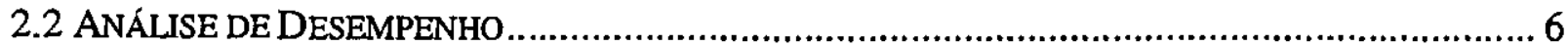

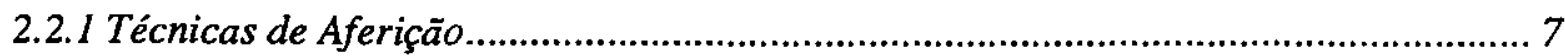

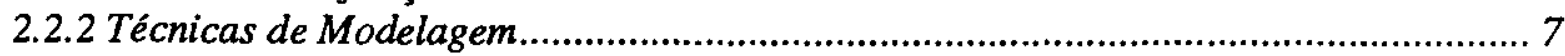

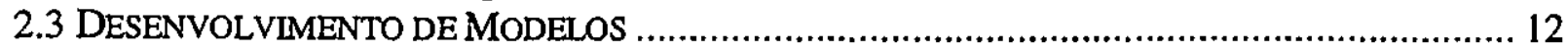

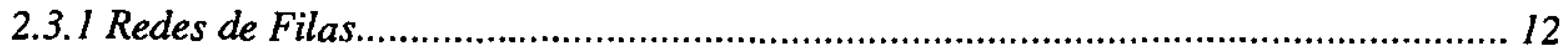

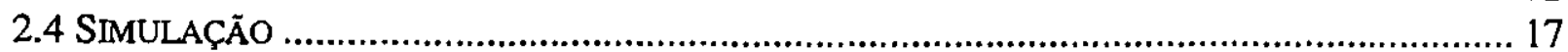

2.4.1 Simulação Orientada a Evento...................................................................... 18

2.4.2 Simulação Orientada a Processo …………...................................................... 19

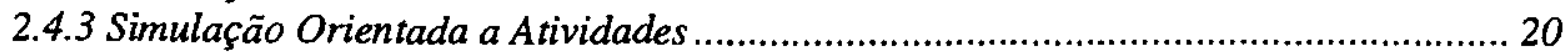

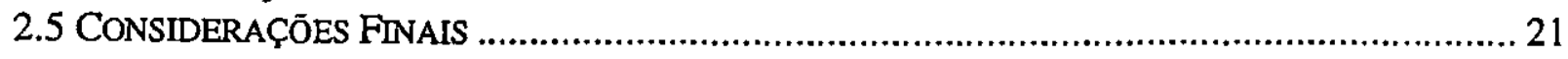

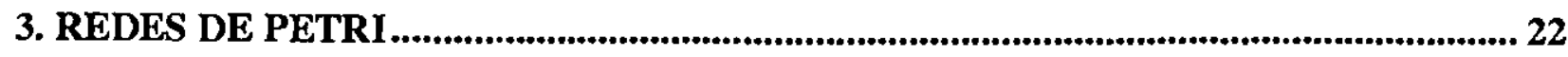

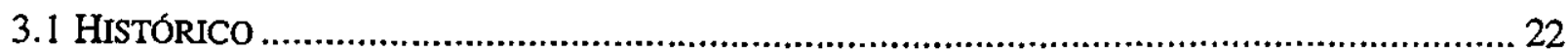

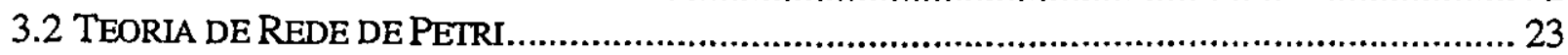

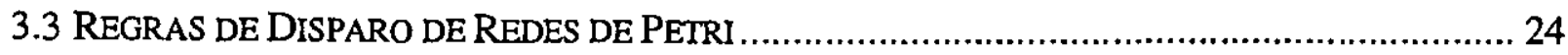

3.4 MODELOS BÁSICOS DE REDES DE PETRI ……………................................................ 25

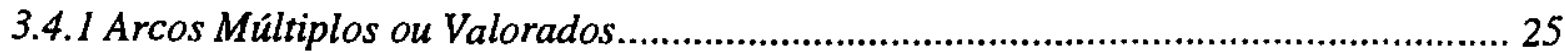

3.4.2 Escolha Não-Deterministica ....................................................................... 27

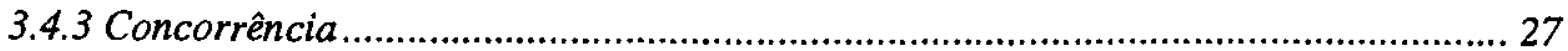

3.4.4 Conflito Estrutural - Conflito Efetivo …………................................................. 28

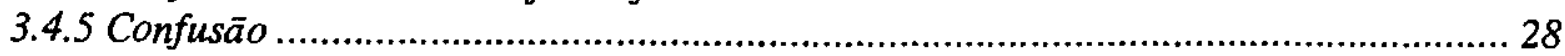

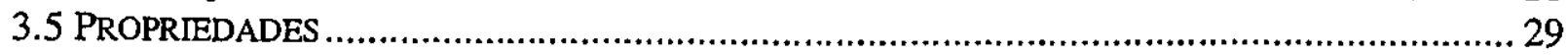

3.5.I Propriedades Comportamentais ........................................................................ 29

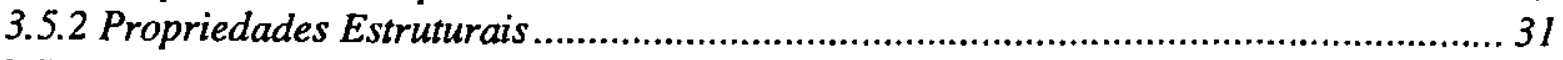

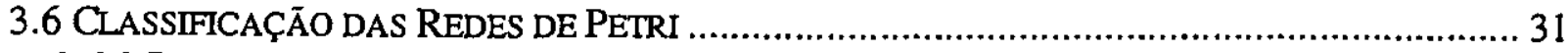

3.6.1 Redes de Petri Binária ou Condição-Evento .................................................... 32

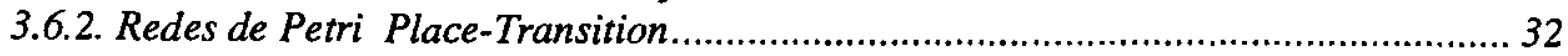

3.6.3 Redes de Petri com Arco Inibidor ......................................................................... 33

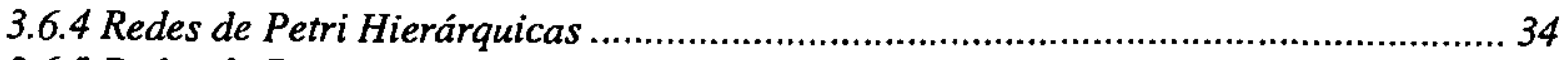

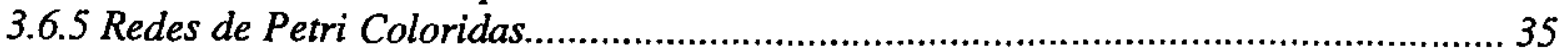

3.6.6 Redes de Petri Temporizada Deterministica........................................................... 37

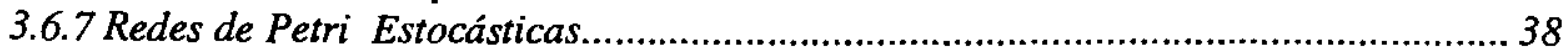

3.6.8 Redes de Petri com Objetos............................................................................... 38

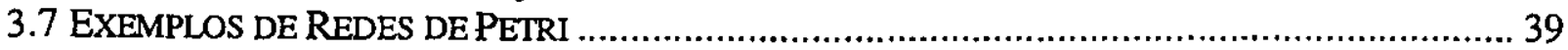

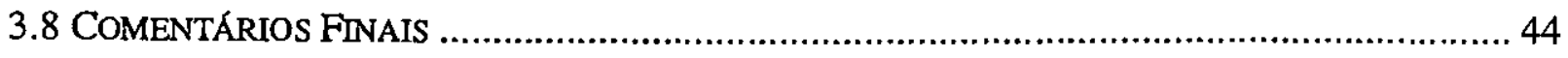

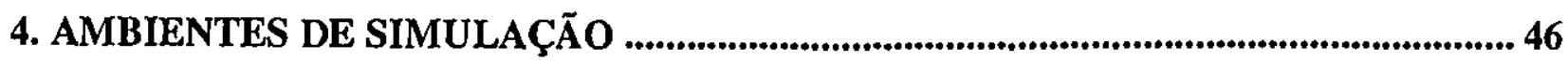

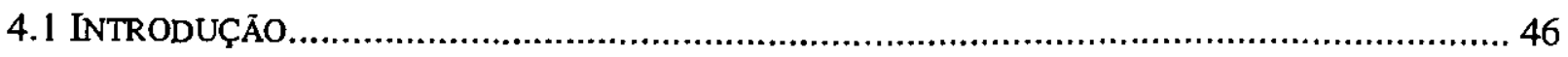

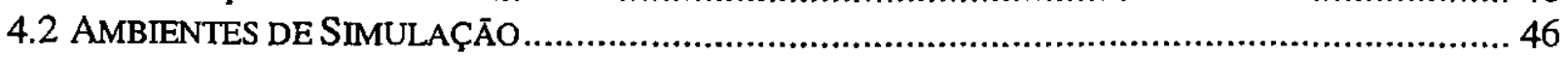

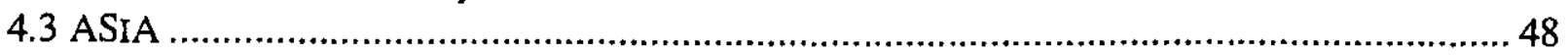




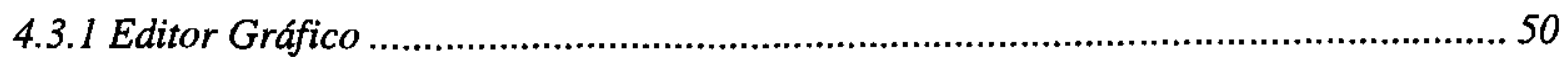

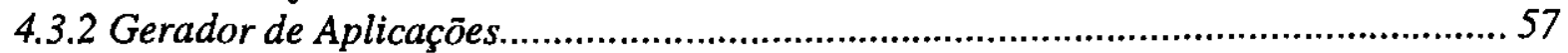

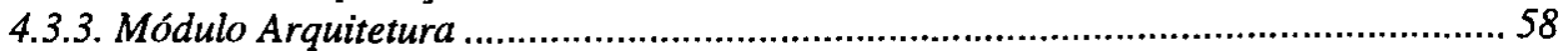

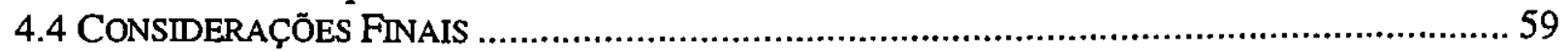

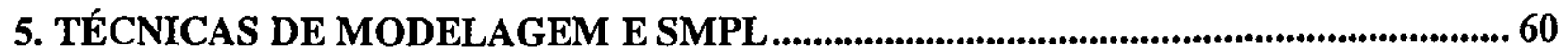

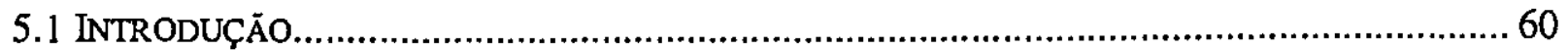

5.2 EXEMPLOS DE SISTEMAS MODELADOS EM REDES DE PETRI......................................... 61

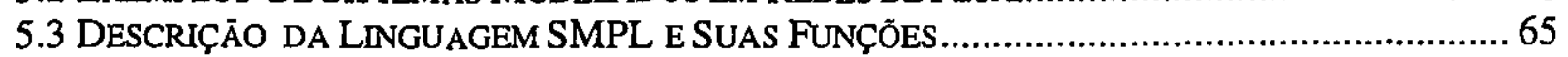

5.4 RELAÇÃO ENTRE REDES DE FILAS, REDES DE PETRI E SMPL ....................................6 67

5.5 DEFINIÇÃO IMPLEMENTAÇÃO DAS ESTRUTURAS BÁSICAS DAS REDES DE PETRI EM SMPL 69

5.6 INICIALUZAÇÕES DO SMPL E SUAS FACILITIES ..................................................... 78

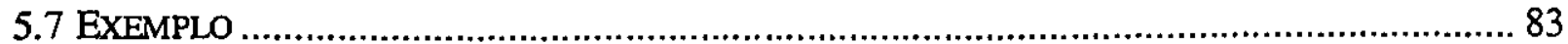

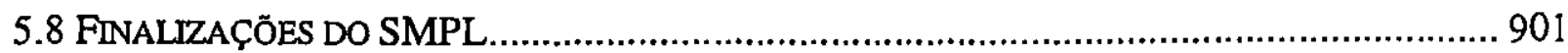

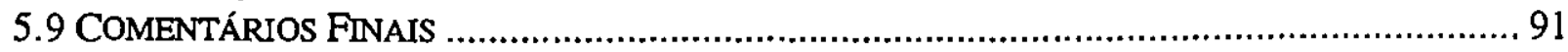

6. ALTERAÇŌES NECESSÁRIAS NO ASIA.......................................................... 923

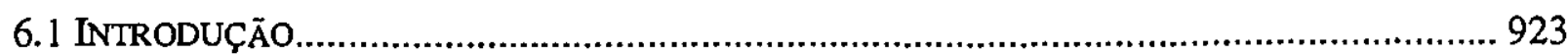

6.2 ALTERAÇŌES NA INTERFACE GRÁFICA DO EDITOR GRÁFICO..................................... 923

6.2.1 Criação de Novos Ícones na Barra de Ferramentas ............................................. 934

6.2.2 Alterações na Barra de Menus............................................................................ 967

6.2.3 Alterações na Barra de Ferramenta Horizontal .................................................... 978

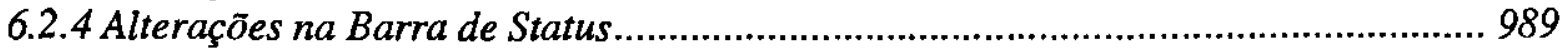

6.2.5 Alteração nas Caixas de Dialogo..................................................................... 989

6.3 ALTERAÇÕES NOS ARQUIVOS DE INFORMAÇÕES PARA O GERADOR DE APLICAÇŌES. .......1012

6.4 ALTERAÇÕES NO GERADOR DE APLICAÇÕES ........................................................1023

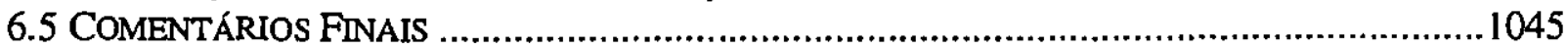

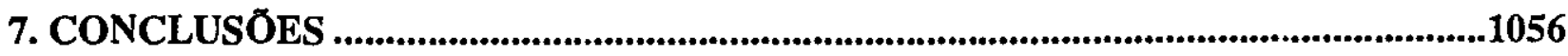

7.1 COMENTÁRIOS FINAIS SOBRE A REVISÃo BIBLIOGRÁFICA ......................................... 1056

7.2 COMENTÁRIOS FINAIS SOBRE O TRABALHO DESENVOLVIDO.................................... 1067

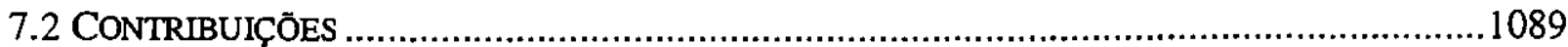

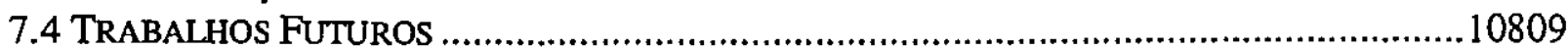

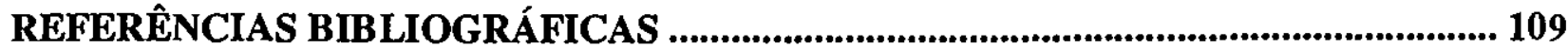




\section{ÍNDICE DE FIGURAS}

FIGURA 2.1: PROCESSO DE MODELAGEM E SIMULAÇÃO.....................................................

FIGURA 2.2: ClASSIFICAÇÃo DOS MODELOS DE REDES DE FILAS........................................13

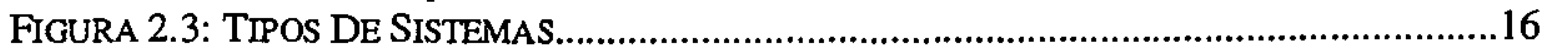

FigURA 2.4: ESTRUTURA Do PROGRAMA DE SIMULAÇĀO ORIENTADO A EVENTOS.............19

Figura 2.5: Estrutura Do Programa DE SimulaÇāo OrIENTADo A Processos..........20

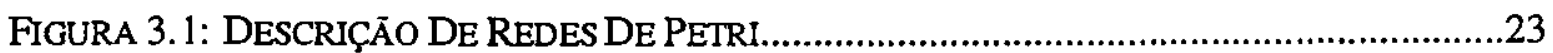

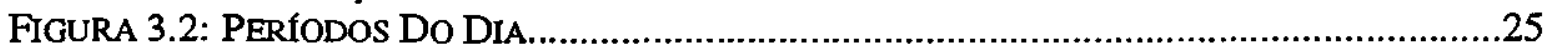

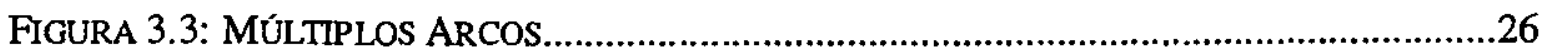

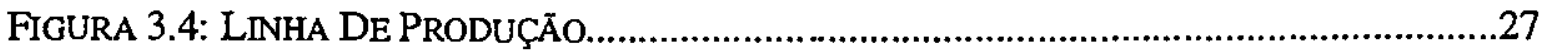

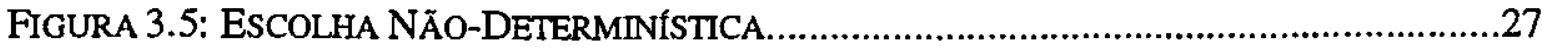

FIGURA 3.6: CONFLITO ESTRUTURALE EFETIVO............................................................28

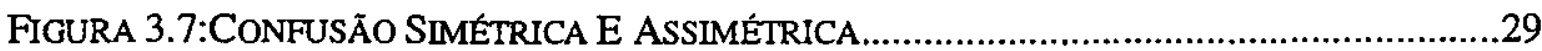

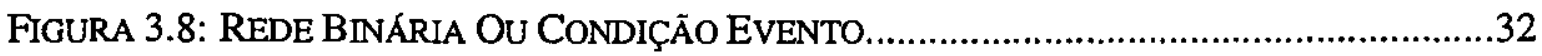

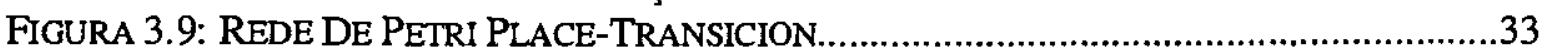

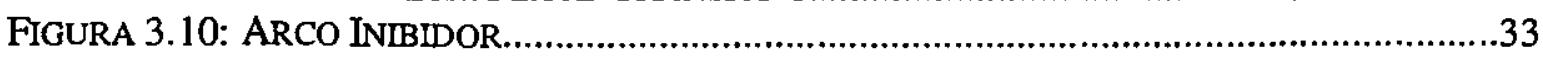

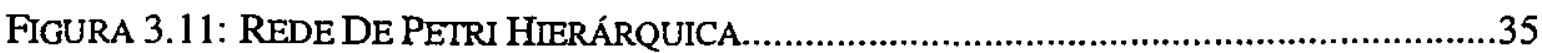

FIGURA 3.12: REDE DE PETRI COLORIDA...................................................................36

FIGURA 3.13: MARCAÇÃO HABILITANDO DUAS TRANSIÇÃO...............................................38

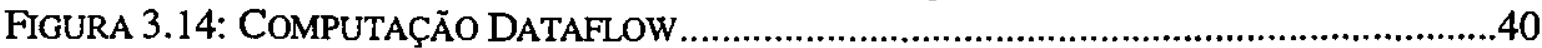

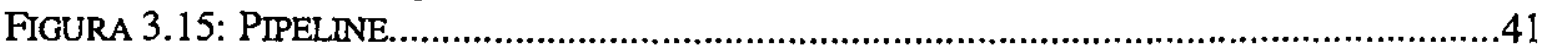

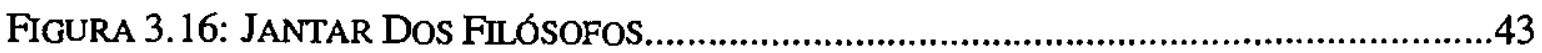

FIGURA 3.17: JANTAR DO FLLÓSOFOS-MODELO COM REDES COLORIDAS..............................44

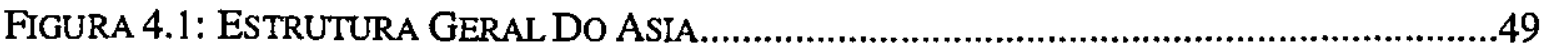

FIGURA 3.2: TELA PRINCIPAL Do ASIA......................................................................50

Figura 3.3: CaIXA De Dialogo Para A ParametrizaÇão Do ReCURSO.........................51

Figura 3.4: CaIXa De Dialogo Para A ParametrizaÇão Da Chegada Do Recurso. 54

Figura 3.5: Caixa De dialogo Para A Parametrizaçāo Do Tempo De Serviço........55

FIGURA 3.6: CAIXA DE DIALOGO PARA A PARAMETRIZAÇÃO...........................................56

Figura 3.7: CAIXA DE Dialogo Para A PaRAMETRIZAÇĀo Do Modelo............................57

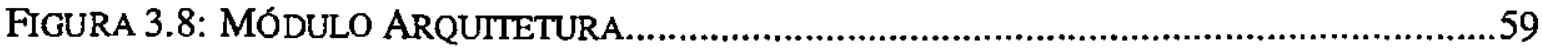

FIGURA 5.1: MODELO Do SERVIDOR CENTRAL REPRESENTAdo PoR REDE DE FILA............61 FIGURA 5.2: MODELO DE COMPUTAÇÃo SiMPLES REPRESENTADO POR REDE DE PETRI.....62 FIGURA 5.3: FluXDO DE COMPUTAÇÃO SIMPLES REPRESENTADO POR REDE DE FILA.........62 FIgURA 5.4: FluXDO DE COMPUTAÇĀo SimPLES REPRESENTADO POR REDE DE PETRI......63 FIGURA 5.5: SIMULAÇÃO DO BANCO.........................................................................63 FIGURA 5.6: SiMULAÇÃo Do BANCO POR REDE DE PETRI...................................................64 
Figura 5.7: AtENDIMENTO Do PROFEsSOR AO Aluno REPRESENTAdo O REDE DE

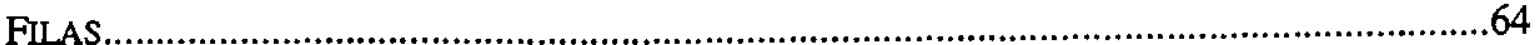

FIGURA 5.8: MODELO DE ATENDIMENTO DO PROFESSRO AOS ALUNOS............................65

FIGURA 5.9: REDES DE FILAS E REDES DE PETRI........................................................68

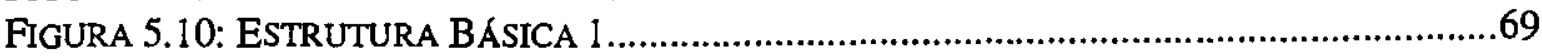

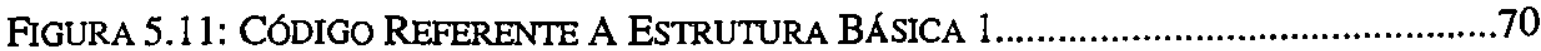

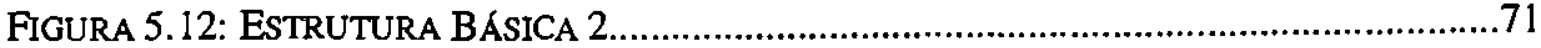

FIGURA 5.13: CódIGO REFERENTE A ESTRUTURA BÁSICA 2 .........................................72

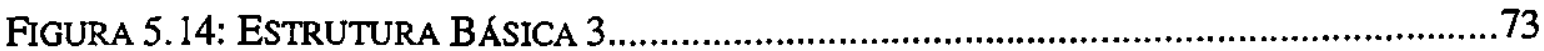

FIGURA 5.15: CódIGO REFERENTE A ESTRUTURA BÁSICA 3 ....................................... 74

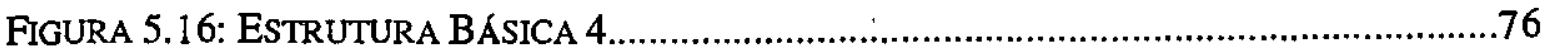

FIGURA 5.17: CóDIGO REFERENTE A ESTRUTURA BÁSICA 4 .........................................77

FIGURA 5.18: INICIALIZAÇÃo DO PROGRAMA E DAS VARIÁVEIS......................................79

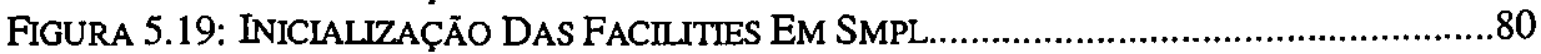

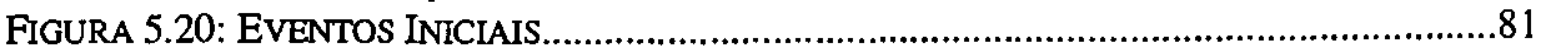

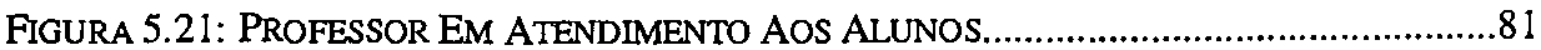

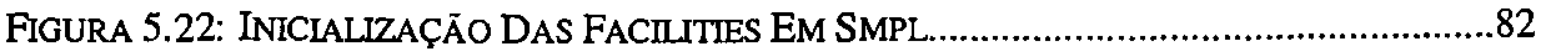

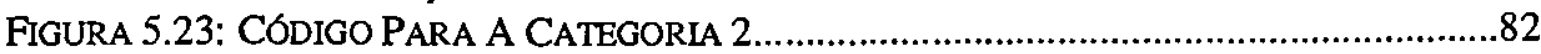

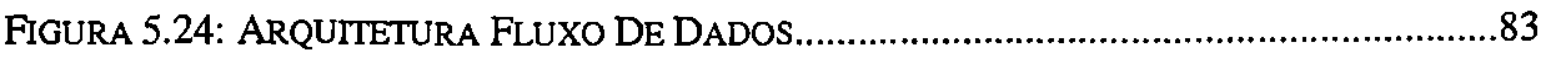

FIGURA 5.25: INICIALIZAÇÃo DO PROGRAMA E DAS VARIÁVEIS.......................................84

FIGURA 5.26: INÍCIO DA FUNÇÃo PRINCIPAL DO PROGRAM DE SIMULAÇĀO.........................85

FIGURA 5.27: CÓDIGO QUE REPRESENTA A GERAÇĀO DE X E Y ......................................86

FIGURA 5.28: ENVIO DE X E Y PARA SUAS RESPECTIVAS FILAS.....................................87

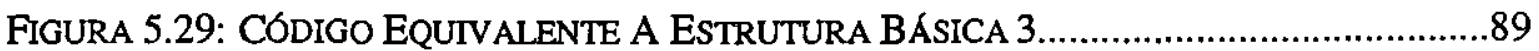

FIGURA 5.30: CÓdIGO QUA FAZ A Divisão EXPONENCIAÇÃo DA EXPRESSÃo...................90

FIGURA 5.31: FINALIZAÇĀO DE UM PROGRAM EM SMPL..............................................91

FIGURA 6.1: EDITOR GRÁFICO ASIA - REDES DE FILAS............................................95

FIGURA 6.2: EDITOR GRÁfICO DO ASIA - REDES DE PETRI..........................................96

FIGURA 6.3: ESTRUTURA DA NOVA BARRA DE MENUS DO EDITOR GRÁFICO....................97

FIguRa 6.4: CAIXA DE DIALOGo PARA PARAMETRIZAÇÃo DA CHEGADA DO RECURSO... 100

Figura 6.5: CaiXa De Dialogo Para Parametrização Do Tempo De Serviço Do

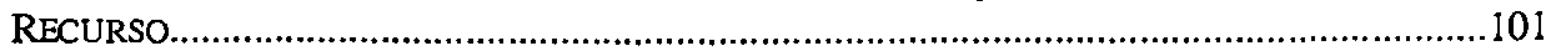

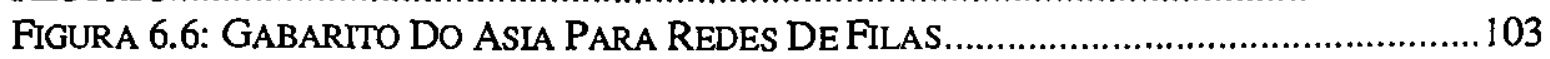




\section{Capítulo 1}

\section{INTRODUÇÃO}

Uma das áreas da computação que tem se tornado essencial com a grande evolução das arquiteturas de computadores, é a avaliação de desempenho. Diversas ferramentas têm sido utilizadas para este fim, sendo que, a escolha entre elas depende fundamentalmente do objetivo da avaliação em andamento e do tipo de avaliação desejada [ORL95, SAN94]. Para exemplificar a afirmação acima, pode-se citar a comparação de diversas máquinas disponíveis no mercado. Neste caso, as arquiteturas a serem avaliadas existem e pode-se utilizar monitores (hardware ou software) ou benchmarks.

Para o caso em que se deseja avaliar um projeto, em que a máquina ainda não está disponível, as técnicas mencionadas no parágrafo anterior tornam-se inviáveis. Neste caso, a utilização de modelos de simulação pode auxiliar no entendimento do projeto, na sua validação e na avaliação do desempenho que será obtido [SWA95]. Uma outra situação em que simulação pode ser utilizada com grande vantagem é na avaliação de modificações em arquiteturas existente. Esta técnica é capaz de responder de forma tanto quantitativa quanto qualitativa às perguntas (e se?) feitas constantemente pelos projetistas de sistemas. Como um exemplo desta situação pode-se citar a avaliação da influência de um processador duas vezes mais rápido no desempenho de uma máquina. Assim, conclui-se que simulação é uma ferramenta flexível e que pode ser utilizada em diferentes situações. Outras vantagens que podem ser citadas sobre simulação são baixo custo, popularidade, possibilidade de analisar alterações de projetos com facilidade, etc [SOA92, MAC87].

Outra característica importante de simulação é a utilização tanto para avaliação de sistemas já existentes (utilizada para comparar sistemas e verificar possíveis alterações nos mesmos) como para prever o funcionamento de sistemas não existentes.

Mesmo com todas essas vantagens a implementação de um programa de simulação não é tão fácil como pode parecer inicialmente. Primeiro é preciso construir um modelo fiel ao sistema que será avaliado, depois elaborar e executar um programa de simulação. A execução do programa é baseada na utilização de variáveis aleatórias garantindo assim a validade dos 
resultados da simulação. Os resultados produzidos pelo programa serão analisados e validados através de gráficos, tabelas e utilizando-se técnicas estatísticas.

Das técnicas de avaliação de desempenho (construção de protótipos, modelagem analítica, monitores de hardware e de software) simulação é mais fácil de implementar, mas para obtenção de resultados confiáveis é necessário a execução de vários passos que requerem o conhecimento do sistema a ser analisado. Além disso, o usuário geralmente não é um especialista, tornando a execução da simulação um tarefa difícil.

Encontram-se na literatura, exemplos de sistemas complexos, cujo comportamento é de interesse de projetistas e analistas, nos sistemas de computação, nas redes de comunicação, nas linhas de produção. Os sistemas, cuja modelagem, simulação e análise serão considerados nesta dissertação, são sistemas computacionais compostos de recursos . Usuários fazem uso desses recursos ao visitá-los e requererem seus serviços.

Como discutido nos parágrafos anteriores, quando as técnicas de simulação são empregadas deve-se construir o modelo do sistema a ser analisado.

Pode-se classificar os modelos baseando-se nas estruturas usadas na sua construção em dois tipos: Redes de Filas e Redes de Petri.

Rede de Filas consiste de entidades chamadas centros de serviços e um conjunto de entidades chamadas usuários, que recebem serviços nos centros. Um centro de serviços consiste de um ou mais servidores, correspondentes a recursos no sistema modelado, e uma área de espera (uma fila) para usuários que estão requisitando o serviço.

O Grupo de Sistema Distribuídos e Programação Concorrente vem utilizando simulação para a avaliação de sistemas computacionais. Para facilitar e incentivar a utilização de simulação, estão em desenvolvimento no grupo ferramentas que auxiliam a avaliação de desempenho através de simulações [SAN96a, SAN96b]. Todas as ferramentas desenvolvidas e as avaliações efetuadas utilizam modelos baseados em Redes de Filas para representar o sistema a ser avaliado [SOA92]. Outra forma de representação de modelos deve ser considerada, principalmente para a modelagem de sistemas concorrentes, assíncronos, distribuídos e paralelos que são a maioria dos sistemas avaliados no grupo.

Uma forma de representação utilizada para o tipo de sistema descrito acima são as Redes de Petri, que são constituídas de quatro elementos básicos: tokens, lugares, transições e arcos, e um conjunto de regras que governam a operação da rede como um todo. A operação das Redes de Petri é baseada na visão de tokens movendo-se em uma rede abstrata [MOO95a, MOO95b] e 
podem caracterizar a operação de sistemas concorrentes. Nos últimos anos, as Redes de Petri foram estendidas, para que fosse possível representar os vários sistemas computacionais, tais como: sistemas distribuídos, arquiteturas paralelas, sistemas orientados a eventos, etc [MUR89, HEU90].

Atualmente, muitos sistemas têm utilizado Redes de Petri co mo uma ferramenta gráfica que oferece uma técnica de modelagem visual [WWW1]. Exemplos desses sistemas podem ser vistos no Capitulo 4.

Dentre as ferramentas que auxiliam a avaliação de desempenho de sistemas computacionais, em desenvolvimento no Grupo de Sistemas Distribuídos e Programaçāo Concorrente, ressalta-se o Ambiente para Simulação Automático (ASiA). O ASiA é um ambiente que visa afastar o usuário da tarefa de escrever um programa de simulação e de utilizar técnicas estatísticas para garantir a validade dos resultados gerados.

Um editor gráfico é utilizado para que o usuário forneça o modelo de sistemas a ser avaliado. Baseando-se no modelo fornecido, o ASiA gera um programa de simulação.

$\mathrm{Na}$ versão atual do ASiA, o usuário deve utilizar Redes de Filas para representar seu modelo. A partir deste modelo são obtidos os dados necessários para que um gerador de aplicações gere um programa de simulação.

A ferramenta utilizada no ASiA para simulação é o SMPL, uma extensão funcional da linguagem $C$ para simulação de sistemas.

O objetivo deste trabalho é analisar a viabilidade de se utilizar Redes de Petri no ASiA. A idéia é permitir a possibilidade de escolha ao usuário. Isto é, o usuário poderá escolher a técnica, para qual estiver mais familiarizado (Redes de Filas ou Redes de Petri). Para efetuar esta adaptação no ASiA é necessário verificar, inicialmente, o que pode ser mantido na atual versão do ASiA e o que deverá ser alterado. Assim, esse estudo da viabilidade deve analisar diversos aspectos, tais como:

$\rightarrow$ Possibilidade de utilização da linguagem SMPL para simular um Rede de Petri;

$\rightarrow$ Alterações necessárias no Gerador de Aplicações e no gabarito utilizado pelo ASiA;

$\rightarrow$ Avaliação das modificações necessárias no Editor Gráfico, analisando se é possível manter-se o mesmo editor com algumas alterações ou se é mais viável implementar um novo editor. 
$\rightarrow$ Funções a serem acrescentadas ao SMPL para que seja possível simular sistemas representados em Redes de Petri.

A importância deste trabalho, deve-se ao fato de o ASiA estar implementado utilizando Redes de Filas e a extensão funcional SMPL. A possibilidade de se adotar Redes de Petri e manter-se o SMPL, simplifica a alteração do ambiente.

O trabalho desenvolvido nesta dissertação de mestrado pode ser subdividido em três etapas necessárias para atingir os objetivos descritos nos parágrafos anteriores. Inicialmente uma revisão bibliográfica dos tópicos necessários para o desenvolvimento do trabalho, que está descrita nos Capítulos 2, 3 e 4 desta dissertação, sendo que:

$\rightarrow$ Capítulo 2 - Modelagem e Simulação. Nesse capítulo são discutidos os conceitos de análise de desempenho, técnicas de modelagens, modelos utilizando-se Redes de Filas e as abordagens para simulação.

$\rightarrow$ Capítulo 3 - Redes de Petri. Nesse capítulo é apresentado a teoria sobre as Redes de Petri, os tipos de Redes de Petri, exemplos tirados da literatura e outros exemplos desenvolvidos durante a execução desse trabalho além de uma comparação entre a utilização de Redes de Petri e Redes de Filas.

$\rightarrow$ Capítulo 4 - Ambientes de Simulação. Nesse capítulo são analisados alguns ambientes de simulação. O ASiA será explicado em detalhes.

Na segunda etapa é apresentada uma comparação entre Redes de Filas e Redes de Petri e a utilização de SMPL, esta fase é apresentada no Capítulo 5 - Técnicas de Simulação e SMPL. Nesse capítulo é feita uma comparação entre as técnicas de simulação Redes de Filas e Redes de Petri. A linguagem SMPL é explicada com detalhes e como esta linguagem suporta a técnica de modelagem Redes de Petri.

A terceira etapa analisa as alterações necessárias no ASiA para inclusão de Redes de Petri. Nesse capítulo são explicadas as modificaçōes necessárias ao ASiA para que o ambiente também possa suportar implementações de sistemas modelados em Redes de Petri.

Finalmente, o Capítulo 7 apresenta as conclusões deste trabalho. Nesse capítulo são feitas considerações sobre a bibliografia, o trabalho desenvolvido e são apresentadas algumas sugestões de trabalhos futuros. 


\section{Capítulo 2 \\ MODELAGEM E SIMULAÇÃO}

\subsection{Introdução}

Técnicas de análise de desempenho são importantes em qualquer sistema computacional para obtenção de informações que auxiliem na validação e na avaliação dos referidos sistemas.

Em sistemas existentes, as análises têm a finalidade de avaliar o seu desempenho ou para avaliar as consequiências de possíveis mudanças. Para o caso de sistemas que se encontram em fase de projeto, as técnicas de análise são importantes tanto para a validação do projeto como para avaliar seu desempenho. Quando o sistema está em fase de projeto, abordagens empregando modelagem são normalmente utilizadas.

Modelos são abstrações de sistemas computacionais. Durante a fase de modelagem devese ter como diretriz básica que somente as características essenciais do sistema devem ser refletidas no modelo [ORL95]. Essas características podem ser representadas através de diferentes técnicas de modelagem. A técnica a ser considerada deve oferecer:

$\rightarrow$ uma representação gráfica para o sistema, clara e de fácil aprendizado;

$\rightarrow$ flexibilidade para poder abstrair todas as características essenciais do sistema.

Duas técnicas de modelagem têm sido utilizadas para o desenvolvimento de modelos para simulação: Redes de Filas e Redes de Petri.

Após o desenvolvimento do modelo (utilizando uma das técnicas citadas), uma nova etapa deve ser considerada: a solução do modelo utilizando técnicas analíticas (os modelos são resolvidos por equações matemáticas) ou a simulação que utiliza programas de simulação.

Nesse capítulo serão discutidas primeiramente técnicas para análise de desempenho e aferição de sistemas. Serão discutidas ainda as formas de representação de modelos por Redes de Filas e a solução de modelos através de simulação. A utilização de Redes de Petri em simulação será considerada no Capítulo 3. 


\subsection{Análise de Desempenho}

Desempenho para um sistema computacional corresponde ao resultado de uma análise da quantidade de serviços prestados em relação ao tempo total decorrido desde o início desses serviços. Assim o desempenho passa a ser prioritariamente observado pelos usuários através dos tempos de resposta por ser ele o agente que mostra o andamento do sistema [SAN94, ORL95].

As medidas de desempenho podem ser agrupadas em duas categorias: medidas orientadas ao usuário e medidas orientadas ao sistema.

As medidas orientadas ao usuário incluem quantidades como tempo de ciclo (turnaroundtime) em um ambiente baseado em processamento de lotes e o tempo de resposta em um sistema de tempo real e/ou iterativo. Geralmente os pedidos são colocados em classes de prioridades diferentes. Dessa forma associa-se a um pedido individual o valor de prioridade de sua classe, conhecendo-se assim, sua importância e as características e demanda do recurso. O tempo de ciclo e o tempo de resposta, usualmente são definidos e calculados separadamente para cada classe de prioridade.

As medidas orientadas ao sistema são tipicamente a capacidade de trabalho (throughput) e a utilização. A capacidade de trabalho corresponde ao número médio de pedidos processados por unidade de tempo - avalia o grau de produtividade que o sistema fornece. Geralmente a carga do sistema é expressa em função da razão entre a carga máxima que o sistema pode controlar e a utilização do sistema.

Técnicas de análise de desempenho são métodos pelos quais informações associadas aos parâmetros significativos à análise podem ser obtidas a partir do próprio sistema (técnicas de aferição) ou então através de um modelo representativo do sistema (técnicas de modelagem).

As técnicas de modelagem são bastante utilizadas uma vez que os sistemas computacionais modernos são complexos e a utilização das técnicas de aferição, não é uma tarefa fácil de ser conduzida. As técnicas de aferição são empregadas quando se deseja analisar o desempenho de um sistema já implementado (ou em fase final de desenvolvimento) ou quando se deseja comparar vários sistemas existentes. As técnicas de modelagem podem ser empregadas em qualquer estágio de desenvolvimento: sistemas existentes, sistema na fase de projeto ou comparação de sistemas. 


\subsubsection{Técnicas de Afexição}

Técnicas de aferição são ferramentas utilizadas para analisar o desempenho de um sistema através de sua experimentação. Entre as principais técnicas de aferição citam-se a construção de protótipos, benchmarks e coleta de dados.

Construção de Protótipos: um protótipo é uma versão funcional de um produto na qual faltam certas características não essenciais. A construção de protótipos apresenta um custo menor de desenvolvimento em relação à construção do sistema, adiantando algu mas informações sobre o comportamento do futuro sistema. Protótipos também são utilizados na verificação de alternativas para sistemas inexistentes ou existente onde poucas modificações são necessárias. $O$ desenvolvimento de protótipos não é garantia de sucesso, porém essa estratégia possibilita detectar erros conceituais [SAN94, ORL95].

Benchmarks: são programas escritos em linguagem de alto nível, e indicados para a comparação de diferentes sistemas. A comparação do tempo de execução fornece uma indicação do desempenho dos sistemas. Whetstone, Dhrystone, Linpack, SPEC, NAS são exemplos de alguns benchmarks [SHA94, NAI95].

Coleta de dados: é a ferramenta que fornece o válor mais preciso para as medidas de desempenho. Deve ser utilizada somente em sistemas já existentes. A coleta não deve interferir no comportamento do sistema para não gerar interpretações enganosas sobre o desempenho do sistema. A coleta de dados pode ser feita por monitores de hardware ou software [SAN94, ORL95].

\subsubsection{Técnicas de Modelagem}

A técnica de modelagem consiste no desenvolvimento de um modelo que contenha as características essenciais do sistema a ser avaliado. A solução do modelo desenvolvido pode ser feita através de técnicas analíticas ou de simulação.

Técnicas Analíticas: permite escrever uma relação funcional entre os parâmetros do sistema e os critérios de desempenho escolhidos, em termos de equações que podem ser resolvidas analiticamente. Esta técnica fornece resultados precisos, mas a medida em que a complexidade do sistema aumenta, também aumenta a difículdade da resolução analítica. Essa 
técnica possui custo relativamente baixo e tempo para obtenção da solução dependente da complexidade do problema [SAN94, ORL95].

Simulação: consiste em modelar o sistema para então transformá-lo em um programa que represente o sistema real. É uma técnica prognostica que examina as possíveis consequiências das diferentes sequiências de comportamento do sistema existente ou inexistente [SAN94, ORL95].

A figura 2.1 ilustra os passos para o processo de Modelagem e Simulação. Cada um dos passo serão descritos em seguida [SAN94, ORL95]. 


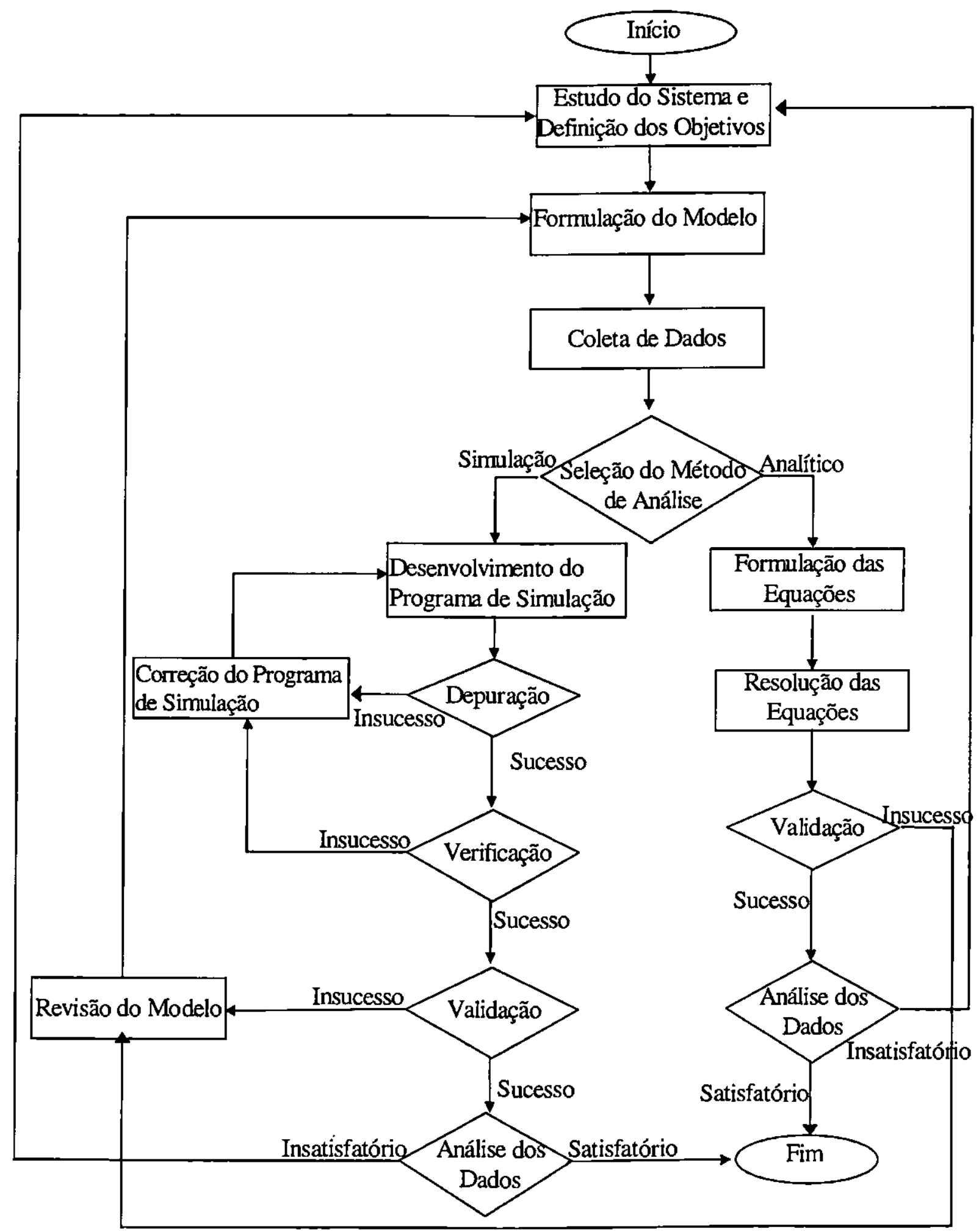

Figura 2.1: Processo de Modelagem e Simulaçāo. 
Estudo do Sistema e Definição dos Objetivos: consiste na identificação das características essenciais do sistema a ser avaliado e dos objetivos da avaliação. Essa fase deve ser definida com grande precisão, pois é a partir da definição dos objetivos que os próximos passos serão direcionados. Caso ocorra uma compreensão errônea pode-se determinar conseqüências danosas para o estudo em questão.

Formulação do Modelo: é feita uma abstração do sistema real e suas características principais devem ser mantidas no modelo. Podem ser necessárias algumas suposições ou simplificações de forma a viabilizar sua solução, as quais devem ser documentadas para possíveis correçōes. Os modelos para avaliaçāo de sistemas computacionais são normalmente. representados por Redes de Filas ou por Redes de Petri. Redes de Filas são discutidas na seção 2.3.1 e Redes de Petri no capítulo 3.

Coleta de Dados: consiste na obtenção dos parâmetros do modelo. Quando a modelagem é feita sobre um modelo existente, os parâmetros podem ser medidos diretamente (por monitores de hardware ou de software) ou indiretamente.

Seleção do Método de Análise: consiste em escolher entre métodos analíticos ou de simulação. Esta escolha é feita com base nos objetivos da avaliação, no nível de detalhes do modelo, flexibilidade e nos passos anteriores.

No caso em que a escolha é simulação tem-se os seguintes passos:

$\rightarrow$ Desenvolvimento do Programa de Simulação: consiste na transformação do modelo para uma linguagem aceitável pelo computador. Para a realização da simulação podem ser utilizadas ferramentas tais como: linguagens de programação de propósito geral (onde é necessário que o programador crie um ambiente de simulação); linguagens específicas de simulação (as quais são projetadas especificamente para simulação); extensões funcionais de linguagens de programação (consiste em desenvolver bibliotecas contendo as primitivas necessárias para a criação de um ambiente de simulação e inseri-las em uma linguagem de programação de propósito geral).ou pacotes de simulação (os quais são dedicados à simulação de tipos específicos de sistemas).

$\rightarrow$ Depuração: o programa de simulação deve ser conferido para garantir que esteja livre de erros (de lógica e programação) devendo produzir resultados razoáveis. 
$\rightarrow$ Verificação: neste passo é verificado se o programa de simulação é uma implementação válida do modelo. A técnica normalmente utilizada consiste em uma revisão cuidadosa no programa e no modelo.

$\rightarrow$ Correção do Programa de Simulação: esse passo será feito somente se um erro for detectado na depuração ou na verificação. Caso se detecte um erro deve-se rever e modificar a implementação.

$\rightarrow$ Validação: o modelo deve ser uma representação válida do sistema real devendo reproduzir o comportamento do sistema com fidelidade para satisfazer aos objetivos da análise.

$\rightarrow$ Revisão do Modelo: este passo somente será executado se na validação ficar constatado que o modelo não é consistente, o modelo deve ser reavaliado e todos os passos anteriores devem ser refeitos.

$\rightarrow$ Análise dos Dados: assim que o programa de simulação é executado, um conjunto de valores é gerado e então é feita a análise desses valores. Caso os resultados obtidos sejam insatisfatórios, todos os passos anteriores desde o estudo do sistema e definição dos objetivos devem ser refeitos. No caso dos resultados obtidos serem satisfatórios a simulação termina com sucesso.

A utilização de simulação para avaliação de sistemas computacionais será discutida na seção 2.4. No caso em que a melhor escolha sejam métodos analíticos tem-se os seguintes passos:

$\rightarrow$ Formulação das Equações: o modelo é representado em forma de equações seguindo as características do sistema.

$\rightarrow$ Resolução das Equações: o modelo é solucionado através da resolução das equações, a resolução é feita por métodos numéricos.

$\rightarrow$ Validação: uma das formas possíveis para se validar um modelo é através da simulação, se o modelo não for considerado válido então será feita a revisão e em seguida serão refeitos os passos a partir da formulação do modelo.

$\rightarrow$ Análise dos Dados: é feita a partir dos resultados obtidos na resolução das equações. Caso os resultados obtidos sejam considerados insatisfatórios os passos anteriores desde o estudo do sistema e definição dos objetivos devem ser refeitos. No caso dos 
resultados serem satisfatórios a modelagem por métodos analíticos termina com sucesso.

\subsection{Desenvolvimento de Modelos}

A modelagem de um sistema que está em fase de projeto visa prever o comportamento do novo sistema proposto e selecionar o melhor projeto a partir de uma série de alternativas. Para um sistema existente, a modelagem avalia as conseqüências de diferentes mudanças nas características do sistema e em sua carga de trabalho [SOA92].

Modelos são a descrição de sistemas e devem ser construídos para resolver problemas específicos. Sendo assim existem vários modelos de um mesmo sistema cada um deles mais adequado para a resolução de um problema específico [SOA92]. Desta forma, modelos são a abstração de sistemas reais e a abstração das características de um sistema é influenciada pela visão que se tem sobre o sistema [SAN94, ORL95].

Os modelos podem ser classificados como de mudança discreta e de mudança contínua, de acordo com o modo no qual o modelo representa as mudanças de estado no sistema em estudo, quanto aos dois tipos de sistema tem-se [SAN94]:

$\rightarrow$ Sistemas Discretos: em sistemas desse tipo as mudanças de estado ocorrem em pontos discretos do tempo. Esses sistemas são representados por modelos discretos.

$\rightarrow$ Sistemas Contínuos: nesses sistemas as mudanças de estado ocorrem continuamente no tempo e são representados por modelos contínuos.

Os modelos devem ser representados utilizando-se técnicas de modelagem de sistemas tais como, Redes de Filas e Redes de Petri. Redes de Petri serão descritas no Capítulo 3; Redes de Filas serão descritas na próxima seção.

\subsubsection{Redes de Filas}

Uma rede é um conjunto de recursos com filas de espera para utilização dos recursos. Um modelo de Redes de Filas é uma representação de alto nível dos recursos de um sistema [SOA92]. 
Redes de Filas são compostas por centros de serviço denominados servidores os quais prestam serviços aos usuários (clientes) e por uma área de espera denominada fila onde os clientes esperam para serem atendidos pelos servidores [SAN94, SPO94a, SOA92].

Os modelos podem ser classificados quanto ao número de servidores e quanto ao número de filas (figura 2.2) em:

1. uma fila e um servidor (figura 2.2.a);

2. uma fila e vários servidores (figura 2.2.b);

3. várias filas e um servidor (figura 2.2.c);

4. várias filas e vários servidores (figura 2.2.d).

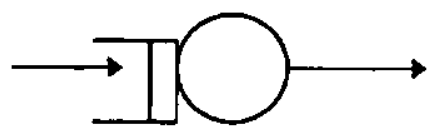

Uma Fila e Um Servidor

(a)

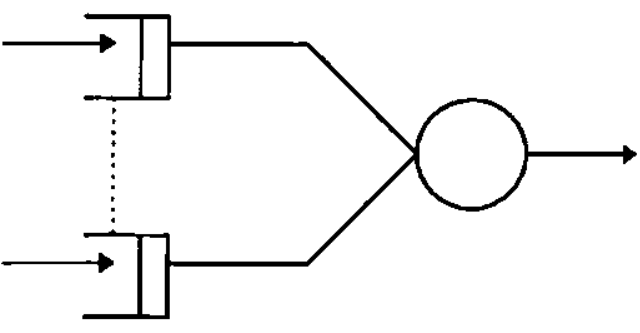

Várias Filas e Um Servidor

(c)

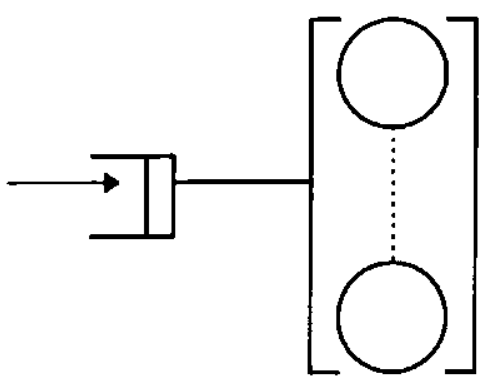

Uma Fila e Varios Servidores

(b)

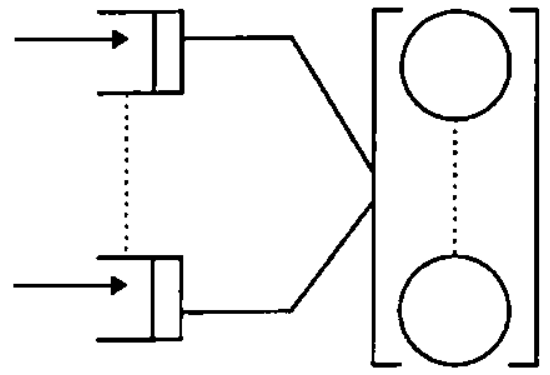

Várias Filas e Vários Servidores

(d)

Figura 2.2: Classificação do Modelos de Redes de Filas.

O modelo composto por uma fila e um servidor é o mais simples e os clientes esperam na fila, para serem atendidos. Assim que o servidor estiver livre o primeiro cliente da fila é 
atendido. Um exemplo de sistema que pode ser representado por este modelo é a bilheteria de um cinema [SAN94, SPO94a].

No modelo com uma fila e vários servidores, os clientes esperam na fila para serem atendidos pelo primeiro servidor que ficar livre. Um exemplo de sistema que possa ser representado por este modelo é a agência bancária [SAN94, SPO94a].

No modelo composto por várias filas e um servidor os clientes esperam em uma das filas para ser atendido pelo único servidor. Um exemplo de sistema que pode ser representado por este modelo é a agência bancária com um caixa e filas distintas, por exemplo, uma comum e outra preferencial [SAN94, SPO94a].

No modelo composto por várias filas e vários servidores os clientes esperam em uma das filas para serem atendidos por qualquer um dos servidores. Um exemplo de sistema que pode ser representado por este modelo é a agência bancária que possui filas para diversos tipos de serviços e uma fila preferencial, todos os servidores estão aptos para atender qualquer um dos serviços oferecidos [SAN94, SPO94a].

Todos os modelos acima descritos necessitam de parâmetros para especificação completa do modelo, tais como: tempo entre chegadas e de serviço; algoritmos de escolha entre os servidores, em qual fila entrar e de qual fila retirar o próximo cliente e algoritmo de escalonamento [SAN94, SPO94a].

Tempo entre as chegadas e de serviço: tempo entre as chegadas é necessário para estimar o tempo da chegada do próximo cliente ao sistema e o tempo de serviço é o tempo necessário para que o servidor execute uma tarefa. As funções que estimam o tempo da próxima chegada e de serviço devem produzir valores aleatórios seguindo uma distribuição previamente definida.

Algoritmos de escolha entre os servidores: quando mais de um servidor estiver livre, o servidor deverá ser selecionando aleatoriamente, ou seguindo algum tipo de prioridade. Este parâmetro está presente nos modelos das figuras 2.2.b e 2.2.d.

Algoritmos de escolha em qual fila entrar: o cliente pode escolher uma fila aleatoriamente ou seguindo algum tipo de prioridade. Este parâmetro está presente nos modelos das figuras 2.2.c e 2.2.d. 
Algoritmos de escolha de qual fila retirar o próximo cliente: quando um servidor estiver disponível ele pode retirar o próximo cliente seguindo a prioridade de cada fila ou aleatoriamente. Este parâmetro está presente nos modelos das figuras 2.2.c e 2.2.d.

Algoritmo de escalonamento: existem vários algoritmos de escalonamento utilizados para o gerenciamento de filas:

$\rightarrow$ FIFO (first in first out): o primeiro cliente a entrar na fila será o primeiro a ser atendido;

$\rightarrow$ LIFO (last in first out): o último cliente a entrar na fila será o primeiro a ser atendido, como a estrutura de pilha;

$\rightarrow$ RR (round robin): cada cliente é atendido por um intervalo de tempo pequeno denominado quantum. No caso desse tempo não ser suficiente o cliente volta para o final da fila, e o próximo é atendido. O processo se repete até que o serviço se complete;

$\rightarrow$ tempo de serviço: o cliente com o menor ou maior tempo de serviço é retirado da fila.

$\rightarrow$ uso de prioridade: prioridades são utilizadas para dar preferência a alguns clientes podendo ou não ser preemptiva. No caso da preempção a chegada de um cliente com maior prioridade na fila, faz com que o cliente de menor prioridade volte para a fila. No caso da não preemptiva o cliente de menor prioridade termina seu trabalho e só então o cliente com maior prioridade é atendido.

Os sistemas de Redes de Filas podem ser divididos em abertos, fechados ou mistos e estāo representados na figura 2.3[ORL95]:

$\rightarrow$ Sistemas abertos : os clientes entram por uma fonte e abandonam o sistema por um sorvedouro assim que terminarem a execução (figura 2.3.a);

$\rightarrow$ Sistemas fechados: existe um número fixo de clientes circulando no sistema e que não o abandonam; do ponto de vista do sistema é como se não houvesse nem entrada nem saída (figura 2.3.b);

$\rightarrow$ Sistemas mistos: os sistemas mistos são considerados abertos para uma certa classe de clientes e fechados para outra (figura 2.3.c). 


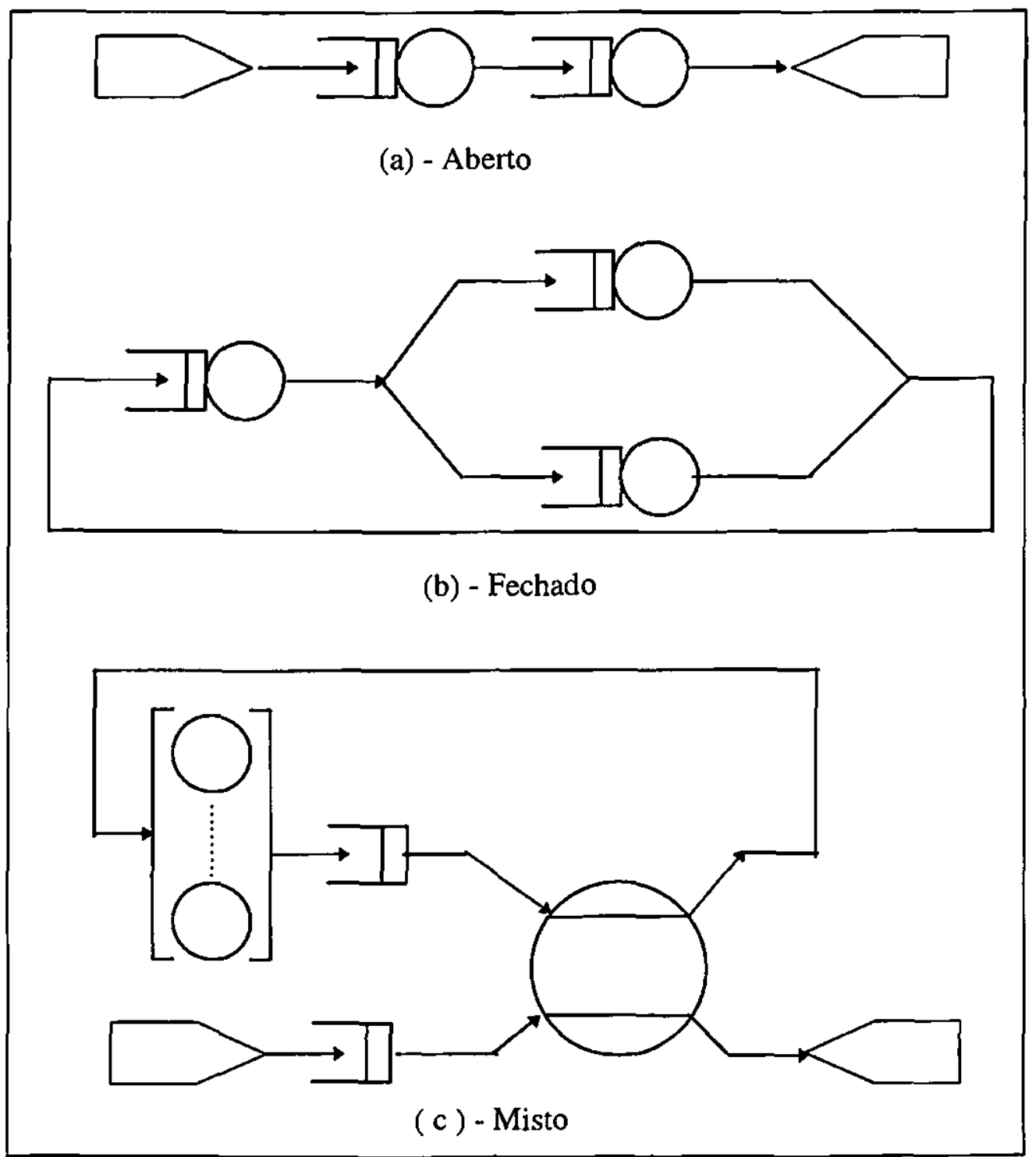

Figura 2.3: Tipos de Sistemas

A análise de Redes de Filas pode ser feita através das seguintes técnicas [ORL95]:

Análise do valor médio: é a técnica mais simples, na qual os parâmetros considerados assumem somente valores médios. É fácil implementar e analisar, mas produzirá resultados incorretos se os parâmetros apresentarem grandes variâncias.

Cálculo dos limites: determina os limites inferior e superior para as medidas de desempenho especificadas. É simples e rápido para calcular os limites. Esta técnica é adequada para eliminar alternativas inadequadas. 
Fluxo de Equivalência e Modelagem Hierárquica: são indicados para modelos mais sofisticados que necessitam de um nível maior de detalhamento. $O$ processo de decomposição hierárquica consiste em dividir um modelo complexo em submodelos menores os quais são avaliados e as soluções individuais são combinadas para obter a solução do modelo original. A recombinação é realizada pelo Centro de Serviço de Fluxo de Equivalência que reproduz o comportamento dos submodelos.

\subsection{Simulação}

Simulação consiste na execução de um programa de computador reproduzindo o comportamento de um sistema real [FER92, ORL95]. Ainda permite inferir nos modelos sem que seja preciso construí-los no caso de serem somente propostos ou mesmo destruí-los para determinar o limite do funcionamento, sem um aito custo operacional.

As vantagens da simulação são [FER92]:

$\rightarrow$ permissão da utilização de modelos em qualquer nível de detalhamento possibilitando que os modelos sejam criados muito próximos ao sistema real;

$\rightarrow$ existênçia de diversas linguagens de programação específicas à simulação, facilitando a criação dos programas e a obtenção dos resultados corretos.

Uma simulação pode ser classificada quanto a natureza do sistema, quanto ao nível de detalhamento e quanto a origem da simulação [ORL95].

\section{Quanto a natureza do sistema tem-se [MAC87, SOA92]:}

$\rightarrow$ Modelos discretos: as mudanças dos estados do sistema são registradas em qualquer intervalo de tempo ou em intervalos pré-determinados.

$\rightarrow$ Modelos contínuos: as mudanças dos estados do sistema são registradas ao longo do tempo, geralmente são descritos por equações diferenciais e são utilizados, por exemplo, em fenômenos físicos.

Simulação discreta é mais utilizada por ser mais adequada a sistemas computacionais.

2. Quanto ao nível de detalhamento: MacDougall em [MAC87] classifica os modelos em três níveis de detalhamento: nível de circuito (utilizado para analisar o comportamento de componentes físicos, tais como, transistores e resistores), nível de 
portas (considerando a transferência de registradores, mutiplexadores, registradores e somadores) e nível de sistema (considerando um nível mais elevado).

3. Quanto a organização da Simulação: simulação pode ser organizada baseando-se em três entidades: atividades (menor unidade de trabalho no sistema considerado); processo (conjunto de atividades logicamente relacionadas) e eventos (mudanças ocorridas no estado do sistema) [ORL95, SPO94b, MAC87].

Um modelo para simulação discreta pode ser baseado na três entidades acima descrita, resultando em uma das seguintes abordagens: simulação orientada a eventos, simulação orientada a processos ou simulação orientada a atividades [MAC87, SOA92], que são discutidos nas próximas seçōes.

\subsubsection{Simulação Orientada a Evento}

Na Simulação Orientada a Evento um sistema é modelado pela definição das mudanças que ocorrem no tempo do evento. O modelador deve determinar os eventos que podem causar mudanças de estado no sistema. Uma estrutura de lista (denominada lista de eventos futuros) define a ordem de execuçāo das rotinas baseadas no tempo do evento [SOA92, ORL95, SPO94a]. Cada entrada na lista de eventos futuros contém o tempo de ocorrência de cada evento, e o identificador de eventos correspondente é inserido na lista por um mecanismo de escalonamento. Após completar todas as operações possíveis em um tempo particular da simulação, o mecanismo escalonador é ativado para selecionar o próximo evento a ser executado [MAC87]. A figura 2.4 ilustra este mecanismo. 


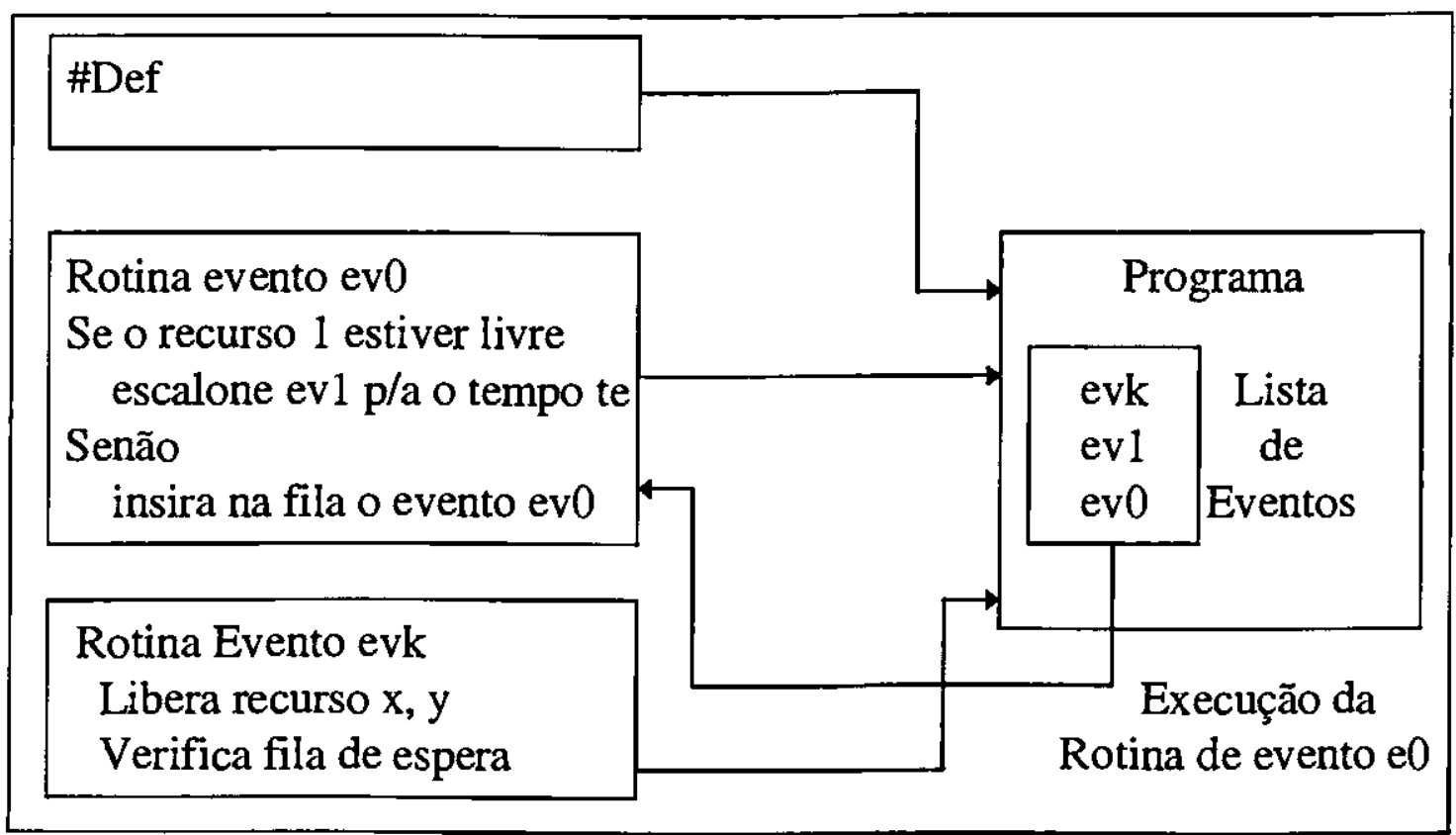

Figura 2.4: Estrutura do Programa de Simulação Orientado a Eventos

Esta abordagem é uma das mais utilizada devido à facilidade de implementação em qualquer linguagem de programação de propósito geral, e extensões funcionais tais como GASP, SIMCRIPT E SMPL [ORL95].

\subsubsection{Simulação Orientada a Processo}

Na Simulação Orientada a Processo o sistema é visto como uma coleção de processos interativos controlados e coordenados pela ocorrência de eventos [SPO94a]. Cada processo possui sua própria área de dados e assume a forma de um procedimento [ORL95].

Analogamente a orientação a eventos, a simulação orientada a processos também possui um mecanismo de escalonamento denominado processo escalonador o qual é responsável pelo gerenciamento da lista de processos prontos, ou seja, é necessário analisá-la antes de decidir qual processo deve ser entrar em execução como ilustra a figura 2.5 [ORL95]. 


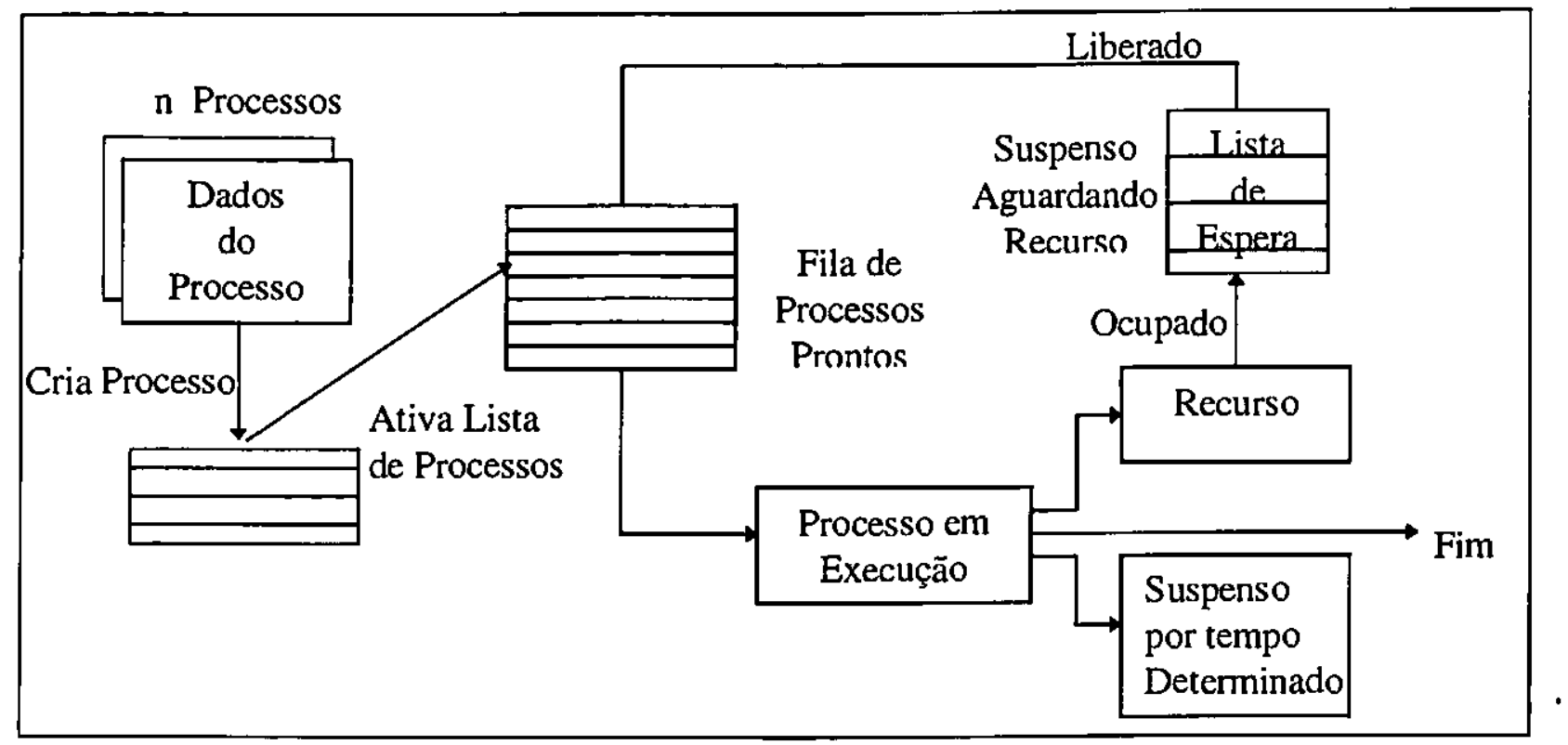

Figura 2.5: Estrutura do Programa de Simulação Orientado a Processos.

Esta abordagem é implementada por linguagens especiais de programação que devem ter suporte para a concorrência entre os processos, pois os processos são independentes e podem ser executados concorrentemente como os demais. Entre as ferramentas que implementam essa abordagem destacam-se ASPOL, SOL, SIMULA, CCSIM [ORL95].

\subsubsection{Simulação Orientada a Atividades}

Na Simulação Orientada a Atividades o modelador descreve cada atividade possível para cada entidade do sistema, definindo as condições que causam seu início e seu término. Os eventos que iniciam ou finalizam uma atividade são escalonados pelo modelador, mas são inicializados a partir das condições especificadas para a atividade [SOA92, SPO94a, SPO94b]. Durante a execução do programa de simulação todo conjunto de atividades é examinado, a cada avanço do tempo, de forma a assegurar que todas atividades sejam consideradas [ORL95]. 


\subsection{Considerações Finais}

Análise de desempenho necessita da utilização de técnicas para obtenção de informaçōes requeridas para a análise. Estas técnicas dividem-se em dois grupos técnicas de aferição e tếcnicas de modelagem. Entre as técnicas de aferição destacam-se a coleta de dados, benchmarks e construção de protótipos. E entre as técnicas de modelagem estão modelagem analítica e simulação.

Modelagem geralmente constitui-se em ferramentas importantes ao projeto e à análise de sistemas computacionais, pois combinam fatores essenciais tais como: custo, precisão e flexibilidade.

Modelos analíticos fornecem resultados precisos, mas devido à complexidade das soluções são necessárias simplificações que podem tornar os resultados pouco confiáveis.

Como a simulação é uma técnica mais flexível pode ser utilizada na avaliação e validação de projeto de novos hardware e software e também é utilizada como ferramenta prognostica indicando o comportamento do sistema mediante algumas alterações. 


\section{Capítulo 3}

\section{REDES DE PETRI}

\subsection{Histórico}

As Redes de Petri foram propostas por Carl Adam Petri em 1962, com o objetivo de modelar sistemas em que aparecem componentes concorrentes [HEU90, MOO95a, MAC96].

A partir da década de 70, o campo de aplicações expandiu-se, atingindo áreas como a modelagem de componentes de hardware, sistemas distribuídos, linguagem de programação, controle de processos e protocolos de comunicação. No início da década de 80 , áreas como sistemas de informação, bancos de dados, automação de escritórios e inteligência artificial passaram também a adotar Redes de Petri [HEU90].

Trabalhos subseqüentes introduziram alterações necessárias no modelo original, com o intuito de melhor adaptar as Redes de Petri às aplicações que foram propostas. Surgiram assim as redes com arcos inibidores, as redes temporizadas determinísticas e as redes estocásticas. Atualmente as Redes de Petri são consideradas uma técnica consolidada para a especificação de sistemas concorrentes, correspondendo a uma técnica de modelagem gráfica e matemática [MAC96].

Como uma ferramenta matemática, Redes de Petri podem ser usadas em conjuntos de equaçōes, equações algébricas, e outros modelos matemáticos, bem como de simulação. Como uma ferramenta gráfica, Redes de Petri fornecem uma técnica de modelagem visual, onde tokens são usados para simular atividades dinâmicas e concorrentes do sistema em estudo [MOO95a].

Atualmente, Redes de Petri têm sido usadas no estudo de uma grande variedade de sistemas, sendo consideradas ideais para a modelagem de sistemas concorrentes, assíncronos, distribuídos, paralelos, nāo determinístico e estocástico, software distribuído, banco de dados distribuído, controle industrial, memória de multiprocessador, sistema data-flow e tolerante a falhas, programação lógica e VLSI, compiladores e sistemas operacionais, linguagens formais, redes locais, fatores humanos e redes neurais entre outros [BRE95]. 


\subsection{Teoria de Rede de Petri}

As Redes de Petri consistem de quatro elementos básicos: tokens, lugares, transições e arcos, como mostra a figura 3.1 e um conjunto de regras que governam a operação da rede como um todo. A operação das Redes de Petri é baseada na visão de tokens movendo-se em uma rede abstrata [MOO95a, MOO95b].

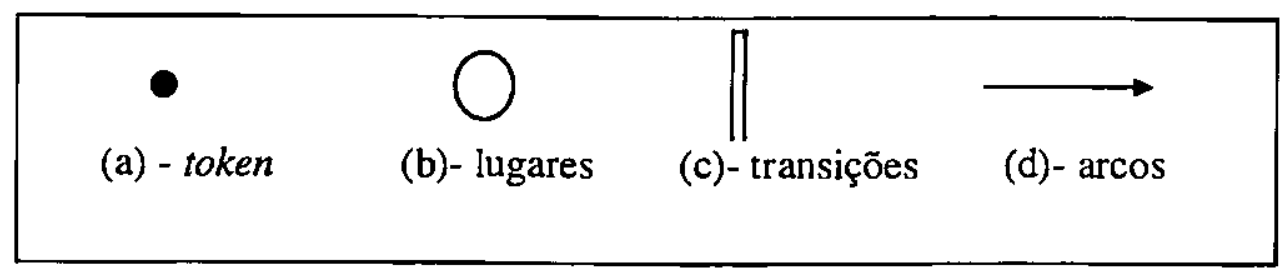

Figura 3.1: Descrição de Redes de Petri.

Tokens são entidades conceituais, que modelam os objetos que se movem por uma rede real. Lugares representam as localizações onde objetos esperam por processamento. Transições representam procesșos, eventos ou atividades. Arcos representam os caminhos dos objetos através do sistema; arcos conectam lugares às transições e transições a lugares (a direção do caminho é indicada por uma seta no final do arco). A figura 3.2 apresenta um exemplo de utilização dos elementos básicos [MOO95a].

Cada transiçāo em uma Rede de Petri tem um número de lugares de entrada e de saída; esses lugares podem representar uma pré-condição ou uma pós-condição de um evento, ou recursos requeridos e liberados por um evento. A tabela 3.1 mostra algumas interpretaçōes para lugares e transições [MOO95a].

\begin{tabular}{|c|c|c|}
\hline Luugares de entrada & Transições & Lugares de saída \\
\hline Pré-condições & Eventos & Pós-condições \\
\hline Dado de entrada & Passo computacional & Dado de saída \\
\hline Sinais de entrada & Sinal do processador & Sinais de saída \\
\hline Recursos necessários & Tarefa ou trabalho & Recursos liberados \\
\hline Condições & Cláusula em lógica & Conclusões \\
\hline Buffers & Processador & Buffers \\
\hline
\end{tabular}

Tabela 3.1: Interpretações comuns de lugares e transições.

Matematicamente, uma Rede de Petri é um grafo bipartido direcionado, com uma marca inicial. Um grafo bipartido é aquele no qual existem dois tipos de nós (lugares e transições) e os arcos vão de um tipo de nó para outro tipo, isto é, um arco não pode conectar dois nós de um 
mesmo tipo. Os arcos têm direção, indicando que o fluxo ocorre em uma única direção. A marca inicial corresponde à distribuição inicial dos tokens nos lugares na Rede de Petri. Um token muda quando uma transição dispara, isto é, quando um evento ou atividade acontece, e o disparo é equivalente à mudança do estado, descrevendo o comportamento dinâmico de uma Rede de Petri [MOO95a].

\subsection{Regras de Disparo de Redes de Petri}

Segundo Moore.[MOO95b], as regras de disparo de uma Rede de Petri especificam o comportamento das transiçōes, isto é, as condições sob as quais processos ou eventos podem ocorrer. Três regras governam o disparo das transições:

1. Quando todos os lugares anteriores às transições são ocupados pelo menos por um token, a transição está habilitada.

2. Uma vez habilitada, a transição dispara.

3. Quando a transição disparar, exatamente um token é removido de cada lugar anterior e exatamente um token é colocado em cada lugar posterior às transições.

Regras de sincronização: estão associadas às transições e representam o tempo requerido para completar alguma atividade. A regra de sincronização pode ser estocástica, baseada em uma função de probabilidade, um valor computado, ou uma constante.

Regras de decisão: estão associadas aos lugares e foram propostas para resolverem casos onde mais que uma transição está habilitada por um mesmo token ou conjuntos de tokens. Existem três tipos de regras de decisão: com prioridade, com probabilidade e construída.

$\rightarrow$ A regra de decisão com prioridade é aquela em que, o token partirá pelo caminho com maior prioridade desde que todas as outras regras de disparo sejam encontradas.

$\rightarrow$ A regra de decisão com probabilidade é aquela em que, o token partirá pelo caminho baseado na probabilidade associada desde que todas as outras regras de disparo sejam encontradas.

$\rightarrow$ A regra de decisão construída permite ao usuário especificar as condições nas quais o token partirá por um caminho particular, dado que as regras de disparo sejam encontradas. 
Um modelo representando os períodos do dia é utilizado no exemplo a seguir para demonstrar a utilização de uma Rede de Petri. O dia é dividido em três períodos: manhã, tarde e noite, que são os lugares da rede. A transição de um período para outro depende da ocorrência dos eventos (transições): amanhecer, entardecer e anoitecer. Para representar a situação atual, ou seja, em que condição encontra-se o sistema modelado, utiliza-se um token no lugar que corresponde a essa situação, por exemplo: a condição atual é manhã. Na figura 3.2.a tem-se o modelo que representa esse sistema e a sua situação atual. Estando nesta condição o único evento que poderá ocorrer é entardecer, que é representado pela transição de mesmo nome. Na ocorrência desse evento, tem-se uma nova situação atual, ou seja: tarde, que é representada graficamente, na figura 3.2.b [MAC 96].

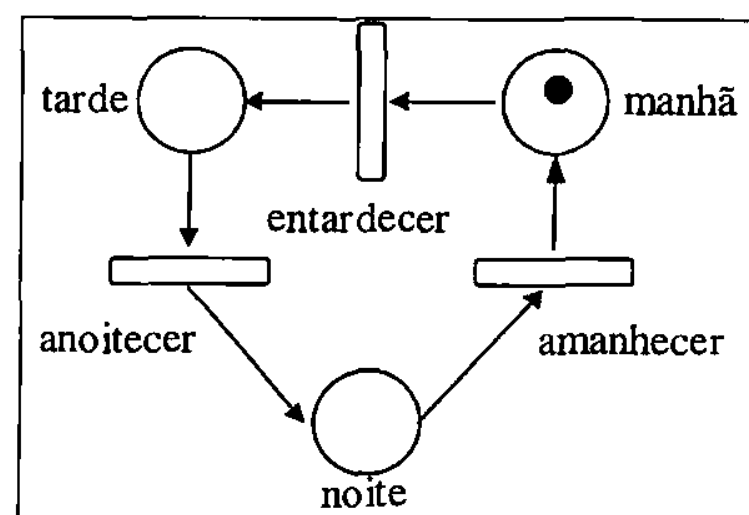

(a)

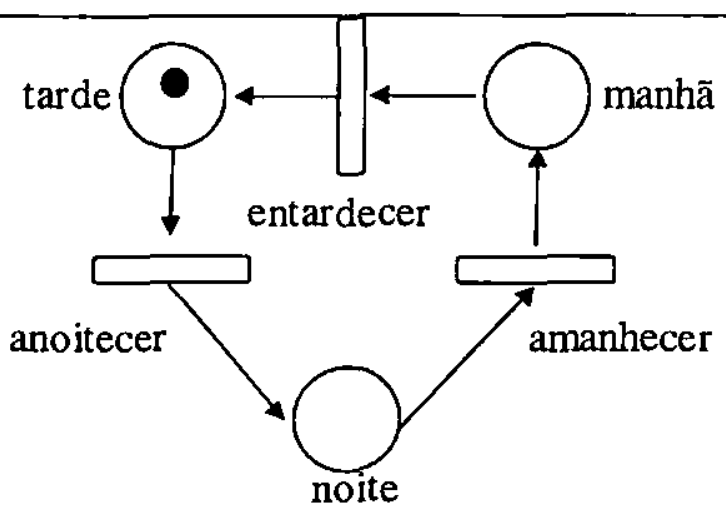

(b)

Figura 3.2: Períodos do Dia.

\subsection{Modelos Básicos de Redes de Petri}

Dependendo da aplicação as Redes de Petri podem ser modeladas utilizando arcos múltiplos ou valorados, escolha não determinística, concorrência, conflito e escolha livre [MAC96].

\subsubsection{Arcos Múltiplos ou Valorados}

Os lugares de uma Rede de Petri podem ser conectados às transiçōes através de arcos múltiplos, da mesma forma que vários arcos podem conectar uma transição a um lugar. Por conveniência, pode-se substituir os arcos múltiplos representados na figura 3.3.a por um único arco valorado, onde o número associado ao arco corresponde ao número de arcos que interligam os vértices, como pode ser visto na figura 3.3.b[MAC96]. 


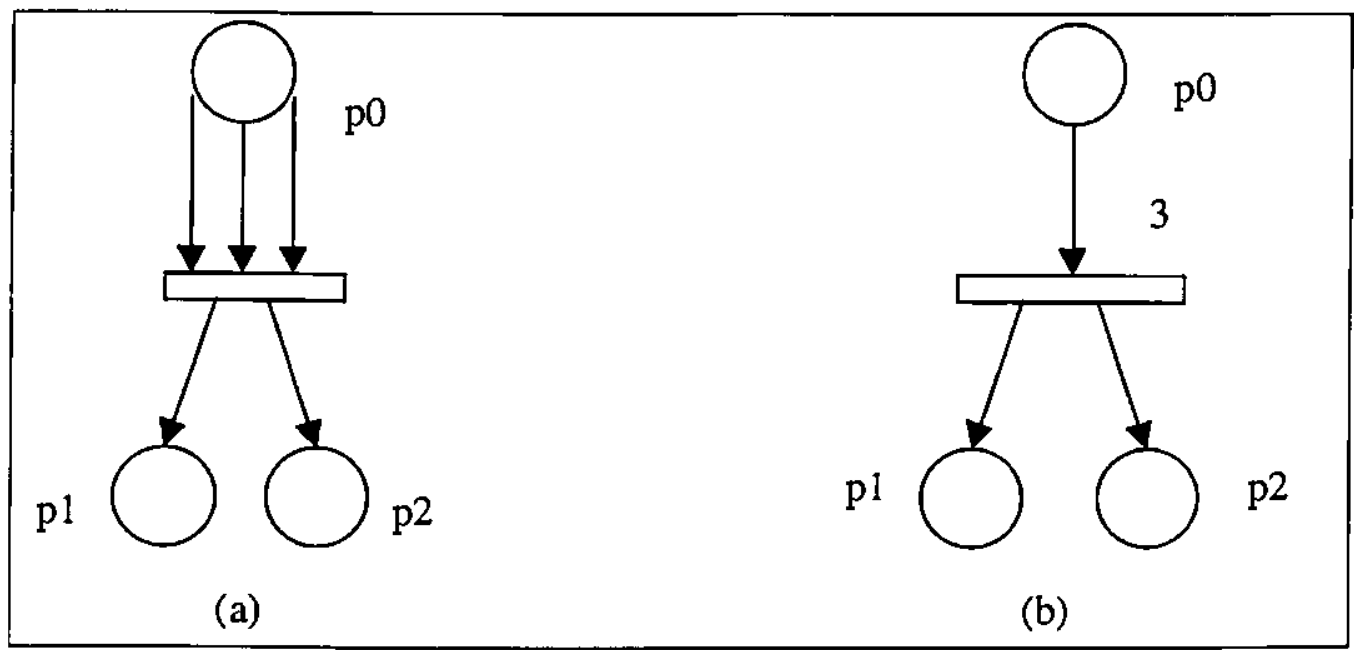

Figura 3.3: Múltiplos Arcos

Assim, os arcos múltiplos ou valorados indicam que é necessária a ocorrência de $\mathrm{n}$ tokens (no caso da figura $3.4, n=3$ ) para que a transição ocorra.

Um exemplo que utiliza o modelo de arcos valorados é o que representa algumas das tarefas de uma linha de montagem, onde são empacotados conjuntos de três parafusos e três porcas. O modelo considerado representa o empacotamento e envio dos pacotes ao setor de expedição. Um novo conjunto só poderá ser empacotado quando o conjunto atualmente produzido for enviado à fase seguinte do processo. A figura 3.4 apresenta o modelo que representa esta linha de montagem [MAC96].

Após a manufatura os tokens que representam os parafusos, sāo depositados no lugar Parafusos. De forma semelhante, as porcas são armazenadas no lugar Porcas. A transição Monta Pacote, que representa a tarefa de formação dos conjuntos (porcas e parafusos), só disparará quando estiver habilitada a disparar, ou seja, quando houver no mínimo três parafusos (tokens) e três porcas (tokens) nos lugares Parafuso e Porcas, respectivamente (figura 3.4.a). Sendo satisfeita esta condição, o disparo de Monta Pacote retira três parafusos (tokens) e três porcas (tokens) e deposita um token no lugar Pacote, que indica a montagem de um conjunto (figura 3.4.b). Tendo sido produzido um pacote, é possível enviar este pacote para o depósito de saída da seção (disparando-se Envia Pacote), para que esteja disponível ao setor de expedição. O pacote, ao ser colocado no depósito, possibilita à máquina montar um outro conjunto, desde que haja parafusos e porcas suficientes, nos respectivos depósitos de entrada. Assim, a transição Envia Pacote envia um token também para o lugar Máquina. 


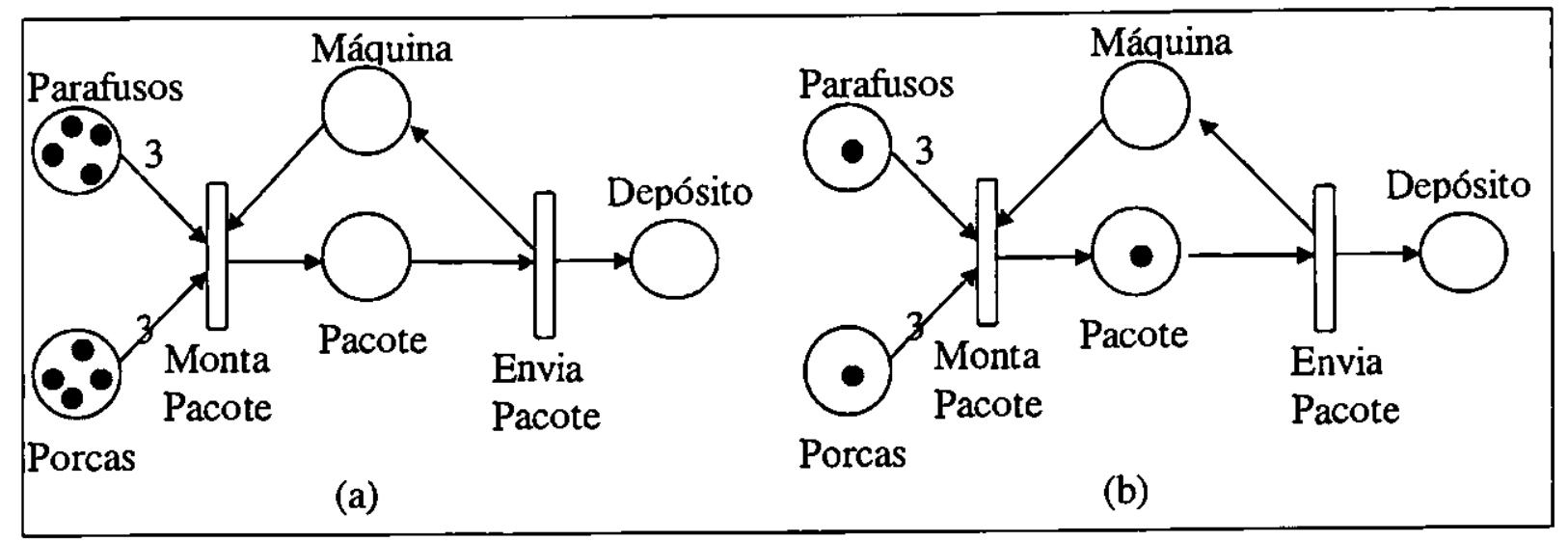

Figura 3.4: Linha de Produção.

\subsubsection{Escolha Não-Determinística}

Escolha não determinística é quando em uma Rede de Petri têm-se duas transições com um mesmo lugar de entrada; a figura 3.5 representa a escolha não-determinística do disparo de transiçס̃es. Neste modelo, o disparo de uma transição inabilita o disparo da outra transição [MAC96].

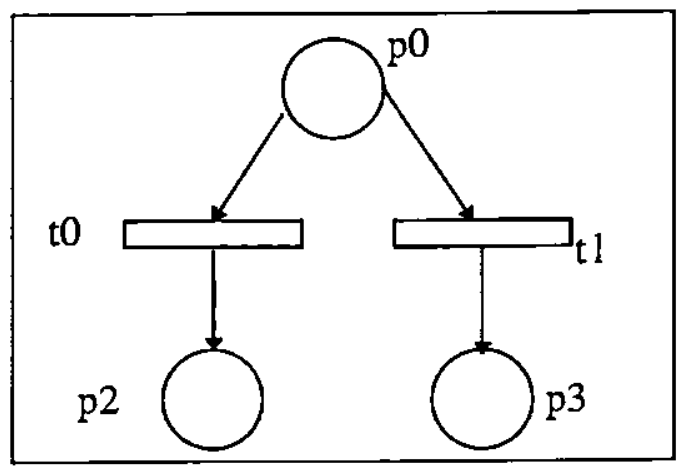

Figura 3.5: Escolha Não-Determinística.

\subsubsection{Concorrência}

Concorrência é quando duas transições independentes estão habilitadas, podendo então ocorrer concorrentemente.

\subsubsection{Conflito Estrutural - Conflito Efetivo}

Conflito estrutural ocorre quando duas transições to e $t l$ têm um lugar comum p3 como entrada, como é ilustrado na figura 3.6.a. 
Conflito efetivo ocorre quando duas transições t0 e $\mathrm{t} l$ estiverem em conflito estrutural e o disparo de uma das transições inabilita o disparo da outra transição como ilustra a figura 3.6.b. Portanto o conflito efetivo considera tanto a estrutura da rede como a marcação [MAC96].

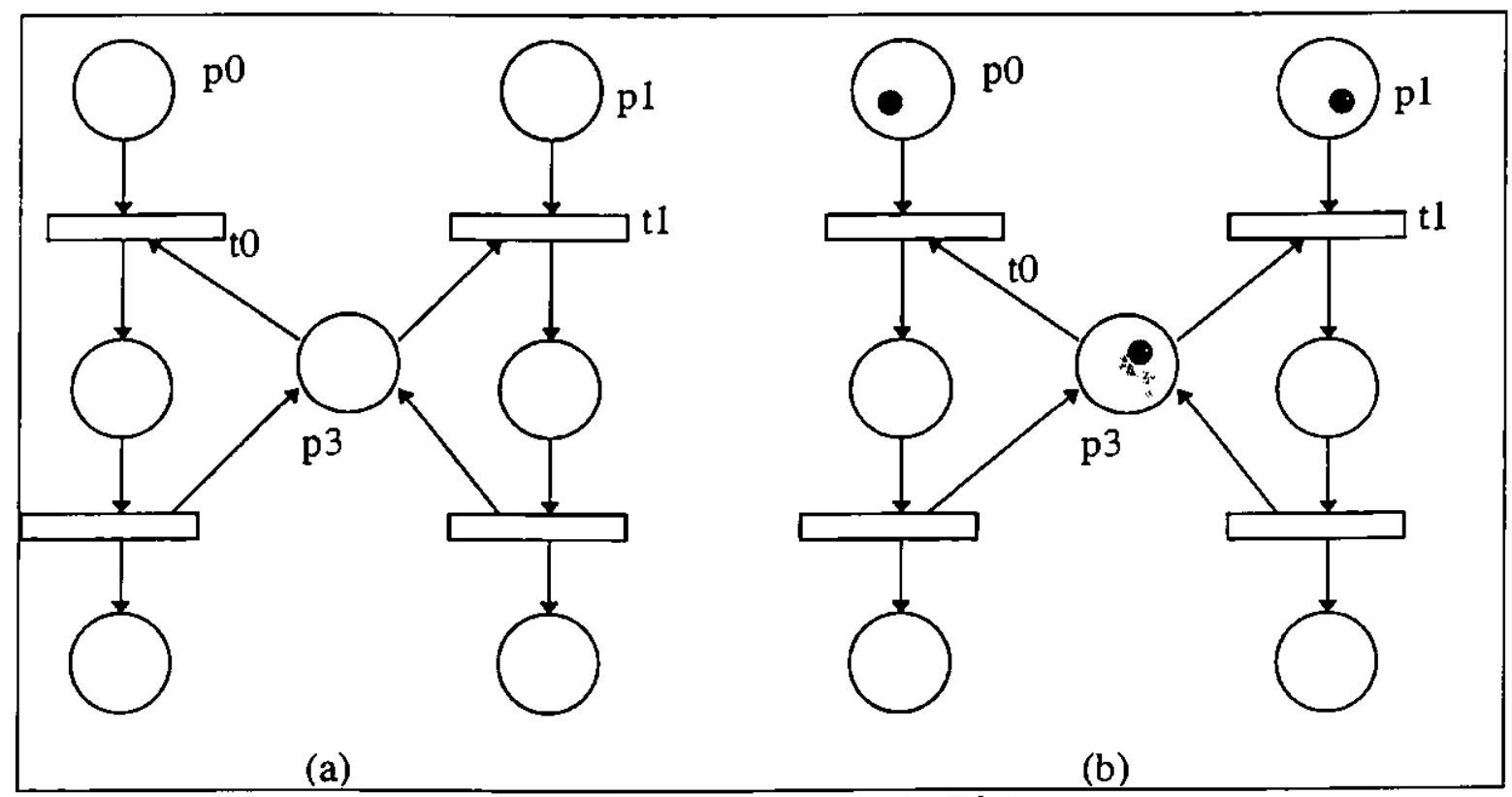

Figura 3.6: Conflito Estrutural e Efetivo.

\subsubsection{Confusão}

Confusão ocorre quando dois eventos estão ao mesmo tẹmpo em conflito e em concorrência. Existem dois tipos de confusōes: confusão simétrica e assimétrica. A figura 3.7.a ilustra a confusão simétrica: neste caso as transições t0 e t2 são concorrentes, no entanto cada uma destas transições está em conflito efetivo com $\mathrm{t} l$, pois o disparo de $\mathrm{t} l$ impossibilita o disparo de t0 e t2 e vice e versa. A figura 3.7.b ilustra a confusão assimétrica: nesse caso as transiçōes t0 e t2 são concorrentes, no entanto se a transição t2 disparar antes da transição t0, tem-se um conflito efetivo entre t0 e 1 [ [MAC96]. 


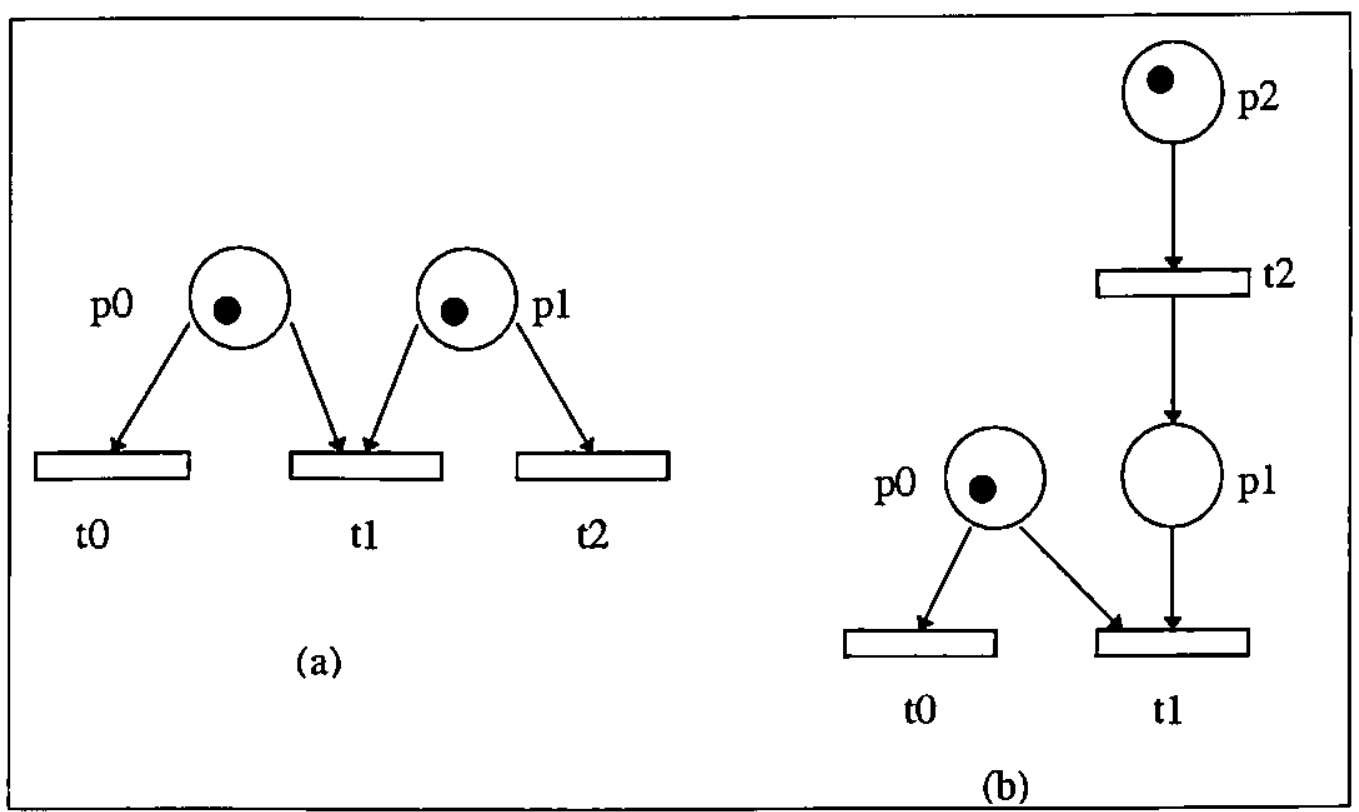

Figura 3.7: Confusão Simétrica e Assimétrica.

\subsection{Propriedades}

As propriedades das Redes de Petri podem ser divididas em dois grandes grupos: propriedades dependentes da marcação (presença de tokens) e as não dependentes da marcação, denominadas propriedades comportamentais e estruturais, respectivamente [MAC96].

\subsubsection{Propriedades Comportamentais}

Alcançabilidade (Reachability): indica a possibilidade de atingir uma determinada marcação pelo disparo de um número finito de transições, a partir de uma marcação inicial (esta propriedade é fundamental para o estudo de propriedades dinâmicas de qualquer sistema).

Limitação (Boundedness): seja um lugar p de uma Rede de Petri, este lugar é dito klimitado ou simplesmente limitado, se o número de tokens de cada lugar não exceder $\mathrm{k}$ em qualquer marcação acessível.

Segurança (Safeness): uma Rede de Petri é segura se todos os lugares dessa rede são seguros, ou seja, todos os lugares desta rede podem conter um ou nenhum token (esta propriedade é importante na especificação de sistemas digitais).

Vitalidade (Liveness): representa a ausência de deadlock em uma rede. Deadlock em uma Rede de Petri representa a impossibilidade do disparo de qualquer transição da rede. Uma 
transição é denominada viva se esta não possibilita a ocorrência de deadlock. É muito complexo observar a presença desta propriedade em sistemas de grande porte (esta propriedade é fundamental em sistemas reais). Portanto, há uma tendência em se relaxar esta condição e adotar niveis de vitalidade para as transições e, conseqüentemente, para as redes. Uma transiçāo é denominada:

Morta ou nível (n0), se esta transição nunca poderá ser disparada em qualquer sequiência;

$\rightarrow \mathrm{Nl}$ - viva, se a transição $\mathrm{t}$ pode ser disparada pelo menos uma vez em alguma seqüiência;

$\rightarrow \mathrm{N} 2$ - viva, se a transição $t$ pode ser disparada pelo menos $k$ vezes em alguma seqüência de disparo;

$\rightarrow \mathrm{N} 3$ - viva, se a transição t aparecer um número infinito de vezes em alguma sequiência de disparo;

$\rightarrow$ N4 - viva ou simplesmente viva, se a transição t é n1 - viva para todas as marcações.

Cobertura (Coverability): esta propriedade está fortemente ligada ao conceito de alcançabilidade e de vitalidade. Uma rede é dita coberta se existir uma marcação para cada lugar da rede.

Persistência: uma Rede de Petri é denominada persistente se a rede possuir duas transições habilitadas, o disparo de uma delas não desabilita o disparo da outra, ou seja, esta transição continua habilitada até o seu disparo (esta propriedade é importante par sistemas paralelos que possuam atividades assíncronas).

Reversibilidade: uma Rede de Petri é denominada reversível se para cada marcação acessível, a marcação inicial pode ser novamente alcançada.

Justiça (Fairness): dois tipos de justiça podem ser considerados: justiça limitada (bounded-fairness ou B-fair) e justiça incondicional. Duas transições são classificadas como Bfair, se o número de vezes que uma delas dispara é limitado, enquanto a outra não dispara.

Justiça incondicional ou global é denominada quando uma sequiência de transições é finita ou se todas as transições da rede aparecem infinitas de vezes nessa sequiência. 


\subsubsection{Propriedades Estruturais}

As propriedades estruturais são aquelas que refletem características independentes da marcação.

Limitação Estrutural: uma Rede de Petri é denominada como estruturalmente limitada se ela for limitada para qualquer marcação.

Conservação: não permite que o número de tokens de uma Rede de Petri sejam alterados, isto é, o disparo de qualquer transição desta rede não altera o número de tokens

Repetitividade: uma rede é classificada como repetitiva se para uma marcação e uma sequiência de transições habilitadas, para esta marcação, todas as transições da rede podem disparar um número infinito de vezes.

Consistência: uma Rede de Petri é denominada consistente se depois que disparado uma sequiência de transições a partir de uma marcação inicial é possível voltar à mesma marcação inicial, porém todas as transições da rede são disparadas pelo menos uma vez.

\subsection{Classificação das Redes de Petri}

As Redes de Petri podem ser classificada como:

$\rightarrow$ Rede de Petri Binárias ou Condição-Evento

$\rightarrow$ Rede de Petri Place-Transition

- Rede de Petri Não-Ponderadas

- Rede de Petri Ponderadas

$\rightarrow$ Rede de Petri com Arco Inibidor

$\rightarrow$ Rede de Petri Hierárquicas.

$\rightarrow$ Rede de Petri Coloridas

$\rightarrow$ Rede de Petri Temporizada

$\rightarrow$ Rede de Petri Estocástica

$\rightarrow$ Rede de Petri com Objetos 


\subsubsection{Redes de Petri Binária ou Condição-Evento}

A classe Binária ou Condição-Evento representa a classe onde as Redes de Petri são mais simples que as redes de outras de classes. Nessa classe, os lugares podem conter no máximo um token e todos os arcos têm peso unitário [MAC 96].

Dentro da interpretaçāo Condição-Evento, cada um dos tokens representa uma condição no modelo. A presença de um token na rede representa a ocorrência de uma condição. A ocorrência de uma alteração da rede, a qual altera a marcação, representa a ocorrência de um evento real no modelo, o qual altera a presença ou não de condições [HEU90]. A figura 3.8. apresenta uma rede que descreve um processo que pode utilizar dois recursos $\mathrm{r} l$ e $\mathrm{r} 2$.

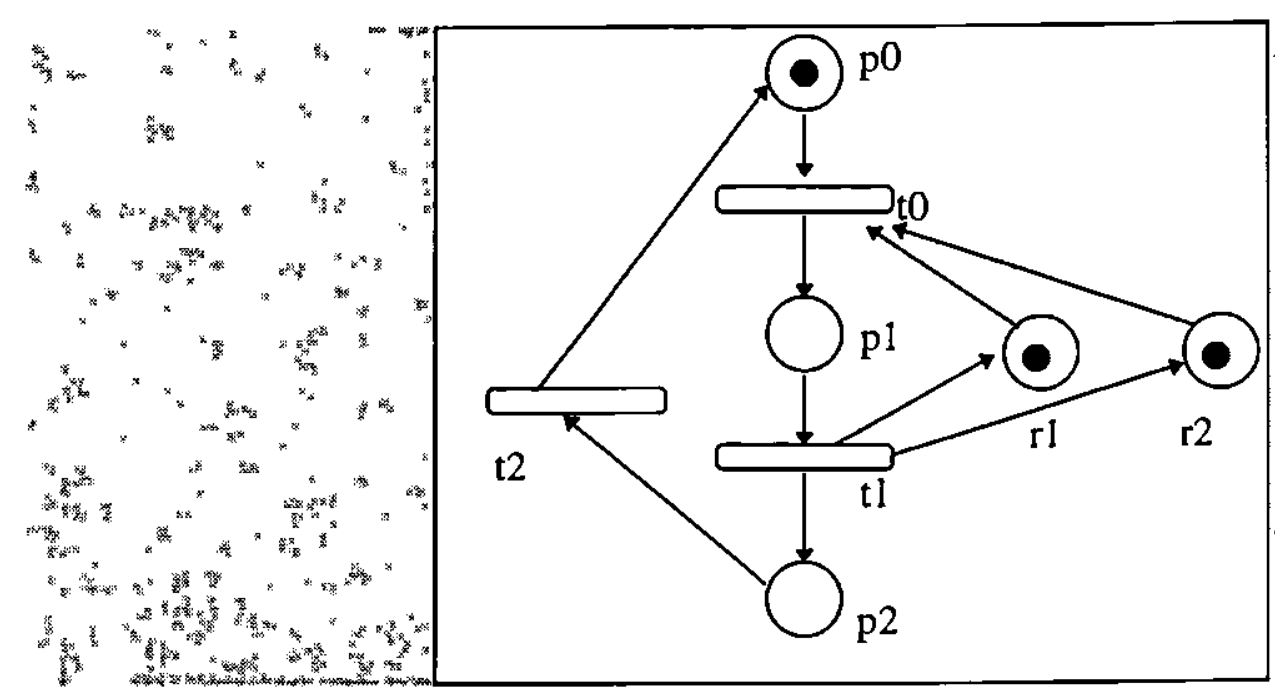

Figura 3.8: Rede Binária ou Condiçāo Evenıo

\subsubsection{Redes de Petri Place-Transition}

Denominam-se Rede Place-Transition aquelas onde os lugares podem armazenar mais que um token, assim como os arcos podem ser valorados. Esta classe de Redes de Petri pode ser dividida em redes não ponderadas e ponderadas. Nas Redes de Petri não-ponderadas os lugares podem ter mais do que um token e a valoração dos arcos é unitária. Uma rede não ponderada (figura 3.9), que representa o mesmo processo utilizado para a Rede de Petri Binária, apresenta uma forma mais compacta, com apenas um lugar representando os recursos. O número de tokens no lugar $r$ indica a quantidade de recursos [MAC96].

Nas redes ponderadas pode-se ter arcos múltiplos, isto é, os arcos possuem pesos associados a eles [MAC96]. 


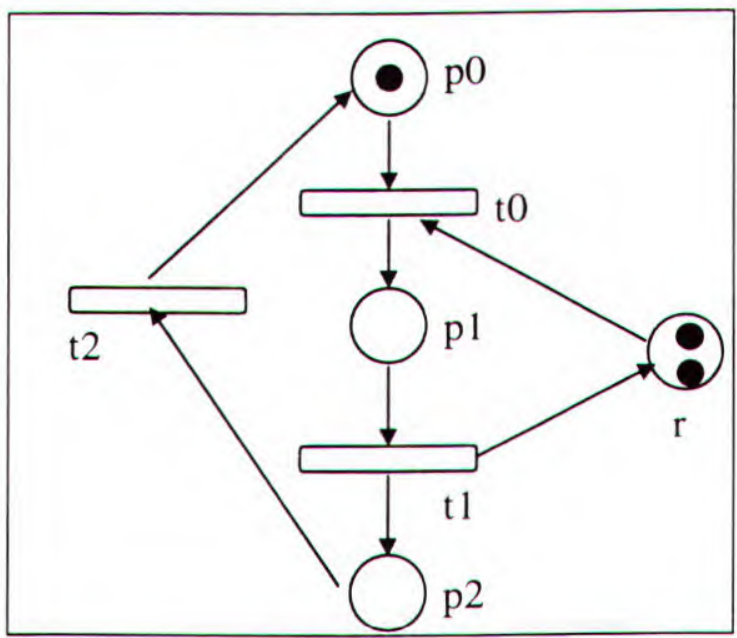

Figura 3.9: Rede de Petri Place-Transition

\subsubsection{Redes de Petri com Arco Inibidor}

Quando uma Rede de Petri possui transições que têm como entrada arcos inibidores a regra de disparo é alterada. Essas transições só estarão habilitadas a dispararem caso os lugares de entrada, que estão relacionados às transições pelos arcos inibidores, não contiverem tokens. Um arco inibidor é diferenciado por um círculo oco no lugar da seta. A figura 3.10 apresenta uma rede com arco inibidor, onde a transição t2 só estará habilitada a disparar quando não houver tokens em p0 e houver em p1 [MAC96].

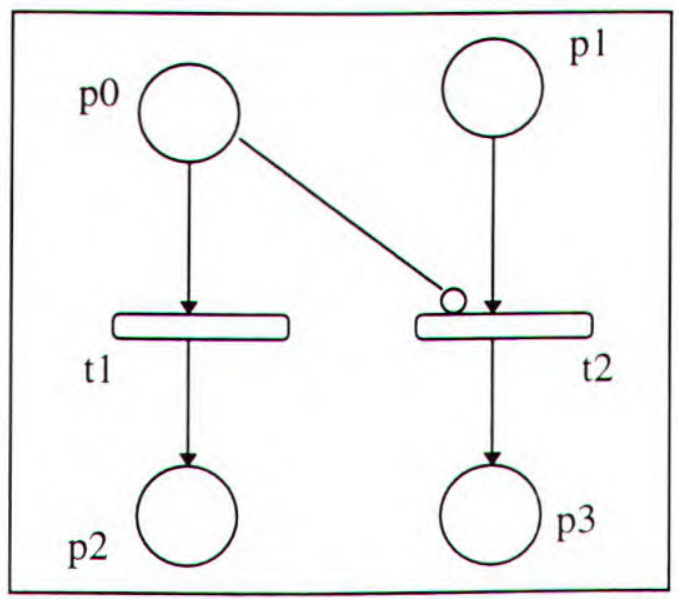

Figura 3.10: Arco inibidor 


\subsubsection{Redes de Petri Hierárquicas}

Segundo Maciel [MAC96], o conceito de hierarquia em Redes de Petri permite o refinamento de lugares e transições. Do ponto de vista teórico, a hierarquia é apenas uma conveniência gráfica que não adiciona nenhum poder computacional, contudo para a modelagem segura de sistemas de grandes dimensões é necessário o uso de ferramentas que utilizem esses mecanismos.

As redes hierárquicas oferecem uma descrição estruturada do sistema, possibilitando sua especificação em níveis de abstração que podem ser refinados quando necessário. Nessa classe de rede, os lugares e as transições dos níveis superiores podem ser refinados, ou seja, podem ser sub-redes da rede global. Estas sub-redes fornecem uma descrição mais detalhada do lugar ou da transiçāo do nível superior. A interface entre um lugar ou transição de mais alto nível e a subrede correspondente é efetuada através de transições ou lugares.

O primeiro refinamento utilizado nesta abordagem para obter a de hierarquia em Redes de Petri é feita a substituição de transições. Cada transição de alto nível designa uma nova página denominada subpágina. Uma transição de alto nível é vista como uma caixa preta (figura 3.11 .a) e a subpágina correspondente representa o detalhamento dessa transição (figura 3.11.b). A transição de alto nível e a página em que está inserida são, para a subpágina, denominadas de superpágina.

Na figura 3.11.a tem-se uma Rede de Petri com duas transições de alto nível e na figura 3.1 l.b apresenta-se uma página que representa o refinamento da transição t0.

Os passos seguintes possibilitam a representação não-hierárquica equivalente da rede:

$\rightarrow$ Remove-se a transição de alto nível.

$\rightarrow$ Insere-se a subpágina, que representa o refinamento da transição.

$\rightarrow$ Fundem-se os lugares da rede de mais alto nível da subpágina. 


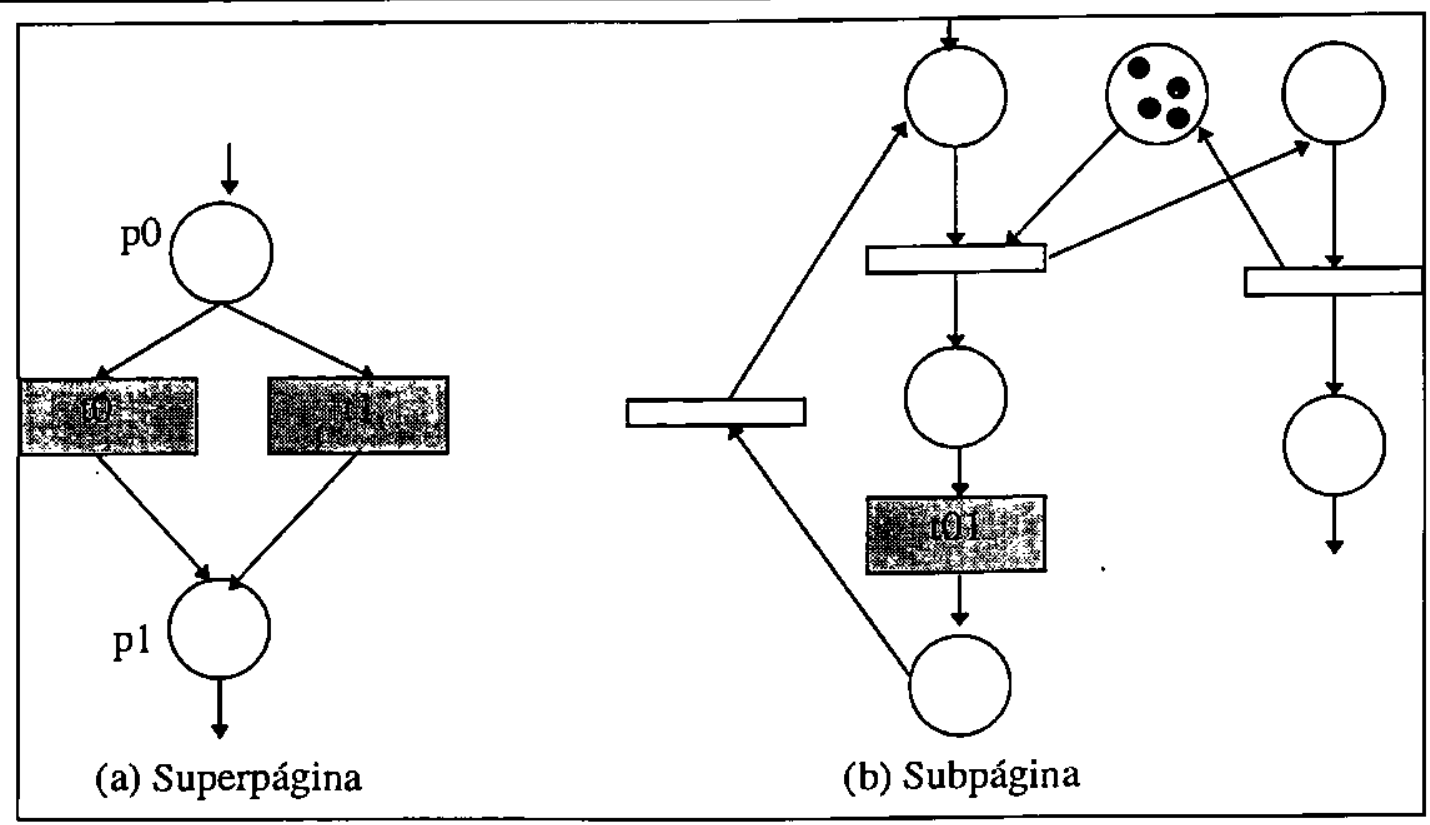

Figura 3.11: Rede de Petri Hierárquica.

\subsubsection{Redes de Petri Coloridas}

Enquanto Redes de Petri oferecem grande poder de modelagem, o gerenciamento de modelos de grande escala fica difícil devido ao fato de existir somente uma representação dos tokens para distinguir diferentes entidades. As Redes de Petri coloridas foram desenvolvidas para fornecer um método para distinção entre os tokens nos lugares [MOO95a].

As Redes de Petri Coloridas têm como objetivo principal a redução do tamanho do modelo, permitindo que tokens individualizados (cores) representem diferentes processos ou recursos em uma mesma rede [MAC96].

A figura 3.12 apresenta um exemplo de Rede de Petri Colorida. Nessa classe os arcos são rotulados com uma ou mais das possíveis cores ou ainda com variáveis. Na figura 3.12 os arcos são rotulados com cores (a, b e c). Para que uma transição desta rede esteja habilitada, é necessário que os lugares que são entradas desta transição tenham tokens do tipo (cor) associado ao arco que interliga estes lugares à transição. A transição t0 não se encontra habilitada, pois o lugar $\mathrm{p} 0$ não possui um token da cor a, contudo a transição $\mathrm{t} l$ está habilitada, pois o lugar $\mathrm{pl}$ possui um token da cor a e o lugar $\mathrm{p} 2$ possui tokens das cores a, b, o que satisfaz as condições rotuladas nos arcos que interligam estes lugares à transição $t 1$. O disparo desta transição retira os tokens das cores associadas aos arcos, dos lugares de entrada e adiciona aos lugares de saída tokens de cor igual à cor associada ao arco que interliga a transição aos lugares de saída. Neste caso, um token de cor c é depositada no lugar p4 [MAC96]. 

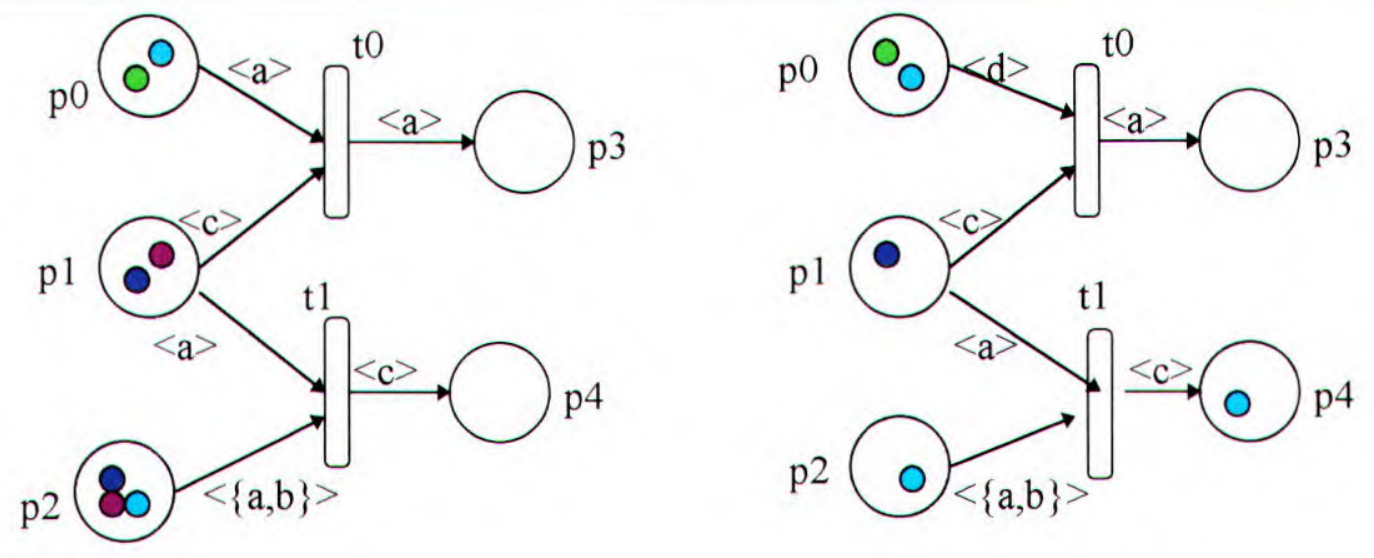

Após o disparo de $\mathrm{t} 1$.

\begin{tabular}{|l|c|}
\hline Cores & Tokens \\
\hline a & 0 \\
\hline $\mathrm{b}$ & 0 \\
\hline $\mathrm{c}$ & 0 \\
\hline $\mathrm{d}$ & 0 \\
\hline
\end{tabular}

Figura 3.12: Redes de Petri Coloridas

Inicialmente, as marcas das Redes de Petri Coloridas eram representadas por cores ou mesmo por padrões que possibilitavam a distinção dos tokens, atualmente as marcas são representadas por estruturas de dados complexas, não relacionando cores aos tokens, a não ser pelo fato de que os tokens são distinguíveis.

As Redes de Petri Coloridas são compostas por três partes: estrutura, declaração, inscrições. A estrutura é um grafo dirigido com dois tipos de vértices (lugares e transições). Cada lugar pode armazenar diversos tokens e cada um desses tokens pode representar valores associados a tipos de dados complexos. As declarações compreendem a especificação dos conjuntos de cores e declarações de variáveis. Nessa classe de rede cada lugar, transição e arcos têm inscrições associadas. Os lugares têm três tipos de inscrições: nomes, conjunto de cores e expressão de valor inicial (marca inicial). As transições possuem dois tipos de inscrições: nomes e expressões guardas, e os arcos apenas um tipo de inscrição dada pela expressão [MAC96]. 


\subsubsection{Redes de Petri Temporizada Determinística}

Segundo Maciel [MAC96], entre as diversas abordagens de Redes de Petri que tratam requisitos temporais, apresentam-se algumas propostas com relação à forma em que os tempos são especificados:

$\rightarrow$ tempo pode estar associado aos lugares, onde os tokens armazenadas nos lugares de saída, após o disparo de uma transição, só estarão disponíveis para disparar uma nova transição após um determinado tempo que é associado ao lugar.

$\rightarrow$ tempo pode estar associado aos tokens, onde os tokens possuem uma informação que indica quando a marca estará disponível para disparar a transição.

$\rightarrow$ tempo é associado à transição.

As Redes de Petri Temporizadas podem ser classificadas como de disparo atômico ou de disparo de três fases. Nas redes onde o disparo das transiçōes é atômico, os tokens permanecem nos lugares de entrada das transições até o tempo associado à transição ter sido "consumido" e então os tokens são removidos dos lugares de entrada e imediatamente armazenados nos lugares de saída. Nas redes temporizadas com disparo em três fases, quando uma transição é habilitada os tokens são imediatamente retirados dos lugares de entrada, mas são apenas depositados nos lugares de sáída após o tempo associado à transição disparada.

Nas Redes de Petri Temporizadas com disparo atômico, quando uma transição é habilitada, um contador é iniciado com o tempo associado à transição. O contador é decrementado a uma taxa constante. Quando o contador atinge o valor zero, a transição dispara.

Observe-se, contudo, o problema que se tem quando duas transiçбes estão habilitadas para uma dada marcação. Na figura 3.13 tem-se uma rede que representa essa situação. Nessa representação, a transição que será disparada será aquela que possuir o menor tempo associado. Um fato interessante é ressaltado com o disparo de uma dessas transições, por exemplo, suponha $\mathrm{dl}<\mathrm{d} 2$, o que proporciona o disparo da transição $\mathrm{tl}$. Nesse caso, qual será a situação do contador associado à transição t2, após o disparo de $\mathrm{t} l$ ? Algumas políticas têm sido utilizadas para tratar esse problema [MAC96]:

Reamostragem: a cada disparo de transição todos os contadores de todas as transiçōes serão reiniciados, ou seja, nenhuma informação anterior é registrada. 
Com Memória: quando ocorre um disparo de uma transição, os contadores associados a cada transição que se torna desabilitada são reiniciados. Os contadores das transições que permanecem habilitadas mantêm os seus valores.

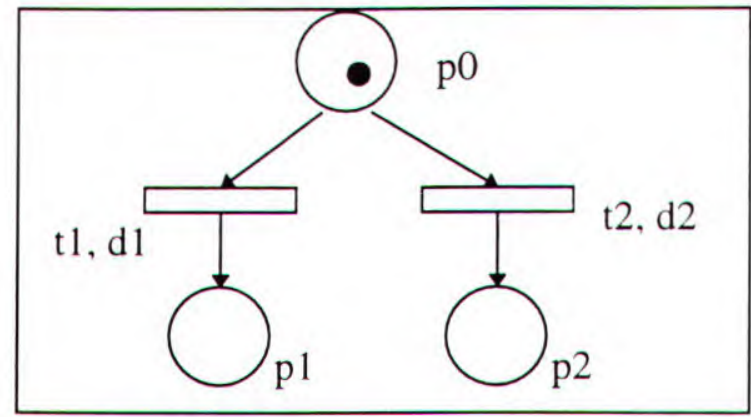

Figura 3.13: Marcação Habilitando Duas Transição

\subsubsection{Redes de Petri Estocásticas}

Uma outra maneira de tratar requisitos temporais através das Redes de Petri é através do ponto de vista probabilístico do disparo das transições. Diversos autores propuseram independentemente a associação de retardos de disparo exponencialmente distribuídos às transições. Essas redes são denominadas Redes de Petri estocásticas, pois o comportamento dessas redes pode ser descrito por um processo estocástico [MAC96].

Redes de Petri Estocásticas permitem o cálculo do provável estado dos lugares e a ocorrência de suas marcações, tornando possível a análise de medidas de desempenho tais como delay e throuput.[MOL82].

Portanto as Redes de Petri Estocásticas facilitam a implementação de modelagem de protocolos de comunicação e permitem a modelagem de processos de alto nível de abstração onde o tempo se torna uma variável aleatória e o sistema se comporta estocasticamente [MOL82].

\subsubsection{Redes de Petri com Objetos}

Redes de Petri com Objetos são aquelas em que os tokens podem ser identificados como sendo objetos, permitindo ser subredes encapsulando suas próprias atividades [LAK95].

Segundo Nketsa [NKE96], Redes de Petri com Objetos são mais difíceis para se estudar e verificar porque os tokens são mais complexos. Não existe nenhum método de análise formal 
para este tipo de Redes de Petri. No entanto, simulação é o meio mais freqüente para análise prática, pois é impossível construir uma Rede de Petri com Objetos sem pensar sobre os efeitos de transiçōes individuais e objetos.

Em uma Rede de Petri com Objetos cada lugar é conectado a uma transição. Cada transição pode estar associada a uma pre-condição, a qual pode ser uma função booleana e pode testar o valor dos lugares de entrada. Cada lugar pode conter um conjunto de tokens,(instancias do objeto). A marca inicial é a distribuição inicial da instancia do objeto nos lugares.

Redes de Petri com Objetos são utilizadas em simulação distribuída [NEK96] e são baseadas em linguagens orientadas a objetos [LAK95].

\subsection{Exemplos de Redes de Petri}

\section{Exemplo 1:}

Computação Dataflow - As Redes de Petri são utilizadas normalmente para modelar fluxo de controle, no entanto possibilitam também a modelagem de fluxo de dados (dataflow) [MAC96].

Em um modelo dataflow não existe fluxo de controle seqüencial como em sistemas de computação convencional. Diversas unidades funcionais podem executar suas tarefas assim que os operandos tornam-se disponíveis. Algoritmos que possuem essas características possibilitam um alto grau de paralelismo em máquinas dataflow.

A figura 3.14 ilustra um exemplo de computação dataflow para a expressão $\mathrm{e}^{(x+y) / y}$, onde os tokens no modelo representam os valores ou a disponibilidade de dados. Inicialmente estão disponíveis os valores x e y nos lugares filax e filay. Quando a transição to dispara os valores x e y são enviados para o lugar soma, depois de executada a soma dispara a transição $t 1$ e o valor da soma é enviado para o lugar servl onde será verificada o valor de y. Se y for igual a zero, então disparará a transição $t 3$ colocando um token no lugar " $z$ é indefinido". Se y for diferente de zero disparará a transição $t 2$ colocando um token no lugar de saída. O disparo da transição t 2 envia o tone para o lugar que representa a divisão entre os termos $\mathrm{x}+\mathrm{y}$ por $\mathrm{y}$, o qual habilita a transição t4 que representa o cálculo da exponenciação $(e(x+y) / y)$, completando assim a operação. 


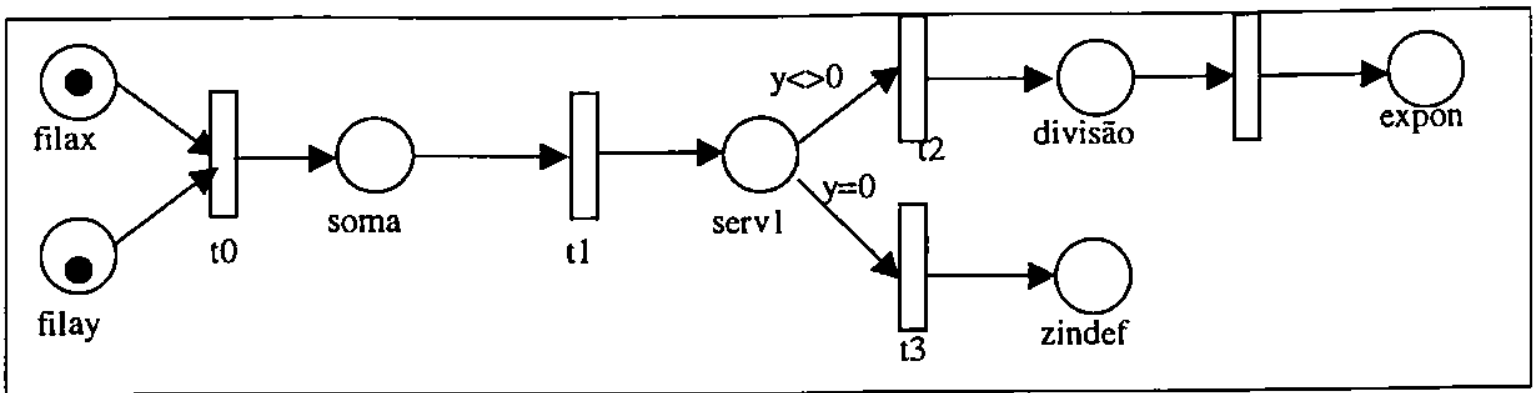

Figura 3.14: Computação Dataflow.

Este estilo de computação possibilita a exploração do paralelismo do sistema. Como pode ser observado, as operações são realizadas quando há a disponibilidade dos novos operandos e das unidades funcionais, enquanto outras operações podem ser realizadas paralelamente podendo ser perfeitamente modela por Redes de Petri.

\section{Exemplo 2:}

Sistema Pipeline - O paralelismo através de pipeline explora os aspectos temporais. Cada processador manipula apenas os dados fornecidos à sua entrada e passa estes dados transformados para o próximo processador (estágio). Uma noção importante nesse tipo de processamento é o fluxo de dados, que são passados de estágio para estágio, ficando a comunicação entre processadores restrita a estágios vizinhos [MAC96].

Um sistema pipeline é composto por um número de estágios que podem estar em execução simultaneamente. Quando um estágio i encerra sua atividade, este transfere o resultado obtido e aguarda por novas informações provenientes de estágios anteriores.

O sistema pipeline pode ser modelado com duas unidades funcionais. Neste sistema as informações são fornecidas ao sistema através de uma entrada da unidade funcional $\mathrm{A}$. Na figura 3.15 apresenta-se uma rede que descreve as tarefas executadas. A entrada do sistema é representada pelo lugar p0, portanto um token nesse lugar indica que há informação a ser tratada pelo sistema. O lugar pl representa a entrada da unidade A com alguma informação para ser tratada e o lugar p3 indica que a entrada está vazia. A leitura da entrada da unidade A (lugar p0) corresponde ao disparo da transição t0, que só está habilitada quando houver informação disponível e esta unidade estiver habilitada para efetuar a leitura. Os lugares p4 e p5 representam a saída da unidade A habilitada (vazia) e com algum dado (bloqueada), respectivamente. A 
transição 1 , que representa o início das operaçōes a serem realizadas pela unidade $A$, só pode ser disparada se houver dado na entrada da unidade (p1) e se a saída desta unidade estiver habilitada (p4). Um token no lugar p2 representa que a unidade A está em operação. Este lugar pode estar sintetizando uma rede complexa que pode representar em detalhes as operações e condições desta unidade. A transição $t 2$ representa a escrita de um resultado na saída da unidade $\mathrm{A}$.

Tokens nos lugares p7 e p8 representam que a entrada da unidade B possui dado e está habilitada. A transição 4 representa a operação inicial para a transferência da informação tratada pela unidade A para a unidade B. O lugar p6 resume a seqüuência de operações relativa à transferência de informações entre a unidade $\mathrm{A}$ e a unidade $\mathrm{B}$ (uma rede que representa os detalhes desta atividade). A transição $t 3$ representa a operaçăo final desse processo de transferência.

De forma semelhante, as operações e condições modeladas para a unidade $\mathrm{A}$, a transição t5 representa o início das operações realizadas pela unidade B. O início dessas operações está condicionado à disponibilidade de dados na entrada da unidade B (token no lugar p7) e que a saída desta unidade esteja vazia (lugar p10 marcado). O lugar p9 sintetiza as operações realizadas pela unidade $B$, a transição $t 6$ representa a operação de escrita na saída da unidade $B$. Um dado na saída da unidade funcional $B$ é representado por um token no lugar p11. A transição t7 modela a operação de escrita na saída do sistema (p12), assim como a liberação da entrada da unidade B (token no lugar p10).

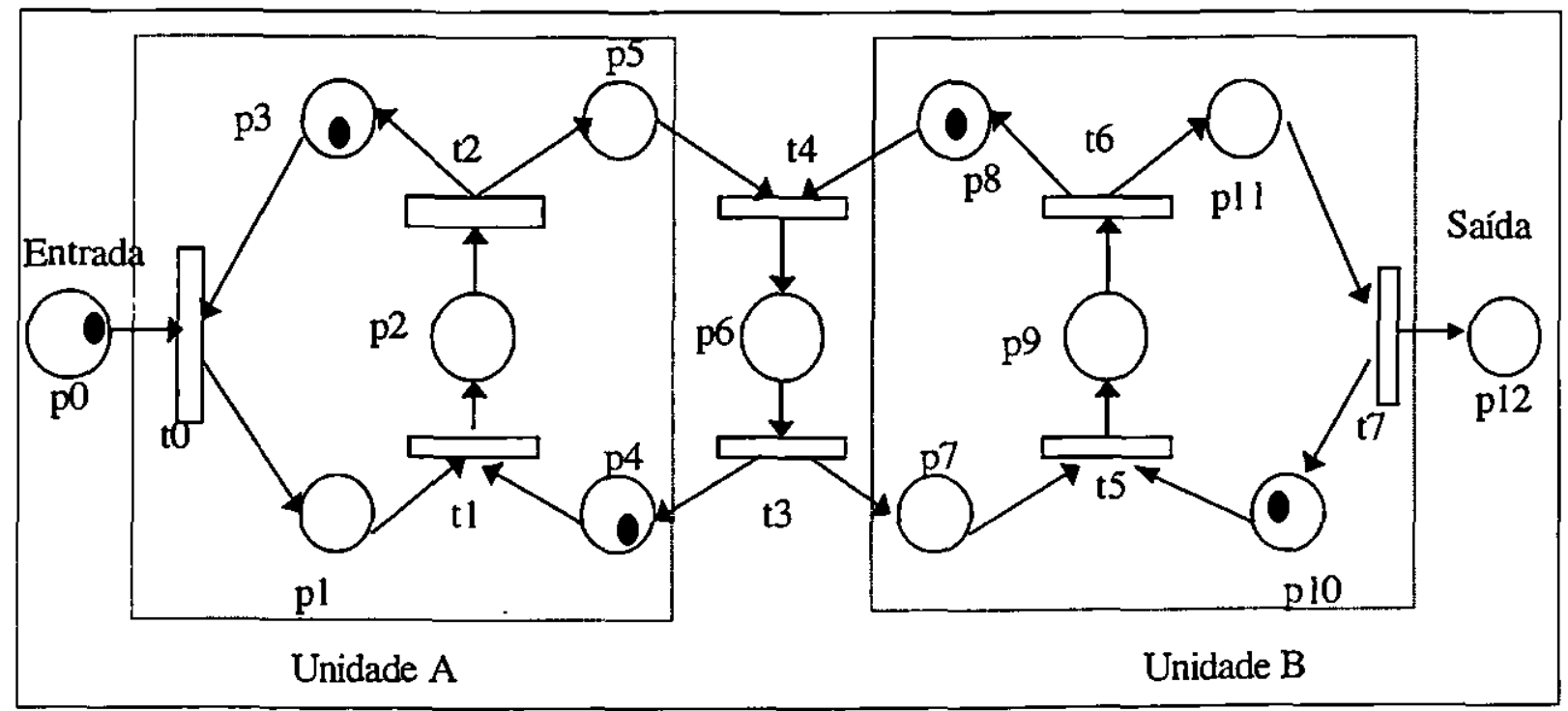

Figura 3.15: Pipeline. 


\section{Exemplo 3:}

Jantar dos Filósofos - Este exemplo considera a modelagem por Redes de Petri do problema do jantar dos filósofos proposto por Dijktra. Este problema descreve uma situação onde os filósofos podem estar comendo, pensando ou com fome. Os filósofos estão sentados em volta de uma mesa e cada um dos filósofos tem um garfo e um prato de comida a sua frente, no entanto, para que cada filósofo possa comer, é necessário que haja dois garfos, ou seja, o seu e o do seu vizinho. O problema em discussão é que, se todos os filósofos pegarem em um mesmo instante o garfo da direita e aguardarem a liberação do garfo a sua esquerda, o sistema entrará em deadlock (travamento) [MAC96].

A figura 3.16 apresenta a solução deste problema para três filósofos. Nesta solução os recursos (garfos) são representados por tokens nos lugares garfo 1, garfo2 e garfo3. Os estados de cada filósofo são representados pelos lugares, ppi, pcfi e pci, que identificam os estados pensando, com fome e comendo, respectivamente. O evento começar-a-pensar é representado pela transição tcpi, assim como tem-fome e começa-a-comer são representados respectivamente por ttfi e tcci.

$\mathrm{Na}$ figura 3.16 pode-se ver que o filósofo3 está pensando (token no lugar pp3), que o filósofo2 está com fome (token no lugar pcf2) e que o filósofol está comendo (token no lugar pci). Quando o filossofol encerra a refeição, esse libera os garfos, depositando-os nos lugares garfol e garfo3 e vai para o estado pensando (token no lugar ppl). O filósofo2 que está com fome pode começar a comer (dispara a transição tcc2, pois esta se encontra habilitada). Ao disparar-se esta transição, são retiradas os tokens dos lugares garfol e grafo2, passando este filósofo para o estado comendo. O filósofol e filósofo 3 que estão pensando podem então ter fome (disparo de tccl e ttf3). Ocorrendo isto, é retirado o token dos lugares ppl e pp3 e armazenados tokens nos lugares pcf1 e pc3. Observe que neste estado, tanto o filosofol como o filósofo3 podem começar a comer, no entanto se um fizer o outro fica impossibilitado de o fazer. Note-se, contudo, que todos os filósofos têm a possibilidade de fazer a refeição. Pode-se também verificar a inexistência de deadlock na rede. 


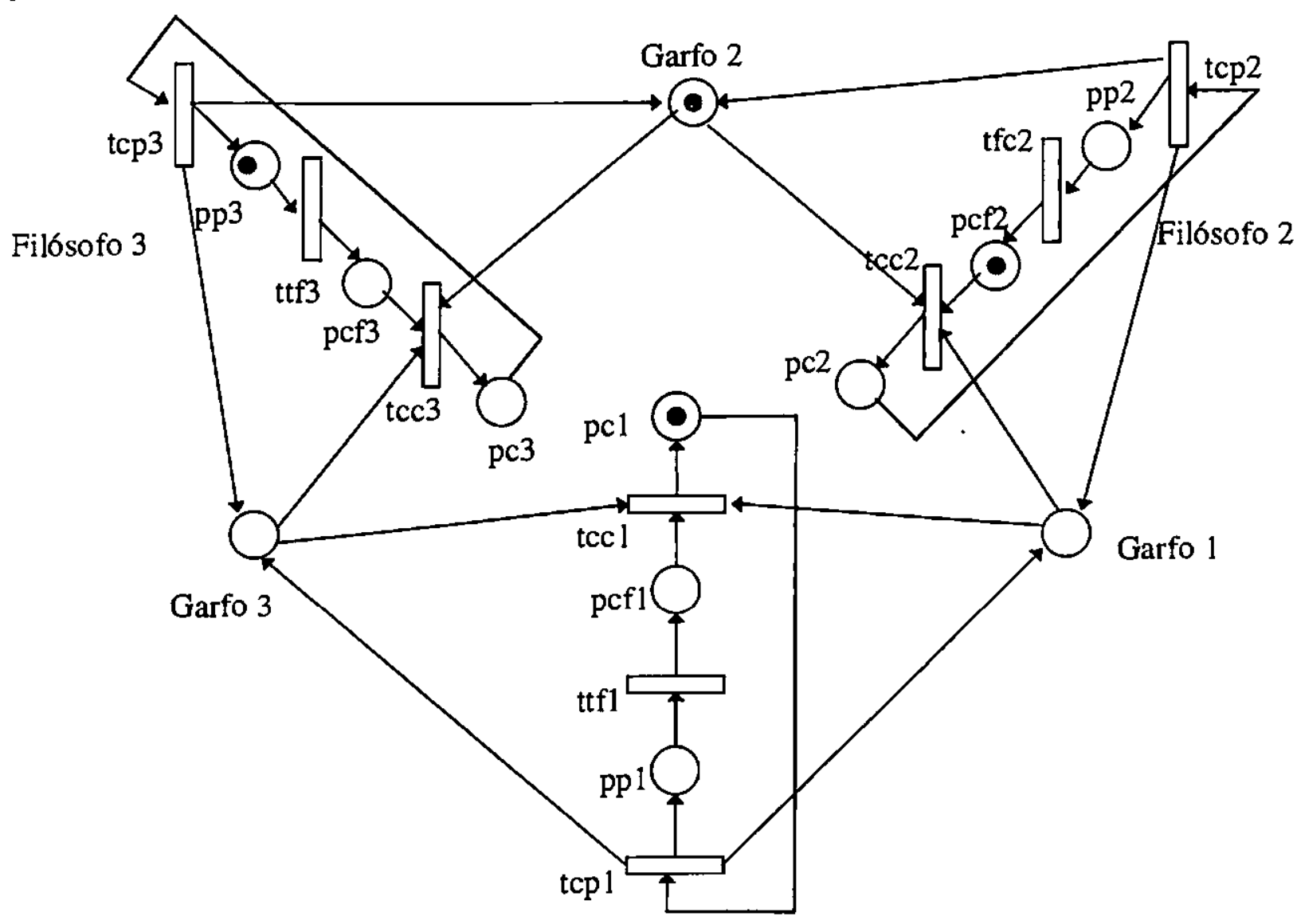

Filósofo 1

Figura 3.16: Jantar dos Filósofos.

A figura 3.17 apresenta uma Rede de Petri Colorida que representa o modelo da figura 3.16. Nesse modelo é ressaltado o número de iterações de cada processo. Os lugares $\mathrm{H}, \mathrm{E}$ e Th representam os estados dos processo e o lugar Garfo os recursos, ou seja, os garfos dos filósofos. O disparo da transição to pode ser efetuado segundo as três atribuições possíveis às variáveis $x$ e i, ou seja, a expressão que inicia o lugar $H$ quando avaliada resulta em três tokens de cores distintas, representando os filósofos e o número de iterações. Caso atribua-se à variável $\mathrm{x} a \operatorname{cor} \mathrm{p}(\mathrm{t} 0, \mathrm{x}=\mathrm{p})$ a expressão do arco que interconecta o lugar Garfo ao lugar t0 é avaliada para l'f1 + l'f2. O disparo de t0 remove o token $l^{\prime}(p, 0)$ do lugar $\mathrm{H}$ e os tokens l'f $1+$ l'f 2 do lugar Garfo e deposita o token l' $(\mathrm{p}, 0)$ no lugar E. Caso a atribuição seja outra, por exemplo, $\mathrm{x}=\mathrm{q}, \mathrm{a}$ avaliação das expressões dos arcos seria outra e ao disparar-se a transição obtém-se uma outra marcação. 


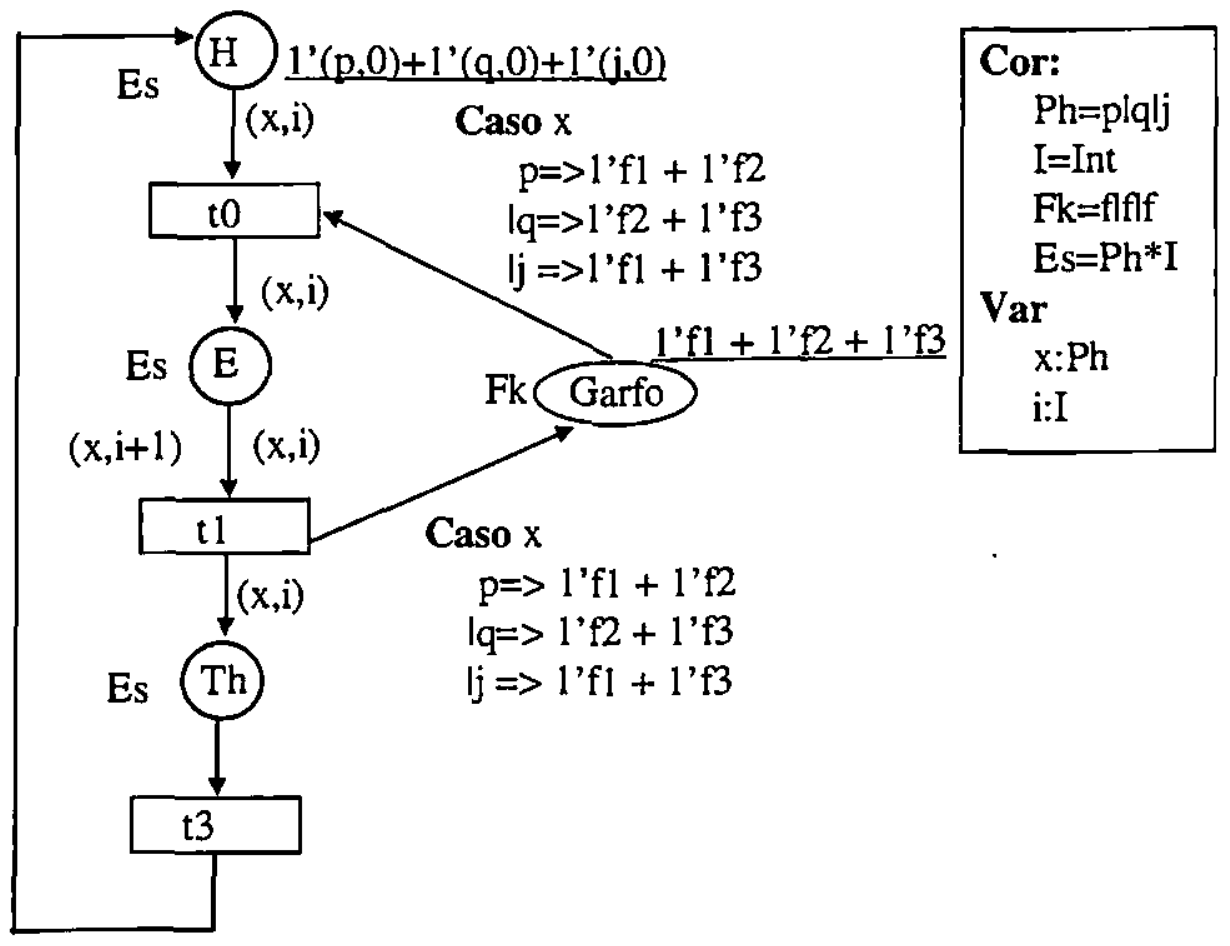

Figura 3.17: Jantar dos Filósofos - Modelo com Redes Coloridas.

\subsection{Comentários Finais}

Todas as classes de redes apresentadas têm o mesmo poder computacional, no entanto algumas dessas classes possibilitam um nível de abstração dos modelos mais alto ou mais baixo. Dependendo da aplicação, ou mesmo do estágio de desenvolvimento, faz sentido a escolha de uma determinada classe de rede para a modelagem do problema [MAC96].

As Redes de Petri oferecem inúmeras vantagens em termos de uma metodologia de modelagem para simulação destacando-se:

$\rightarrow$ Redes de Petri fornecem uma técnica de modelagem gráfica; como uma técnica gráfica, Redes de Petri tornam fácil visualizar o sistema modelado e comunicar o resultado do modelo; técnicas analíticas podem ser aplicadas a modelos pequenos ou submodelos.

$\rightarrow$ Redes de Petri são fáceis de aprender e usar: existe um conjunto pequeno de primitivas e uma rápida curva de aprendizado para ambos, desenvolvedores e usuários do modelo. 
$\rightarrow$ Muitas metodologias de simulação têm recursos limitados para uso paralelo, ou atividades assíncronas. Redes de Petri foram especialmente desenvolvidas para modelar esses tipos de atividades [MOO96]. 


\section{Capítulo 4}

\section{AMBIENTES DE SIMULAÇÃO}

\subsection{Introdução}

Mesmo simulação tendo muitas vantagens sobre as outras técnicas de avaliação de desempenho, as quais foram descritas no Capítulo 2, a implementação de um programa de simulação apresenta algumas dificuldades, tais como:

$\rightarrow$ construção de um modelo fiel ao sistema que será avaliado (conforme discutido no Capítulo 2);

$\rightarrow$ elaboração e execução de um programa de simulação;

A execução do programa é baseada na utilização de variáveis aleatórias garantindo assim a validade da simulação. Os resultados produzidos pelo programa serão analisados e validados através de gráficos e tabelas.

Considerando a dificuldade dos usuários menos experientes, surgiram os ambiente de simulação. Os ambientes de simulação automáticos fornecem a geração do programa de simulação através de especificações textuais ou gráficas. Os ambientes de simulação e suas características são descritos na seção 4.2

Na seção 4.3 é explicado o ASiA (Ambiente de Simulação Automático) que foi desenvolvido no Grupo de Sistemas Distribuídos e Programação Concorrente do ICMC - USP.

\subsection{Ambientes de Simulação}

Os ambientes de simulação automáticos fornecem a geração do programa de simulação através de especificações textuais ou gráficas. Estes ambientes são muito mais que uma simples linguagem para simulação. Cảa um deles apresenta características e aplicações distintas, mas todos oferecem ferramentas para o desenvolvimento de simulação e para a análise dos resultados obtidos através de simulação. 
A maioria dos ambientes de simulação disponíveis apresenta um ambiente gráfico para a definição dos modelos, que podem ser defendidos utilizando-se diferentes técnicas de modelagem. As técnicas mais empregadas são as Redes de Petri e Redes de Filas.

A tabela 4.1 apresenta alguns desses ambientes, que utilizam Redes de Petri para modelar o sistema a ser simulado. Para cada um dos ambientes é apresentado que tipo (ou tipos) de Redes de Petri é (ou são) utilizado (ou utilizados), a plataforma onde o ambiente pode ser executado e os componentes do ambiente [WWW1].

\begin{tabular}{|c|c|c|c|}
\hline $\begin{array}{l}\text { AMBIENTES } \\
\text { DE } \\
\text { SIMULAÇĀO }\end{array}$ & $\begin{array}{l}\text { TIPOS DE REDES } \\
\text { DE PETRI }\end{array}$ & COMPONENTES & PLATAFORMA \\
\hline Alpha/Sim & $\begin{array}{l}\text { Redes de Petri de } \\
\text { Alto Nível } \\
\text { Redes de Petri } \\
\text { Temporizada }\end{array}$ & $\begin{array}{c}\text { Editor Gráfico } \\
\text { Animação do Token } \\
\text { Simulação Rápida } \\
\text { Análise Simples de Desempenho }\end{array}$ & $\begin{array}{c}\text { Sun } \\
\text { MS Windows }\end{array}$ \\
\hline Artifex & $\begin{array}{l}\text { Redes de Petri de } \\
\text { Alto Nível } \\
\text { Redes de Petri Place/ } \\
\text { Transition }\end{array}$ & $\begin{array}{c}\text { Editor Gráfico } \\
\text { Animação do Token } \\
\text { Simulação Rápida } \\
\text { Análise Simples de Desempenho }\end{array}$ & $\begin{array}{l}\text { Sun } \\
\text { HP } \\
\text { Linux }\end{array}$ \\
\hline Elsir & $\begin{array}{l}\text { Redes de Petri de } \\
\text { Alto Nível } \\
\text { Redes de Petri } \\
\text { Temporizada }\end{array}$ & $\begin{array}{c}\text { Editor Gráfico } \\
\text { Animação do Token } \\
\text { Simulação Rápida } \\
\text { Análise Simples de Desempenho }\end{array}$ & Sun \\
\hline Petri Maker & $\begin{array}{l}\text { Rede de Petri Place/ } \\
\text { Transition }\end{array}$ & $\begin{array}{c}\text { Editor Gráfico } \\
\text { Animação do Token } \\
\text { Simulação Rápida } \\
\text { Espaço de Estados } \\
\text { Espaço Condensado de Estados } \\
\text { Lugares Invariantes } \\
\text { Transições Invariantes } \\
\text { Análise Simples de Desempenho }\end{array}$ & MS Windows \\
\hline PetriSim & $\begin{array}{l}\text { Redes de Petri de } \\
\text { Alto Nível } \\
\text { Redes de Petri Place/ } \\
\text { Transition } \\
\text { Redes de Petri } \\
\text { Temporizada }\end{array}$ & $\begin{array}{c}\text { Editor Gráfico } \\
\text { Simulação Rápida } \\
\text { Análise Avançada de } \\
\text { Desempenho }\end{array}$ & MS DOS \\
\hline Stroboscope & $\begin{array}{l}\text { Redes de Petri } \\
\text { Temporizada }\end{array}$ & $\begin{array}{c}\text { Editor Gráfico } \\
\text { Simulação Rápida } \\
\text { Lugares Invariantes } \\
\text { Transições Invariantes } \\
\text { Análise Simples de Desempenho } \\
\text { Análise Avançada de } \\
\text { Desempenho }\end{array}$ & MS Windows \\
\hline
\end{tabular}




\begin{tabular}{|c|c|c|c|}
\hline $\begin{array}{l}\text { AMBIENTES } \\
\text { DE } \\
\text { SIMULAČ̃̃O }\end{array}$ & $\begin{array}{l}\text { TIPOS DE REDES } \\
\text { DE PETRI }\end{array}$ & COMPONENTES & PLATAFORMA \\
\hline THORN/DE & $\begin{array}{l}\text { Redes de Petri de } \\
\text { Alto Nível } \\
\text { Redes de Petri } \\
\text { Temporizada } \\
\end{array}$ & $\begin{array}{c}\text { Editor Gráfico } \\
\text { Simulação Rápida } \\
\text { Análise Simples de Desempenho }\end{array}$ & $\begin{array}{l}\text { Sun } \\
\text { Linux }\end{array}$ \\
\hline TimeNet & $\begin{array}{l}\text { Redes de Petri } \\
\text { Estocásticas } \\
\text { Redes de Petri } \\
\text { Place/Transition } \\
\text { Redes de Petri } \\
\text { Temporizada }\end{array}$ & $\begin{array}{c}\text { Editor Gráfico } \\
\text { Animação do Token } \\
\text { Simulação Rápida } \\
\text { Lugares Invariantes } \\
\text { Análise Simples de Desempenho } \\
\text { Análise Avançada de } \\
\text { Desempenho }\end{array}$ & Sun \\
\hline
\end{tabular}

Tabela 4.1 Ambientes de Simulação.

Os componentes citados na tabela 4.1 apresentam os seguintes objetivos ou características:

$\rightarrow$ Editor Gráfico: interface gráfica a qual suporta edições de redes e suas representaçōes. Presente em todos ambientes estudados.

$\rightarrow$ Animação do token: suporta simulação com animação do flu xo dos tokens.

$\rightarrow$ Simulação Rápida: suporta simulação sem gráficos permitindo desempenho máximo.

$\rightarrow$ Análise Estrutural: suporta análises tais como identificação de topologias especiais: Redes de Escolha Livre, Máquina de Estados Finitos e Grafos Marcados.

$\rightarrow$ Análise Simples de Desempenho: suporta análises de desempenho através de simulação com tempo.

$\rightarrow$ Análise Avançada de Desempenho: suporta análises utilizando outras formas de ferramentas, tais como cadeia de Markov.

\subsection{ASiA}

O Ambiente para Simulação Automático (ASiA) vem sendo desenvolvido pelo Grupo de Sistemas Distribuídos e Programação Concorrente do ICMC - USP - São Carlos com o objetivo de facilitar a implementação de uma simulação através de modelagem definida em Redes de Filas, utilizando interface gráfica. 
Um dos objetivos do grupo é permitir que o usuário escolha a técnica com a qual estiver mais familiarizado (Redes de Filas ou Redes de Petri). A modificações necessárias para atingir este objetivo são analisadas no Capítulo 6. O objetivo citado visa tornar o ASiA compatível com muitos dos ambientes existentes, que utilizam Redes de Petri.

Utilizando o ASiA os usuários poderão descrever seus modelos através do Editor gráfico que oferece primitivas gráficas para auxiliar na modelagem. Em uma segunda fase o modelo deverá ser parametrizado com o auxilio de caixas de diálogo, e menu pop down.

A figura 4.1 ilustra a representação geral do ASiA o qual está dividido em quatro módulos básicos [BRU97]:

$\rightarrow$ Editor Gráfico: fornece ao usuário uma interface gráfica;

$\rightarrow$ Gerador de Aplicação: é o responsável pela geração do programa de simulação;

$\rightarrow$ Estágio de Saídas: análise estatística dos dados;

$\rightarrow$ Saída Gráfica: apresentação dos resultados que permite fácil visualização.

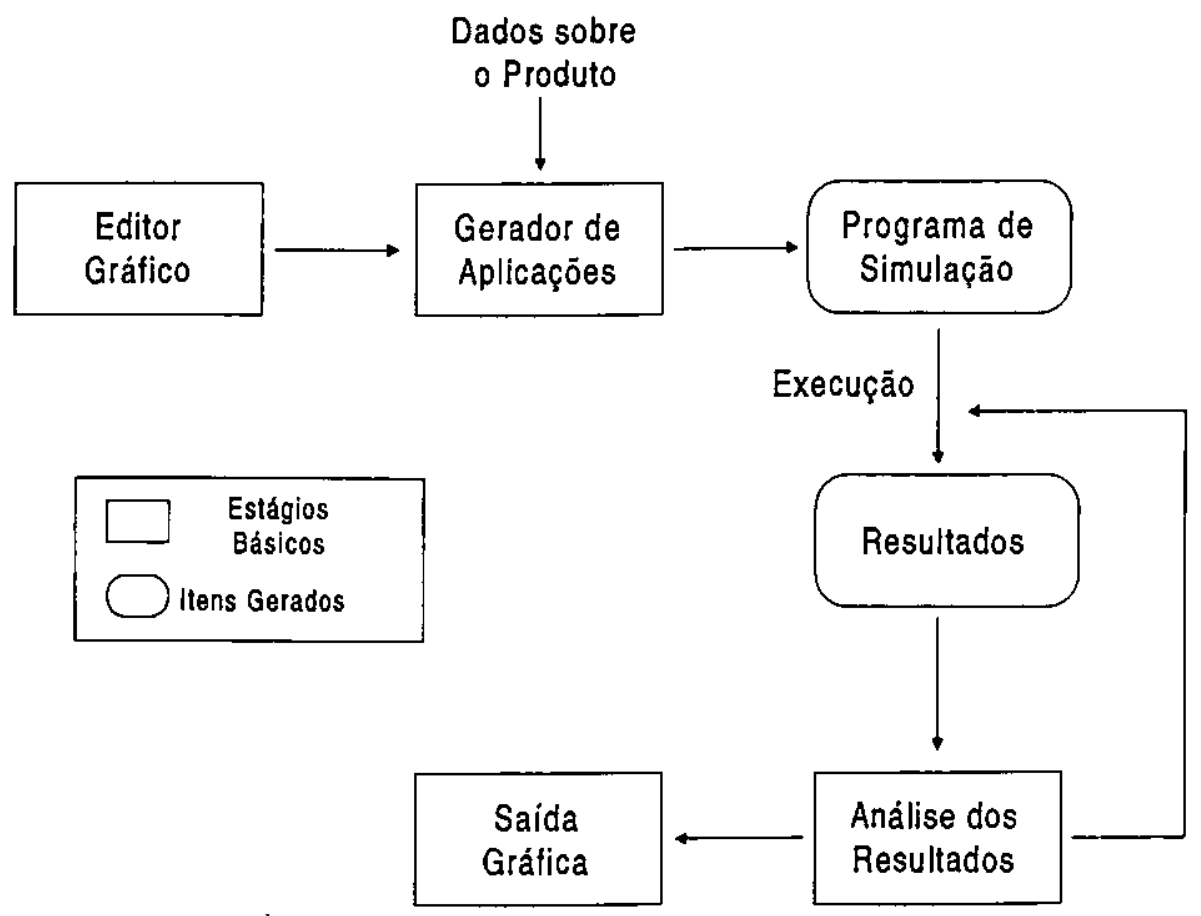

Figura 4.1 Estrutura Geral do ASiA.

As próximas seções descrevem o Editor Gráfico e o Gerador de Aplicações em maiores detalhes por serem esses os módulos que deverão ser adaptadas nesse trabalho. 


\subsubsection{Editor Gráfico}

O Editor Gráfico do ASiA constitui o módulo de interface entre o usuário e o módulo Gerador de Aplicação. O Editor Gráfico foi implementado utilizando-se a linguagem C para plataformas tipo IBM-PC compatíveis e é responsável por [SPO94a, SAN96]:

$\rightarrow$ proporcionar ao usuário a interação com o ambiente ASiA;

$\rightarrow$ captar todos os parâmetros do modelo;

$\rightarrow$ dar manutenção a especificação gráfica (modelo e parâmetros);

$\rightarrow$ estruturar as tabelas que serão utilizadas pelo Gerador de Aplicações.

Um ponto chave no desenvolvimento do Editor Gráfico é a funcionalidade da interface oferecida. Assim, o Editor Gráfico é responsável por fornecer ao usuário uma interface de fácil aprendizado e utilização, e também pela manutenção da parte gráfica, possibilitando desenhar (com verificação automática de consistência), apagar elementos de um modelo, gravar arquivos, recuperar arquivos previamente definidos, etc.

O Editor Gráfico oferece aos usuários um conjunto de ferramentas (barra de ferramentas, barra de menus, janelas, ícones, etc) para a descrição gráfica e parametrização dos modelos considerados. A tela principal do Editor Gráfico, apresentada na figura 4.2, mostra:

$\rightarrow$ barras de ferramentas;

$\rightarrow$ barra de menus;

$\rightarrow$ barra de atalho;

$\rightarrow$ barra de status. 


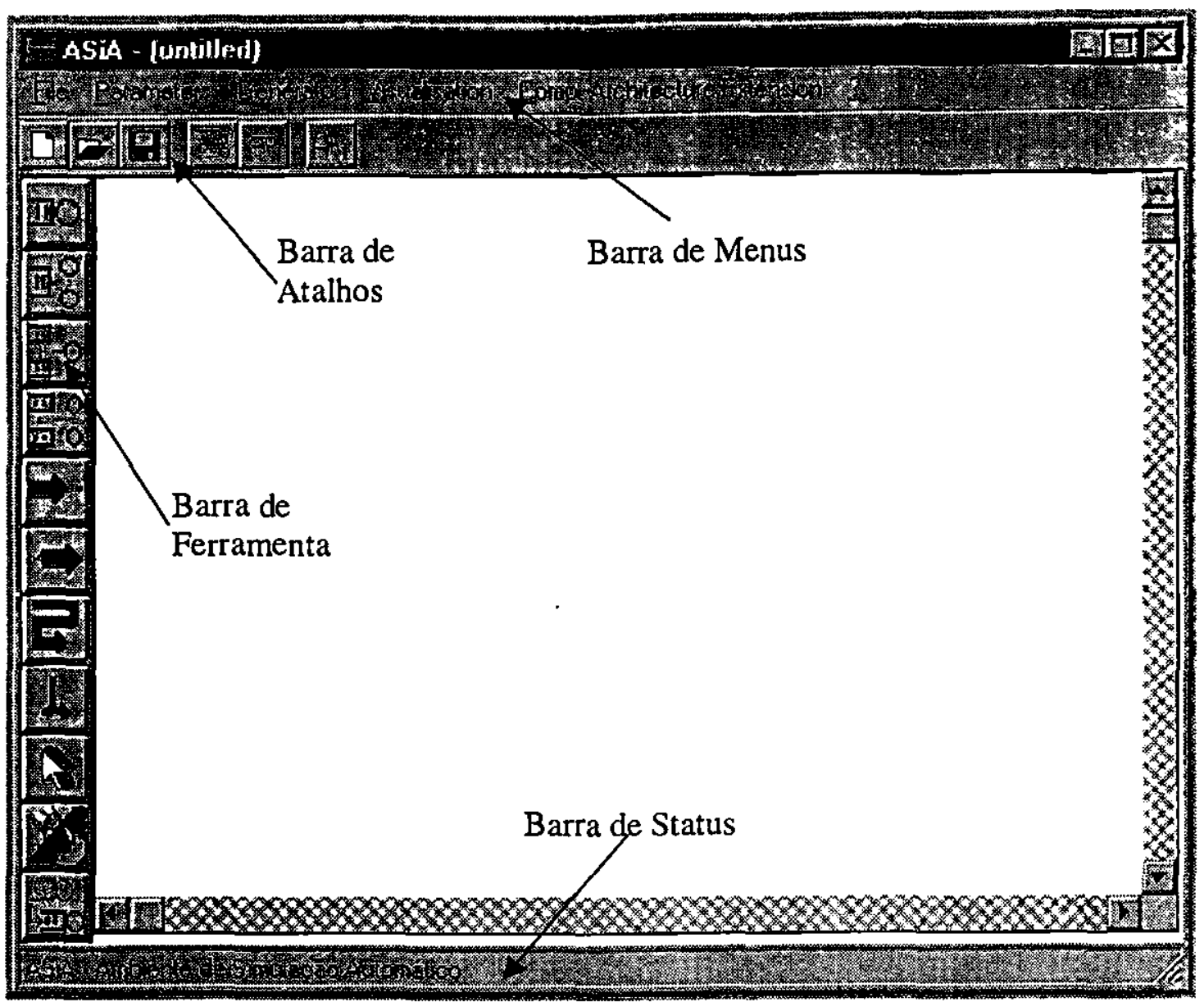

Figura 4.2: Tela principal do ASiA.

A Barra de Menus possibilita [BRU97]:

$\rightarrow$ executar operações relacionadas com arquivos tais como: criar um novo arquivo, abrir um arquivo já existente, salvar o arquivo, salvar com outro nome e sair do ASiA);

$\rightarrow$ parametrizar o modelo e os recursos;

$\rightarrow$ gerar o código do programa fonte e do executável;

$\rightarrow$ visualizar o código gerado e os relatórios da simulação;

$\rightarrow$ ativar a barra de ferramentas do Módulo Arquitetura (módulo específico para simulação de arquiteturas de computadores descrito na seção 4.3.3) ;

$\rightarrow$ ativar a ajuda on-line.

Na Barra de Atalho, localizada abaixo da de menus, existem ícones que servem de atalho às funções do menu: 
$\rightarrow$ criar um novo arquivo para especificação,

$\rightarrow$ abrir um arquivo de especificação,

$\rightarrow$ salvar a especificação que está sendo construída,

$\rightarrow$ parametrizar o modelo,

$\rightarrow$ parametrizar o recurso selecionado,

$\rightarrow$ esconder/mostrar a barra de ferramentas do Módulo Arquitetura.

A Barra de Ferramentas possibilita ao usuário:

$\rightarrow$ desenhar os recursos do sistema que está sendo modelado (centros de serviços com uma ou várias filas e um ou vários servidores);

$\rightarrow$ desenhar as entradas, as saídas e as ligações (inclusive ramificações) entre os centros de serviços, indicando qual o caminho a ser seguido por um cliente;

$\rightarrow$ selecionar um recurso para parametrização;

$\rightarrow$ apagar qualquer símbolo desenhado;

$\rightarrow$ mover qualquer recurso na tela de edição.

A Barra de Status indica ao usuário qual a função de cada um dos ícones da Barra de Ferramentas e a função de cada um dos itens da Barra de Menus.

Quando o usuário faz uma modelagem utilizando o Editor Gráfico as informações necessárias para a geração do programa de simulação (parametrização dos recursos e do modelo) são armazenadas em tabelas. Quando a função de salvar a especificação do modelo é ativada, essas informações que estavam armazenadas nas tabelas, são transferidas para alguns arquivos gerados pelo próprio ASiA [BRU97].

Todas a informações necessárias para a geração automática de um programa de simulação são captadas pelo Editor Gráfico, através de uma análise da própria especificação gráfica e da obtenção dos parâmetros do modelo fornecidos pelo usuário por meio dos menus e caixas de diálogo. Cada um dos centros de serviços do modelo deve ser parametrizado através da caixa de diálogo para a parametrização dos recursos, apresentada na figura 4.3. 


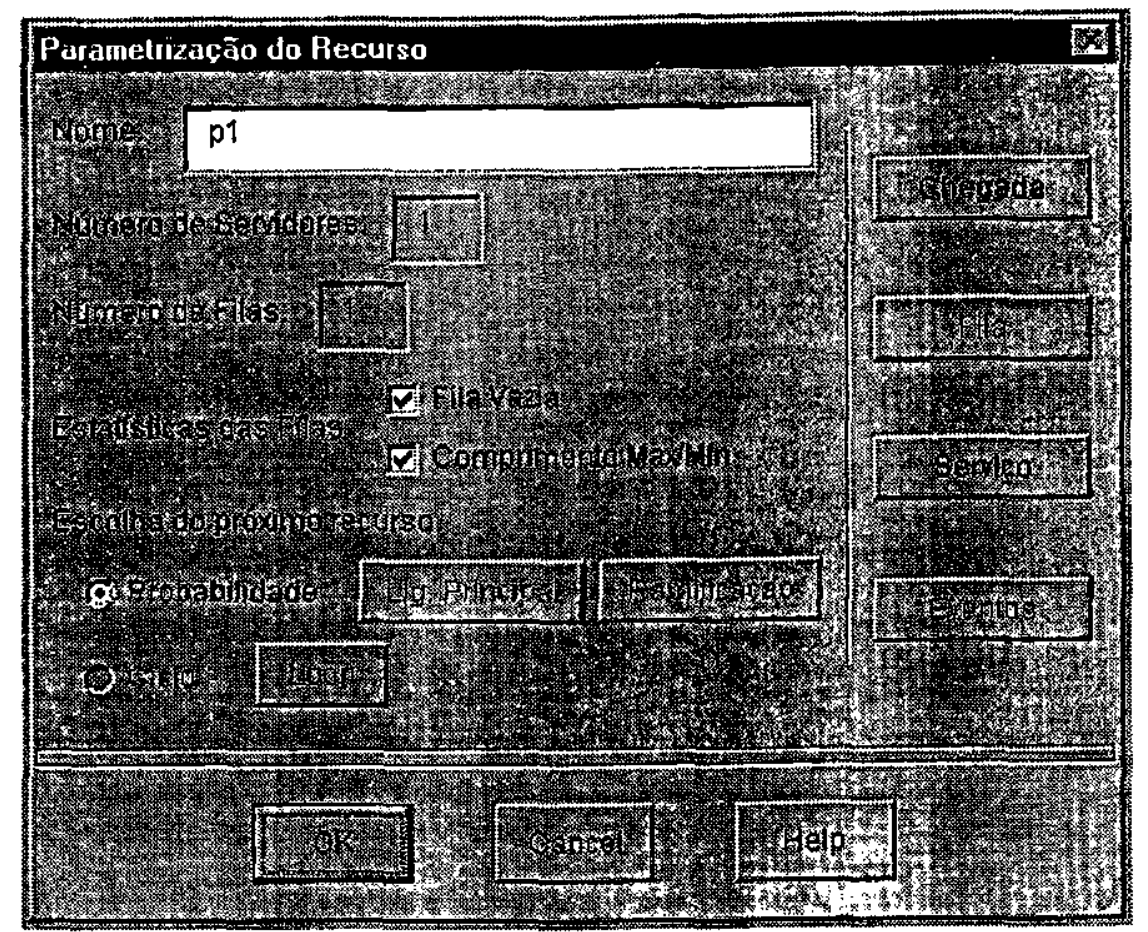

Figura 4.3: Caixa de Dialogo para a Parametrização do recurso.

A caixa de diálogo para a parametrização dos recursos contem os seguintes campos a serem preenchidos pelos usuários

$\rightarrow$ nome do recurso;

$\rightarrow$ número de servidores (utilizados nos casos em que tem-se mais de um servidor);

$\rightarrow$ número de filas ( utilizado nos casos em que tem-se mais de uma fila);

$\rightarrow$ estatísticas das filas

$\rightarrow$ escolha do próximo recurso;

Os botões localizados à direita da caixa de diálogo servem para parametrizar o tempo entre as chegadas dos clientes, disciplina das filas, tempo de serviço e eventos. Cada um desses botões aciona uma outra caixa de diálogo.

A figura 4.4 apresenta a caixa de diálogo para a parametrização da chegada do recurso. $\mathrm{O}$ botão que aciona está caixa está disponível somente quando o recurso selecionado representar a entrada do sistema. 


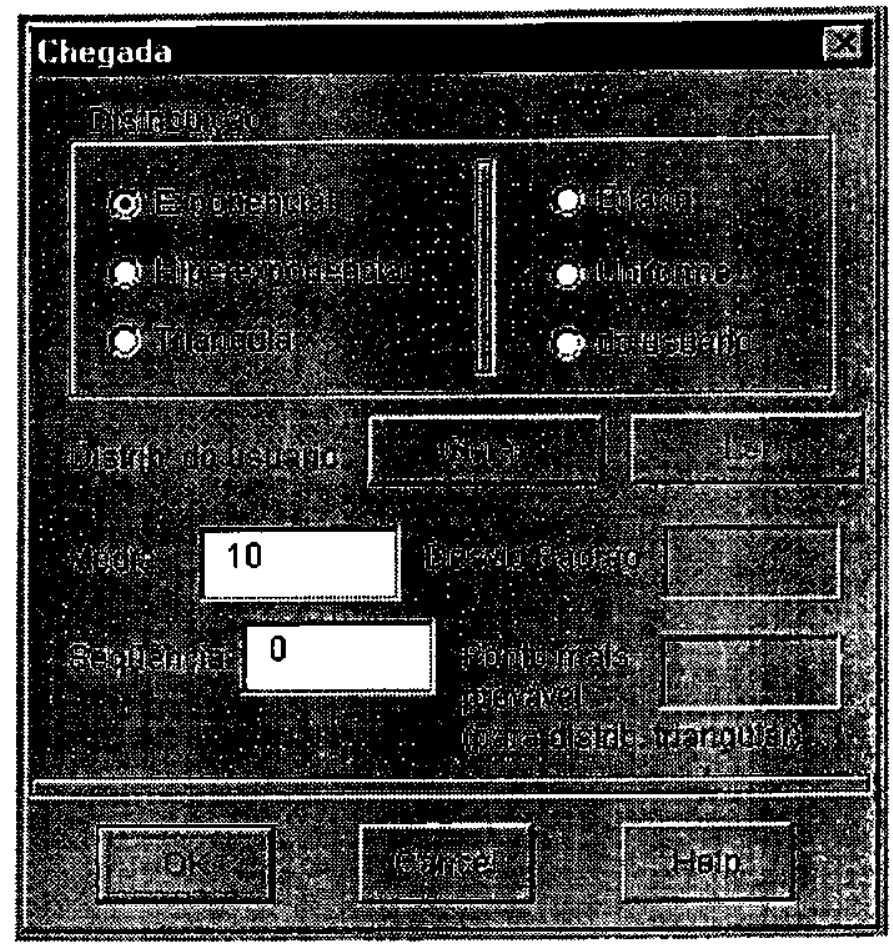

Figura 4.4: Caixa de Diálogo para Parametrizaçāo da Chegada do Recurso.

Conforme pode ser observado na figura 4.4 o tempo de chegada dos clientes é representado por distribuições estatísticas. As distribuições disponíveis no ASiA são:

$\rightarrow$ exponencial;

$\rightarrow$ hiperexponcial;

$\rightarrow$ triangular;

$\rightarrow$ erlang;

$\rightarrow$ uniforme;

$\rightarrow$ do usuário.

Alguns campos são habilitados conforme a distribuição escolhida pelo usuário.A figura 4.5 apresenta a caixa de diálogo para a parametrização do tempo de serviço a do recurso. 


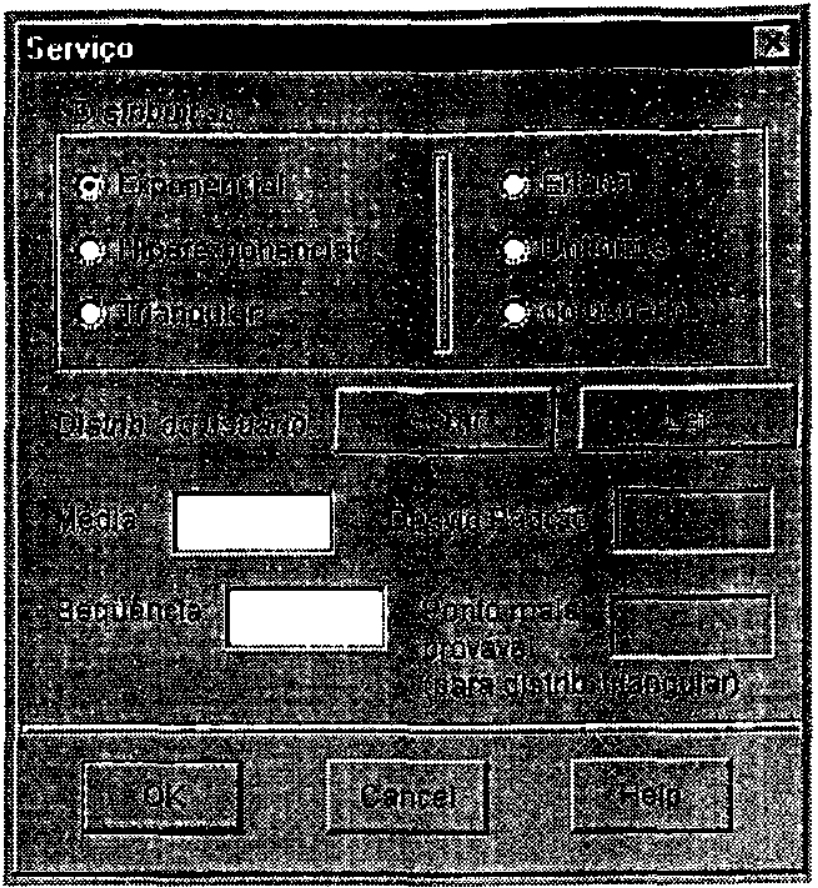

Figura 4.5: Caixa de Diálogo para Parametrização do tempo de serviço.

Assim como o tempo entre a chegada dos clientes ao sistema tempo de serviço também é representado por distribuições estatísticas. Devido a este fato a caixa de diálogo para a parametrização do tempo de serviço é muito parecida com a da caixa de diálogo para a parametrização da chegada entre os clientes.

A figura 4.6 apresenta a caixa de diálogo para a parametrização dos eventos. Esta caixa possui somente úm campo para o tempo de ocorrência do evento. O botão que aciona está caixa está disponível somente quando o recurso selecionado representar um recurso que possui um loop.

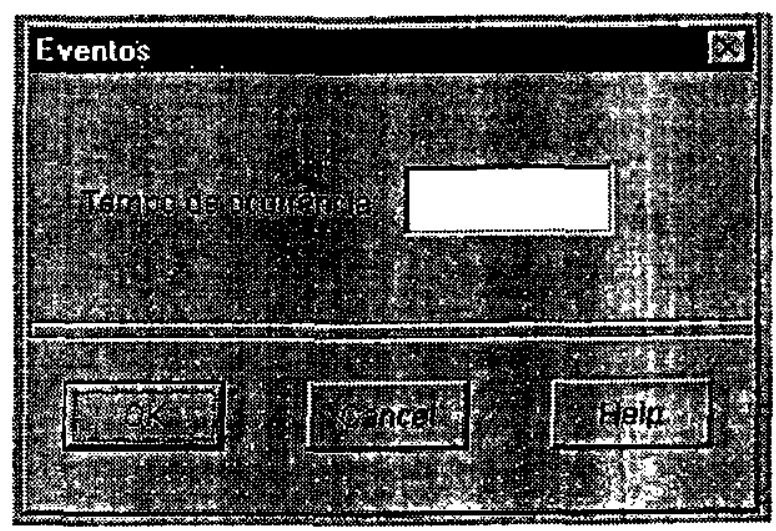

Figura 4.6: Caixa de Diálogo para Parametrização 
A figura 4.7 apresenta a caixa de diálogo para a parametrização do modelo:

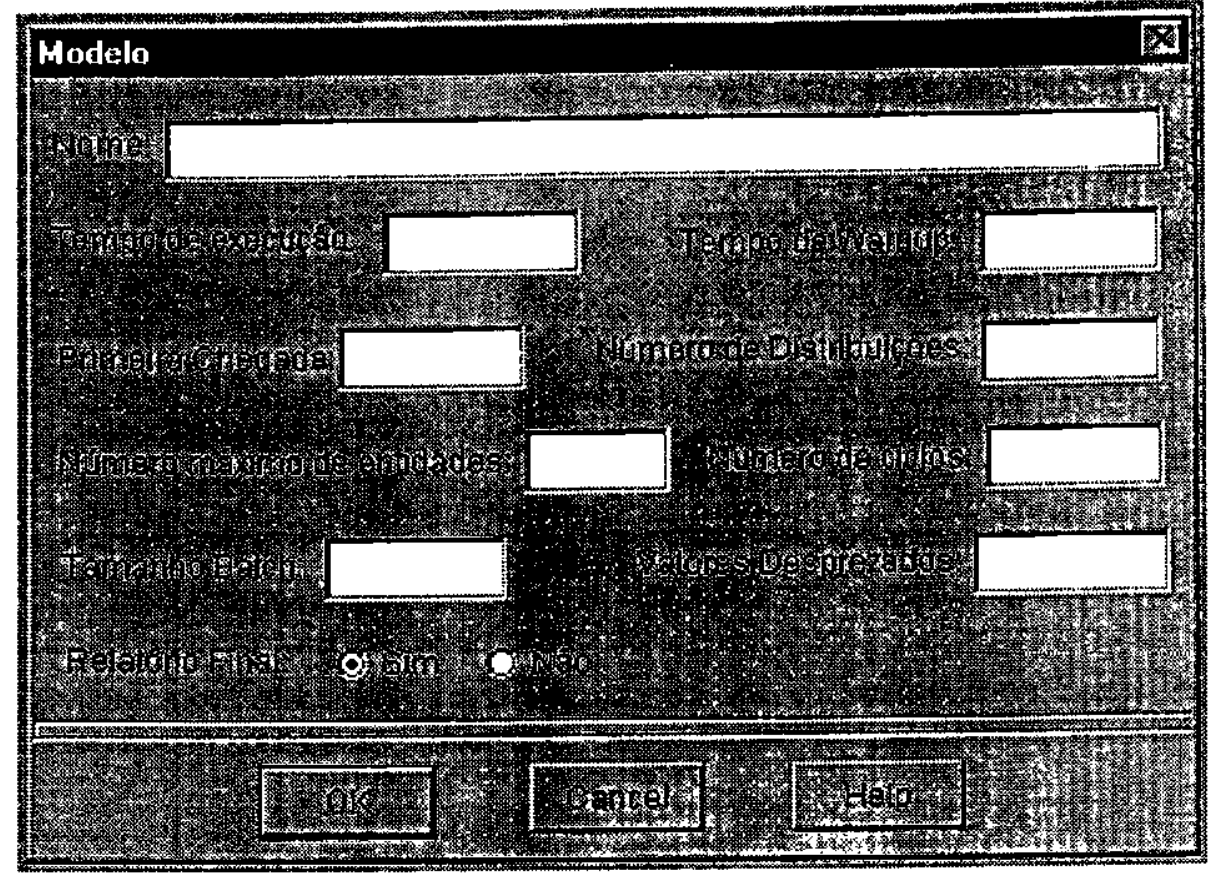

Figura 4.7: Caixa de Diálogo para Parametrização do Modelo.

Conforme apresentado na figura 4.7 tem-se os seguintes campos para serem preenchidos pelos usuários:

$\rightarrow$ nome do modelo;

$\rightarrow$ tempo de execução;

$\rightarrow$ tempo da primeira chegada;

$\rightarrow$ número máximo de entidades (clientes);

$\rightarrow$ tamanho batch (intervalo de confiança para o sistema batch means);

$\rightarrow$ tempo de warmup (tempo para o equilíbrio do sistema);

$\rightarrow$ número de distribuições (utilizado somente para distribuições tabeladas);

$\rightarrow$ número de ciclos (utilizado somente quando tem-se um loop no modelo);

$\rightarrow$ valores desprezados (valores que serão desprezados antes de iniciar a coleta estatística);

$\rightarrow$ relatório final. 


\subsubsection{Gerador de Aplicações}

Os geradores de aplicações foram criados para auxiliar os usuários que não possuem conhecimentos razoáveis em programação e para facilitar o trabalho de programadores experientes. Esses geradores também reduzem o custo de desenvolvimento de software [SPO94a, SPO94b].

O Gerador de Aplicações do ASiA cria programas que utilizam SMPL, uma extensão funcional da linguagem $C$ para simulação orientada a eventos [MAC87], explicada no Capítulo 5. O Gerador de Aplicação em sua versão inicial, foi implementado na linguagem $C$, tendo como plataforma máquinas compatíveis com IBM-PC.

Para obtenção do código do programa o usuário deverá escolher na barra de menu a opção gerar código que ativa o módulo Gerador de Aplicações.

O Gerador é implementado através dos seguintes sub-módulos: Núcleo do Gerador, Ferramentas e Descrição de Produtos.

\section{- Sub-módulo Núcleo do Gerador}

Representa o núcleo do gerador de aplicação, possibilitando a geração dos principais comando da extensão SMPL, responsáveis pelas atividades de preparação do modelo, definição e controle dos recursos, escalonamento e geração de eventos, geração de variáveis aleatórias, depuraçāo do código, coleta de dados e emissão de relatório com estatísticas sobre a simulação.

\section{- Sub-módulo Ferramentas}

É constituído por um conjunto de ferramentas utilizadas pelos diversos módulos do sistema.

\section{- Sub-módulo Descrição de Produtos}

Como o Gerador utiliza na produção dos programas de simulação as informações fornecidas pelo usuário, essas são estruturadas em tabelas. Através delas, o Gerador obtém todas as informações genéricas sobre o modelo e as particularidades de cada um dos recursos que o compõem, além de informações sobre o escalonamento de eventos e definições de ciclos.

O programa é gerado com o auxilio de um gabarito que é parecido com o produto final. Neste gabarito existem trechos de código na linguagem SMPL misturados com comandos que indicam ao Gerador como buscar as informações necessárias nas várias tabelas que serão utilizadas [SAN96]. 
Os trechos de código são copiados para o programa, enquanto os comandos precedidos pelo caracter \% determinam qual a primitiva do Gerador de Aplicações devem ser executadas. Cada uma dessas primitivas é responsável por criar um trecho específico no código final, utilizando as informações contidas nas diversas tabelas.

Os dados obtidos pela parametrização e armazenados na memória em tabelas são transformados em arquivos. São criados 11 arquivos para cada sistema modelado com as seguintes extensões:

$\rightarrow$.out - para o relatório final;

$\rightarrow$.exe - para o programa executável;

$\rightarrow$.cpp - para o código;

$\rightarrow$.esp - para a especificação gráfica;

$\rightarrow$.lig - para guardar informações referentes as ligações dos recurso;

$\rightarrow$.mod - para guardar informações sobre o modelo;

$\rightarrow$. rec - para as informações de cada um dos recursos;

$\rightarrow$.eve - para informações sobre os eventos - é criado somente quando o modelo possuir looppings;

$\rightarrow$.lop - informaçöes sobre os looppings;

$\rightarrow$.dis - quando utilizar distribuição tabela;

$\rightarrow$.arq - para o módulo de arquitetura.

\subsubsection{Módulo Arquitetura}

O Módulo Arquitetura foi implementado com o objetivo de facilitar aos usuários na construção e na simulação de modelos que representem arquiteturas de computadores, buscando avaliar e validar o desempenho das arquiteturas. Poderá, ainda, ser utilizado como uma ferramenta de auxílio ao ensino de arquiteturas de computadores [BRU97].

Esse módulo é uma extensão do ASiA e permite que o usuário defina diferentes tipos de arquiteturas utilizando recursos básicos (processadores, disco, memória). Os usuários também podem utilizar-se de quatro modelos de arquiteturas pré-definidos e já parametrizados: von Neumann, von Neumann com pipeline, MIMD com memoria compartilhada e MIMD com memoria distribuída. 
A figura 4.8 apresenta Editor Gráfico com o Módulo Arquitetura ativado:

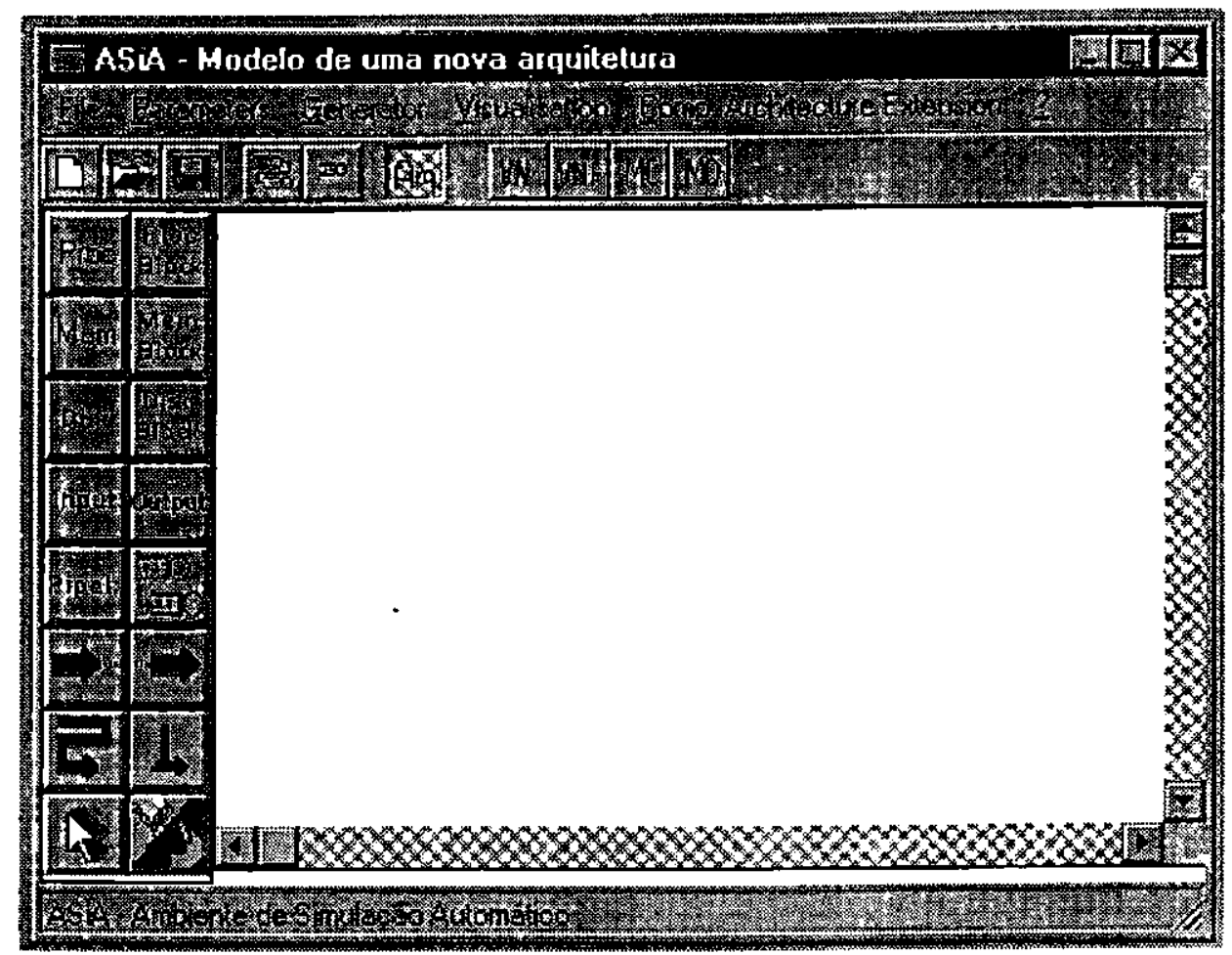

Figura 4.8: Módulo Arquitetura

\subsection{Considerações Finais}

O ASiA foi desenvolvido para modelar e simular sistemas descritos em Redes de Filas. A atual versão do ASiA é resultado de diversos trabalhos de mestrado e iniciação cientifica que desenvolveram cada um dos módulos do ambiente, um sistema de ajuda aprimorado na interface gráfica, inclusāo do Módulo de Arquitetura [BRU97], etc. Também foi proposta uma reengenharia para o ASiA [PIE98].

Diversos outros aprimoramentos estão previstos para o ASiA. A opção entre Redes de Filas e Redes de Petri para representar o modelo a ser simulado é a abordagem considerada neste trabalho. Assim, uma comparação entre Redes de Petri e Redes de Filas para modelagem de sistemas computacionais e as aiterações no ASiA para suportar essas duas técnicas serão consideradas nos próximos capítulos. 


\section{Capítulo 5}

\section{TÉCNICAS de MODELAGEM e SMPL}

\subsection{Introdução}

A versão atual do ASiA utiliza Redes de Filas para modelar os sistemas a serem simulados e a extensão da linguagem C para simulação - SMPL. Conforme descrito na introdução (Capítulo 1) o objetivo desta dissertação é estudar a viabilidade da introdução de Redes de Petri para modelar os sistemas a serem simulados pelo ASiA.

Uma das possibilidades para adaptar o ASiA às Redes de Petri, e que foi adotada neste trabalho, é manter o SMPL. Esta escolha foi feita visando simplificar a modificação do ASiA, uma vez que mantendo-se o SMPL, grande parte do gerador de aplicaçōes atual poderá ser utilizada.

Assim, este capítulo apresenta um estudo sobre a viabilidade de se utilizar SMPL quando o sistema a ser simulado for modelado por Redes de Petri. A realização desse estudo baseou-se em um grande número de exemplos. Inicialmente, foi elaborada uma comparação entre Redes de Filas e Redes de Petri com o intuito de verificar as diferenças e semelhanças dessas duas técnicas, visando a adaptação do SMPL (desenvolvido para Redes de Filas) às Redes de Petri. Esse estudo foi efetuado através de vários exemplos modelados tanto em Redes de Filas quanto em Redes de Petri, os quais estão apresentados na seção 5.2.

A seção 5.3 apresenta uma descrição das principais características da linguagem SMPL.

A seção 5.4 apresenta a relação existente entre as técnicas de modelagem Redes de Filas e Redes de Petri com a linguagem SMPL.

A técnica de modelagem Redes de Petri apresenta quatro estruturas básicas para a execução das Redes de Petri as quais estão descritas na seção 5.5. A implementação dessas estruturas também está descrita na mesma seção.

As inicializações em SMPL de cada um dos elementos de um sistema modelado em Rede de Petri é apresentada em detalhes na seção 5.6. 
Na seção 5.7 é detalhado um sistema modelado em Rede de Petri e sua implementação em SMPL.

O capítulo é finalizado pela seção 5.8 que descreve como deve ser finalizado um programa escrito em SMPL.

\subsection{Exemplos de Sistemas Modelados em Redes de Petri}

Dos exemplos que serão descritos a seguir os problemas e as respectivas representações em Redes de Filas foram tirados da literatura e as representaçōes em Redes de Petri foram desenvolvidas ao longo deste trabalho.

\section{Exemplo 1:}

O modelo do servidor Central representa um sistema em batch em condição de carga alta. Esse modelo é representado por uma Rede de Filas fechada, onde o número de processos é igual ao nível de multiprogramação. O usuário em execução permanece em serviço na CPU, representada pelo centro de serviço CPU da figura 5.1, até que necessite de um recurso de entrada /saída. Nesse caso, então libera a CPU entrando na fila de requisição do novo serviço, aqui representado pelos centros de serviço $\mathrm{E} / \mathrm{Si}$. Ao terminar a operação de entrada/saída o usuário volta a requerer o uso da CPU [SOA92].

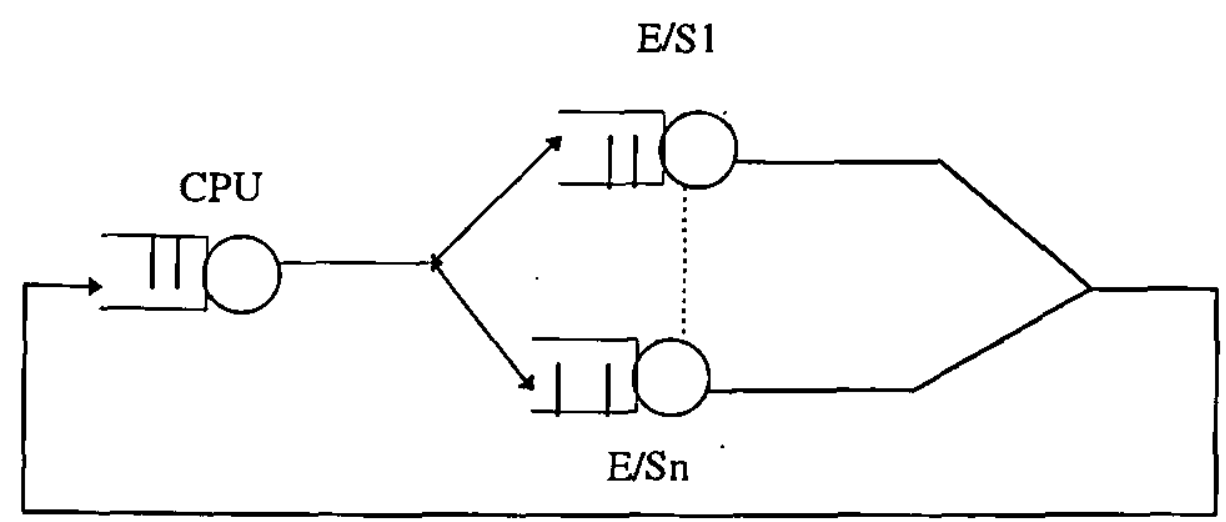

Figura 5.1: Modelo do Servidor Central Representado por Rede de Filas.

O mesmo sistema descrito acima pode ser representado pela Rede de Petri da figura 5.2. Nessa figura a CPU executará se houver um processo na fila (presença do token) e se a CPU estiver livre (presença do token), habilitando a transição t1. Através do disparo da transição tl, a 
CPU passa a estar ocupada. Essa fase é representada pelo centro de serviço CPU no mesmo exemplo representado por Rede de Filas. Após a CPU executar o processo será mandado para a fila de um dos recursos de entrada e saída, através do disparo das transições $t 2$ ou $t 3$, o processo espera na fila até que o recurso se torne livre (presença do token) habilitando a transição t4 ou t5 dependendo da escolha do recurso. Essa fase é representada pelos centros de serviços E/S no mesmo exemplo representado por Rede de Filas. Após a liberação do recurso E/S o processo volta para a fila da CPU e torna o recurso livre.

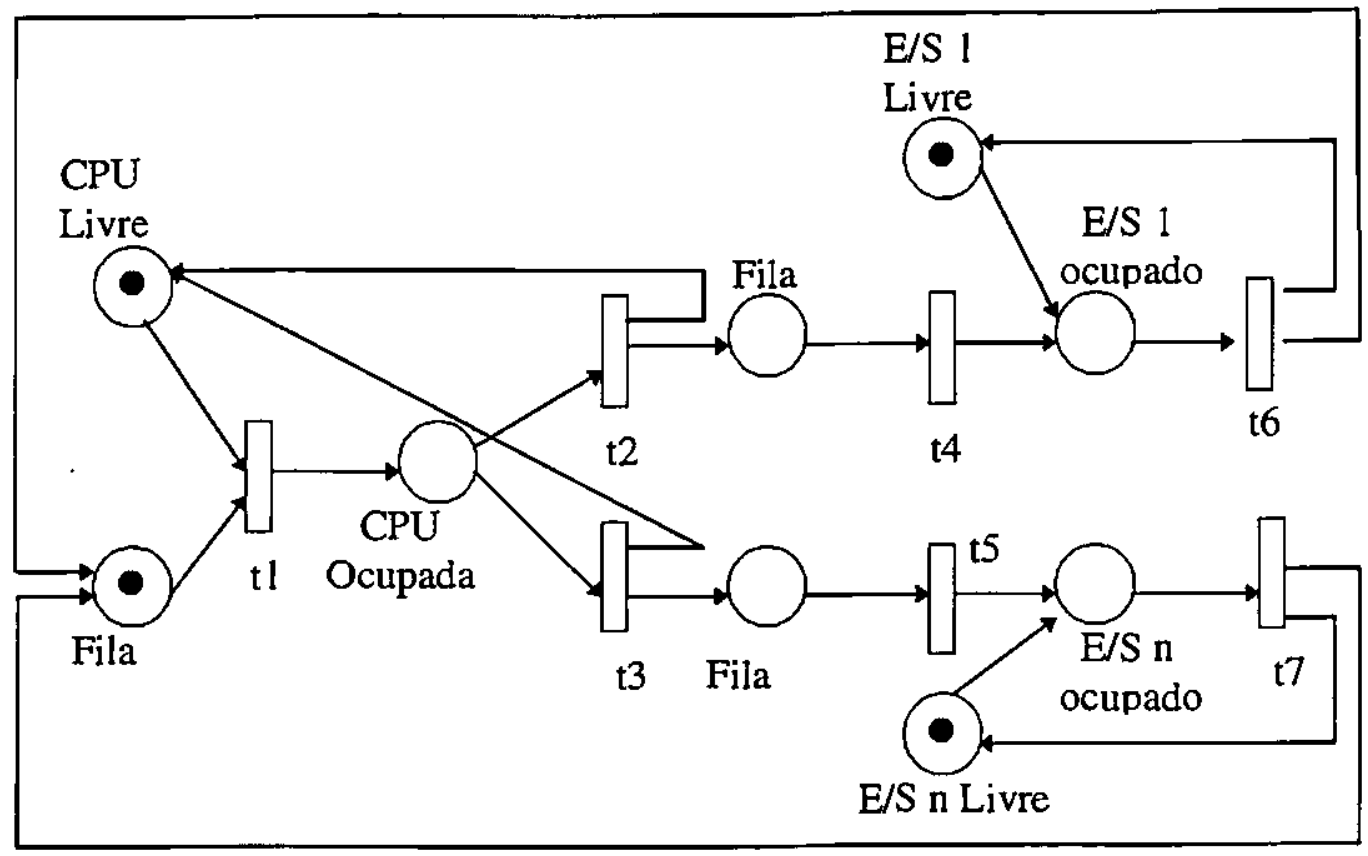

Figura 5.2: Modelo de Computaçăo Simples Representado por Rede de Petri.

\section{Exemplo 2:}

O diagrama de fluxo de computação simples é representado por uma Rede de Filas, onde o processo vem de sua fonte e requer o uso do centro de serviço CPU, depois de liberar a CPU o programa usuário requisita o uso de um dos centro de serviço disco ou floppy, esperando em um fila e em seguida sai do sistema pelo sorvedouro como mostra a figura 5.3 [SOA92].

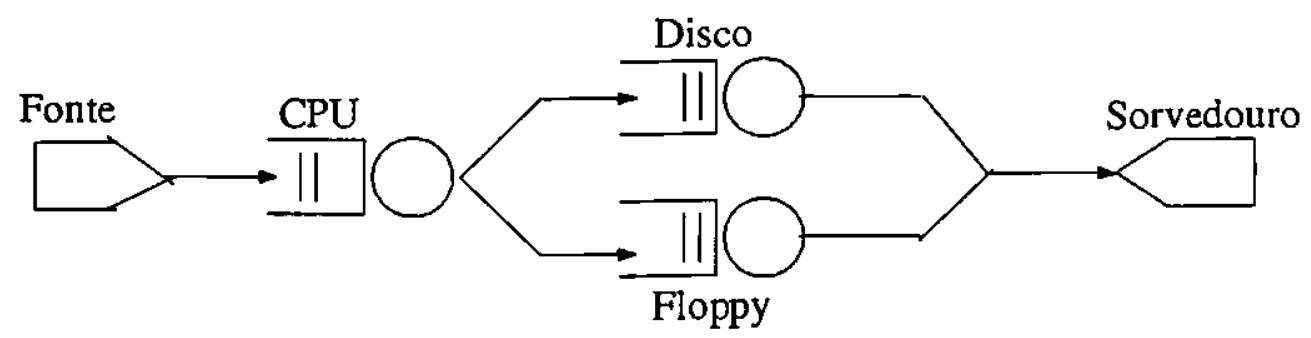

Figura 5.3: Fluxo de Computação Simples Representado por Rede de Filas. 
O diagrama descrito na figura 5.3 pode ser representado pela Rede de Petri ilustrada na figura 5.4. Nessa figura haverá o disparo da transição t1 se houver um processo na fila e se a CPU estiver livre, representado pela presença dos tokens no respectivos lugares. Após a execução na CPU o processo será enviado para uma das filas (disco ou floppy), disparando assim a transição $t 2$ ou a transição 3 , enviando o processo para a respectiva fila (FilaD ou FilaF). Depois que o disco ou o floppy executarem, serão liberados e o processo sairá do sistema.

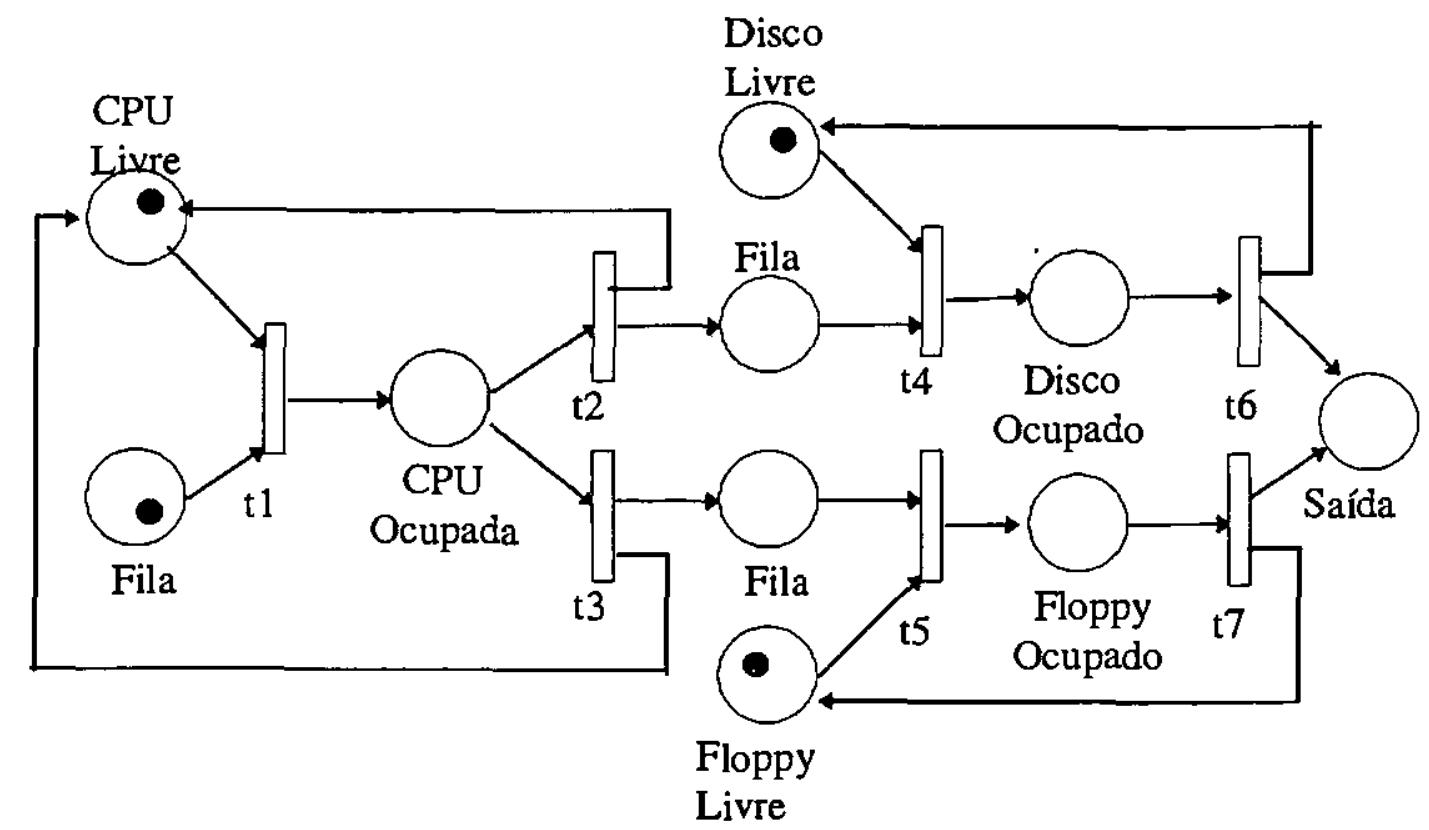

Figura 5.4: Fluxo de Computação Simples Representado por Rede de Petri.

\section{Exemplo 3:}

Esse exemplo descreve o modelo de um banco, onde o sistema é constituído por três servidores (caixas) e uma única fila. A figura 5.5 ilustra a representação por Redes de Filas.

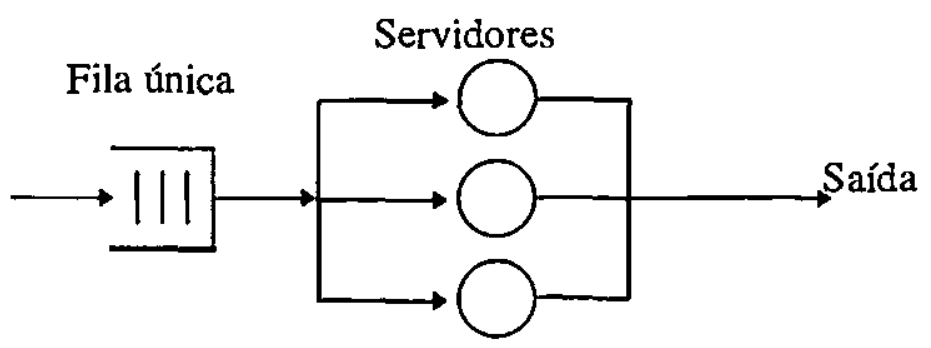

Figura 5.5: Simulação do Banco.

O mesmo modelo é representado por Redes de Petri na figura 5.6. Nesta figura os clientes estão aguardando em uma fila única. Os clientes serão atendidos pelo servidor que 
estiver livre, através do disparo de uma das transições $\mathrm{t} 1, \mathrm{t} 2$, ou $\mathrm{t} 3$. Depois que os clientes foram atendidos eles deixam o sistema pela saída e liberam o servidor, através do disparo de uma das transições $t 4, \mathrm{t} 5$, ou $t 6$.

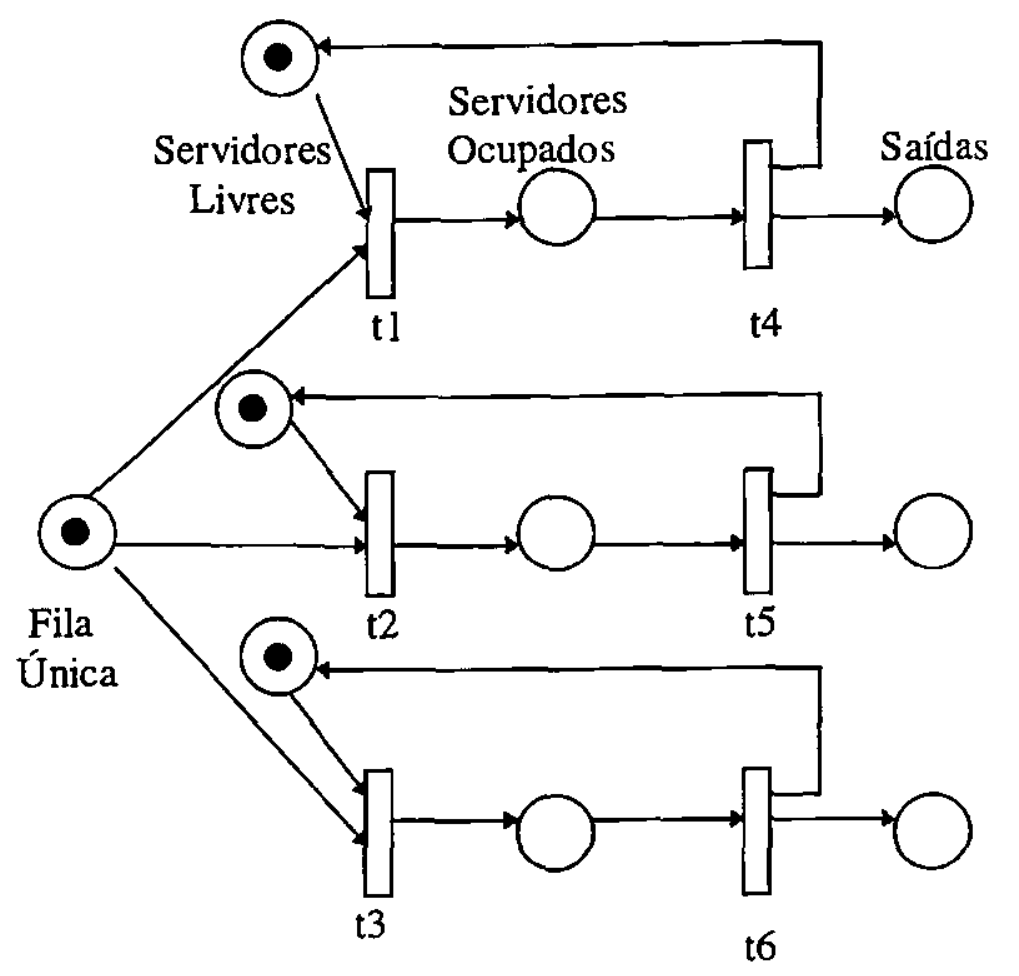

Figura 5.6: Simulação do Banco por Redes de Petri.

\section{Exemplo 4:}

Esse exemplo considera o processo de atendimento a alunos por um professor na véspera de uma prova. Ao chegar na sala do professor, o aluno deve esperar em uma fila até que chegue a sua vez de ser atendido. Quando chega a sua vez, o aluno entra na sala, tira suas dúvidas e, quando se sente satisfeito, vai embora continuar seus estudos, dando oportunidade a que um novo aluno possa ser atendido [SOA90]. Esse exemplo é representado primeiramente em Rede de Filas na figura 5.7 e posteriormente em Rede de Petri na figura 5.8.

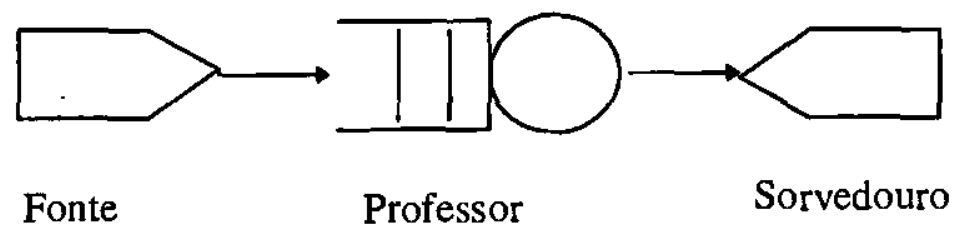

Figura 5.7: Atendimento do Professor ao Aluno Representado por Rede de Filas 
$\mathrm{Na}$ representação em Rede de Petri tem-se que a presença dos tokens nos lugares professor livre e fila tornam a transição $t 1$ habilitada; depois do disparo da transição o token será enviado ao lugar Professor ocupado (presença do token) representando que o professor está atendendo um aluno.

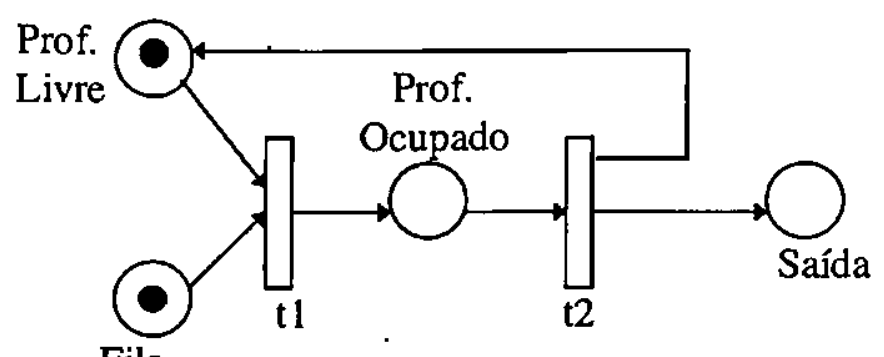

Fila

Figura 5.8: Modelo de Atendimento do Professor aos Alunos.

Através dos exemplos apresentados nesta seção, pode-se observar como diferentes modelos em Redes de Filas podem ser representados em Redes de Petri.

Na seção 5.4 é apresentado uma comparação entre essas duas formas de modelagem.

\subsection{Descrição da Linguagem SMPL e Suas Funções}

A linguagem SMPL é uma extensão funcional da linguagem de programação $C$, criada com o propósito específico de simulação discreta orientada a eventos de sistema computacionais modelados através de Redes de Filas [MAC87]. O objetivo deste capítulo é avaliar como esta linguagem pode ser utilizada na simulação de sistemas modelados em Redes de Petri. Nesta seção são apresentadas as características principais e as funções disponíveis em SMPL.

SMPL fornece ferramentas adicionais, tais como, depuração, coleta de dados, funções de análise da saída juntamente com uma interface interativa para simulação. Seu objetivo é fornecer uma linguagem que facilite a avaliação de desempenho de sistemas computacionais através de simulação.

Em SMPL, a simulação de um sistema é efetuada baseando-se em três tipos de entidades: 
$\rightarrow$ Facilities: representam de forma estática, por exemplo, os recursos;

$\rightarrow$ Tokens: representam as entidades ativas do sistema, isto é, o comportamento dinâmico que é modelado pelo movimento de tokens através de um conjunto de facilities;

$\rightarrow$ Events: representam a mudança de estado de qualquer entidade do sistema. ativa ou passiva, isto é, os eventos.

- SMPL executa a simulação através da manipulação dessas entidades por um conjunto de funçōes. Algumas dessas funções são descritas a seguir.

$\rightarrow \operatorname{smpl}(\mathbf{m}, \mathbf{s}):$ função que inicia a simulação, limpando as estruturas de dados e igualando o tempo de simulação à zero;

$\rightarrow f=$ facility $(s, n)$ : função que cria um nome e uma facility (servidor) retornando seu descritor, onde $s$ é um ponteiro para o nome do servidor usado para identificar o recurso no relatório da simulação e $n$ é o número de servidores;

$\rightarrow r=$ request $(f, t k n, p r i)$ : função que requisita o recurso; no caso em que o recurso estiver ocupado a função retorna o valor l e a requisição é colocada em uma fila, caso contrário retorna 0 . Esse valor é utilizado para verificar se o recurso foi reservado. $O$ parâmetro $f$ é o descritor da facility; pri é a prioridade do token, isto é, a prioridade do cliente;

$\rightarrow r=$ preempt $(f, t k n, p r i):$ funçāo que faz a preempção do recurso, isto é, quando o recurso estiver ocupado pelo cliente 1 de prioridade mais baixa que o cliente2, que fez a requisição, então o clientel deve deixar o recurso e voltar para a fila, para que o cliente2 com maior prioridade, utilize o recurso. Essa função executa de forma semelhante a anterior;

$\rightarrow$ schedule $(e v, t e, t k n)$ : função que escalona o evento $e v$, no intervalo de tempo te entre os eventos. A função verifica se o tempo é maior que zero e então adiciona-o ao tempo de simulação corrente para obter o tempo de ocorrência do evento. $O$ escalonamento de úm evento significa que o mesmo é colocado em uma lista. Essa lista é chamada lista de eventos futuros, e é ordenada de forma decrescente quanto ao tempo de ocorrência dos eventos. Eventos com o mesmo tempo de ocorrência são ordenados segundo a regra FIFO (First In First Out); 
$\rightarrow$ realease $(f, t k n):$ função que libera o servidor reservado. Depois da liberação é feita a verificação na fila. Caso a fila possua um cliente, este é tirado da fila e então é feito um novo reescalonamento do evento que faz a requisição do servidor. O parâmetro $f$ é o descritor da facility e tkn é o identificador do cliente;

$\rightarrow$ cause (ev,tkn): função que remove o evento da lista de eventos futuros, avança o tempo de simulação e executa a ocorrência do evento;

$\rightarrow r=s t a t u s(f)$ : função que faz a verificação do estado do recurso. Se a funçăo retornar 1 o recurso está ocupado e se retornar 0 o recurso está livre;

$\rightarrow r=\operatorname{expntl}(x)$ : função que gera uma distribuição exponencial com x como média;

$\rightarrow r=$ erlang $(x, s)$ : função que gera uma distribuição k-Erlang com $x$ como média e $s$ como padrão de derivação;

$\rightarrow r=$ hyperx $(x, s)$ : função geradora da distribuição hiperexponencial com $\mathrm{x}$ como média e s como padrão de derivação;

$\rightarrow k=\operatorname{random}(i, j):$ função que gera um número aleatório no intervalo entre i e j;

$\rightarrow$ trace (n): função que executa o programa de simulação passo a passo. Para $\mathrm{n}=0 \mathrm{a}$ função é desativada, $n=1$ o resultado da simulação é mostrada sem pausa, $n=20$ resultado da simulação é enviada a tela com pausa a cada tela, $\mathrm{n}=3$ a pausa é feita a cada instrução.

Utilizando-se as funções descritas nesta seção é possível simular uma Rede de Fila utilizando-se o SMPL. Nas próximas seções é verificado se com essas mesmas funções pode-se simular um Rede de Petri.

\subsection{Relação entre Redes de Filas, Redes de Petri e SMPL}

Um mesmo modelo pode ser representado de várias maneiras, isto é, podem-se utilizar as diferentes técnicas de modelagem descritas anteriormente, tais como, Redes de Petri, Redes de Filas, Statecharts. Algumas técnicas mostram-se mais adequadas a tipos específicos de sistemas 
ou de objetivos. Por exemplo: Redes de Filas são apropriadas para sistemas que utilizam como forma de análise a teoria de filas.

Como já discutido, o SMPL foi desenvolvido para simular sistemas representados em Redes de Filas. Para se analisar a viabilidade da utilização de SMPL para simular modelos representados em Redes de Petri, foi inicialmente verificada a relação entre Redes de Filas e Redes de Petri.

Redes de Filas possuem um tipo básico de elemento (centro de serviço) e algumas variações que já foram apresentadas no capítulo 3. Um centro de serviço em Redes de Filas está relacionado a um conjunto de elementos em Redes de Petri, como um lugar para representar a fila e um outro para representar o servidor, uma transição para representar a saída da fila e a entrada no servidor, duas ligações entre os lugares e a transição, e um token para representar a presença de um cliente na fila. Vale ressaltar que a transição somente disparará se o servidor estiver livre implicando em uma condição extra no disparo da transição como é mostrado na figura 5.9.

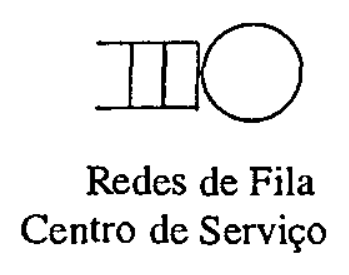

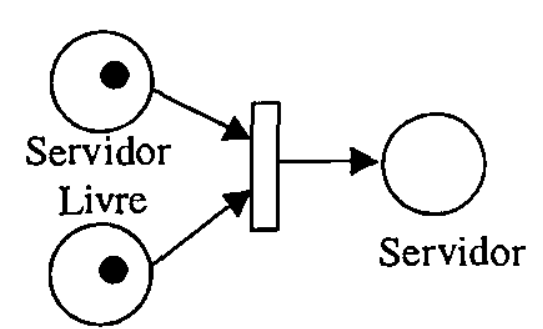

Fila

Figura 5.9: Redes de Filas e Redes de Petri

As Redes de Fila e de Petri apresentadas na figura 5.9 representam o mesmo modelo. Assim, observa-se que um centro de serviço (fila + servidor) em Redes de Fila é equivalente, em Redes de Petri a três lugares (um representando que o servidor está livre, um representado a fila e o servidor propriamente dito), uma transição e dois tokens.

Os três lugares da Rede de Petri da figura 5.9 podem ser comparados a recursos, isto é, tem-se nesse caso o recurso fila, o recurso servidor e o recurso servidor livre. As transições e os tokens não aparecem explicitamente nas Redes de Filas.

Apesar das transições e tokens não aparecerem nas Redes de Filas, podem-se relacionar esses componentes da Rede de Petri às entidades "events" e "tokens" do SMPL, isto é, atravês da representação gráfiça de uma Rede de Fila não é possivivel observar as transições e os tokens, porém para o desenvolvimento da simulação o SMPL introduz esses conceitos. 
Dessa Forma a relação entre Redes de Petri e SMPL pode ser feita da seguinte maneira:

$\rightarrow$ lugares representam os servidores em um modelo de Redes de Petri e são associados às facilities em SMPL;

$\rightarrow$ transições representam os eventos e associam-se a elas os events em SMPL;

$\rightarrow$ tokens representam os clientes ou seja, aquela entidade que se movimenta pela rede e em SMPL associam-se a eles os tokens.

A tabela 5.1 mostra a relação entre Redes de Filas e Redes de Petri e SMPL.

\begin{tabular}{|c|c|c|}
\hline REDES DE PETRI & REDES DE FILAS & SMPL \\
\hline Lugares & Servidores & Facilities \\
\hline Transições & - & Events \\
\hline Tokens & - & tokens \\
\hline
\end{tabular}

Tabela 5.1: Comparação entre Redes de Filas, Redes de Petri e SMPL.

Nas próximas seções serão apresentados como diferentes modelos representados em Redes de Petri, podem ser simulados através da utilização de SMPL.

\subsection{Definição e Implementação das Estruturas Básicas das Redes de Petri em SMPL}

Observando-se diversos exemplos de modelos em Redes de Petri é possível verificar que esses são compostos por algumas estruturas básicas que se repetem em diferentes combinações. As estruturas básicas identificadas representam as possíveis formas de mudanças de estado nos sistemas a serem simulado. Cada uma dessas estruturas pode ser automatizada com a utilização da linguagem de simulação SMPL, como apresentado nos itens a seguir.

\section{- Estrutura Básica 1:}

A estrutura básica 1 é considerada a mais simples onde o token deverá sair do lugar pl e ir para o lugar $\mathrm{p} 2$.

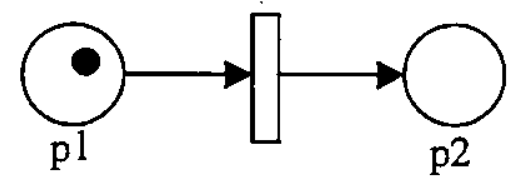

Antes do Disparo

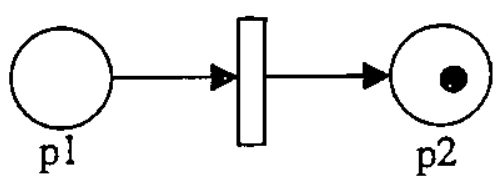

Depois do Disparo

Figura 5.10: Estrutura Básica 1. 
Para exemplificar essa estrutura, considera-se uma arquitetura com um processador e um disco representados respectivamente pelos lugares p1 e p2 e um processo representado pelo token. O processo executa primeiro no processador e em seguida faz um acesso ao disco.

Considerando que cada um desses lugares representa um recurso, essa estrutura pode ser simulada em SMPL pelo código apresentado na figura 5.11 .

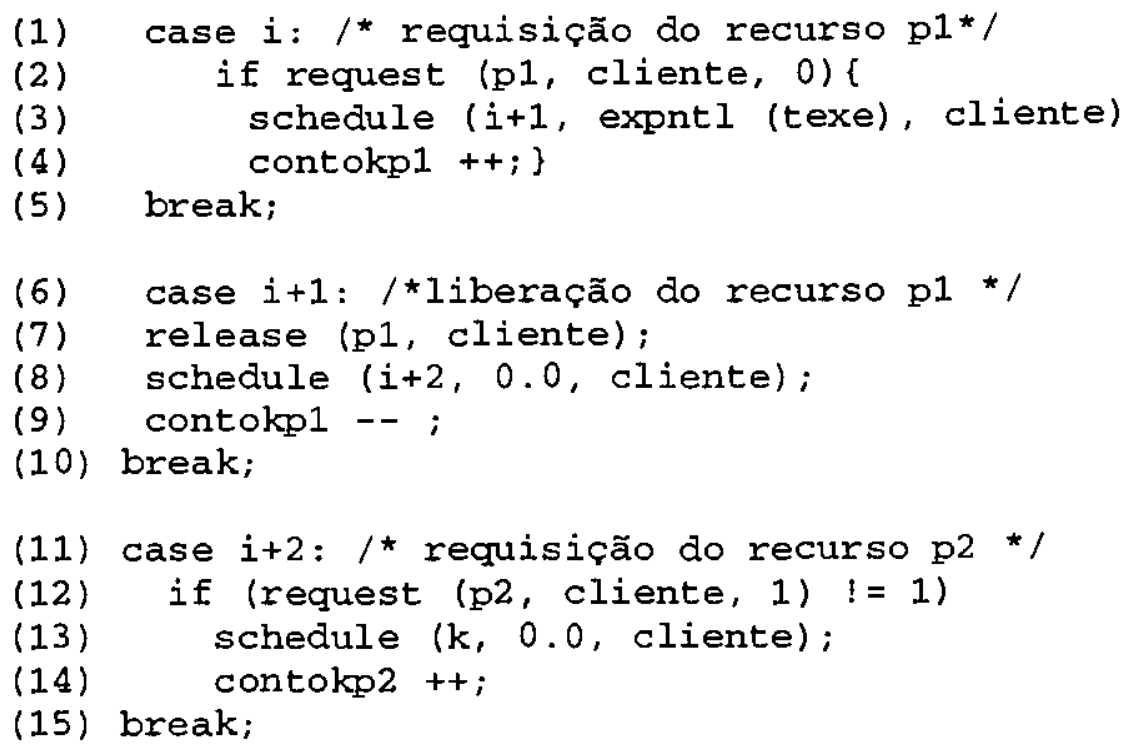

Figura 5.11: Código referente a Estrutura Básica 1.

$\mathrm{Na}$ estrutura apresentada na figura 5.10, têm-se que os lugares p1 e p2 serão facilities em SMPL e a transição será um evento. O número de tokens da Rede de Petri deverá ser representado no SMPL por um contador de tokens para cada um dos lugares. No momento do disparo dessa estrutura, que depende da existência de pelo menos um token no lugar pl, têm-se os seguintes eventos representados na figura 5.11:

$\rightarrow$ requisição do recurso pl e entrada do token (linha (2));

$\rightarrow$ escalonamento do próximo evento (linha(3));

$\rightarrow$ incremento do contador de tokens (linha (4));

$\rightarrow$ liberação do lugar pl e conseqüientemente a saída do token (linha (7));

$\rightarrow$ escalonamento imediato do próximo evento que é a requisição do lugar p2 e consequitentemente a entrada do token em p2 (linha (8));

$\rightarrow$ decremento do contador de tokens do lugar pl(linha (9)); 
$\rightarrow$ escalonamento do próximo evento, seguindo distribuição estipulada (linha(13));

$\rightarrow$ incremento do contador de tokens do lugar p2 (linha (14)).

A representação desse modelo em SMPL requer ainda a definição das facilities, pl e p2 e a inicialização dos contadores de tokens de cada lugar com comandos do tipo:

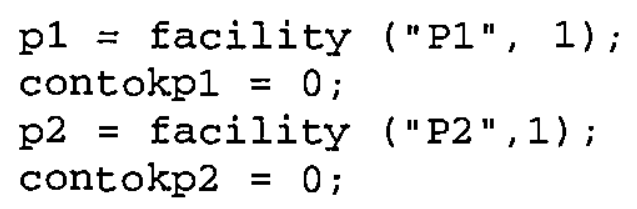

Os comandos de inicialização e finalização serão descritos com maiores detalhes na seção 5.6.

\section{- Estrutura Básica 2:}

Na estrutura básica 2 o token deverá sair do lugar pl e um token deverá ser inserido em cada um dos lugares de saída p2 e p3.

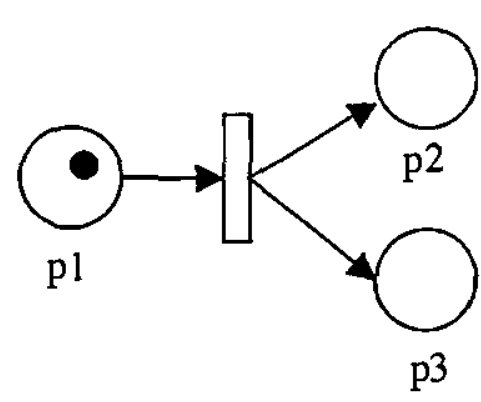

Antes do Disparo

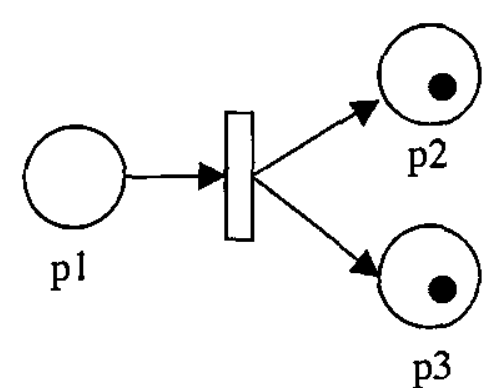

Depois do Disparo

Figura 5.12: Estrutura Básica 2.

Como exemplo dessa figura tem-se uma arquitetura com três processadores sendo dois deles paralelos representados pelos lugares p1, p2 e p3. Nessa arquitetura o processo representado pelo token executa primeiro no processador $\mathrm{pl}$ e em seguida ele passa a executar nos dois processadores paralelos $\mathrm{p} 2 \mathrm{e} \mathrm{p} 3$.

Conforme apresentado na figura 5.12 para a simulação deste exemplo é necessário a utilização de três eventos em SMPL como é apresentado na figura 5.13. 
(1) case i: /*escalonamento do recurso $\mathrm{p} 1$ */

(2) if request ( 1 , cliente, 0$)\{$

(3) schedule ( $i+1$, expntl (texe), cliente)

(4) contokp1 $++i)$

(5) break;

(6) case $i+1:$ / Iiberação do recurso p1 */

(7) release ( 1 , cliente);

(8) schedule $(i+2,0.0$, cliente);

(9) schedule $(i+3,0.0$, cliente);

(10) contokp1 --;

(11) break;

(12) case $i+2: /$ * requisição do recursos $\mathrm{p} 2$ */

(13) if (request ( 22 , cliente, 0$) !=1$ )

(14) schedule (i+4, expntl (tfila), cliente);

(15) contokp2 ++;

(16) break;

(17) case $i+3:$ * requisição do recurso p3 */

(18) if (request (p3, cliente, 0) ! = 1)

(19) schedule ( $i+5$, expntl (tproc), cliente);

(20) contokp3 ++;

(21) break;

Figura 5.13: Código referente a estrutura básica 2 .

Na estrutura básica 2 apresentada na figura 5.12 têm-se o recurso pl como lugar de entrada e os recursos p2 e p3 como lugares de saída, todos representados como facilities em SMPL. A transição é representada como evento. No momento do disparo da transição, o token deverá partir do lugar $\mathrm{p} 1 \mathrm{e}$ ir tanto para $\mathrm{p} 2$ como $\mathrm{p} 3$ simultaneamente, conforme representados na figura 5.1. O seguintes passos são executados:

$\rightarrow$ requisição do recurso pl e entrada do token (linha (2));

$\rightarrow$ escalonamento do próximo evento (linha(3));

$\rightarrow$ incremento do contador de tokens (linha (4));

$\rightarrow$ liberação do lugar pl e partida do token (linha(7));

$\rightarrow$ escalonamento dos eventos seguintes onde serão feitas as requisições dos lugares p2 e p3 e conseqüentemente a entrada dos tokens nos respectivos lugares (linhas(8) e (9));

$\rightarrow$ decremento do contador de tokens do lugar pl(linha(10)); 
$\rightarrow$ requisição do lugar p2 e escalonamento do evento seguinte caso a requisição tenha ocorrido com sucesso (linhas (13) e (14));

$\rightarrow$ incremento do contador de tokens do lugar p2 (linha(15));

$\rightarrow$ requisição do lugar p3 e escalonamento do evento seguinte caso a requisição tenha ocorrido com sucesso (linhas (18) e (19));

$\rightarrow$ incremento do contador de tokens do lugar p3 (linha(20)).

A representação desse modelo em SMPL requer ainda a definição das facilities, pl, p2 e p3 além da inicialização dos contadores de tokens de cada lugar com comandos do tipo:

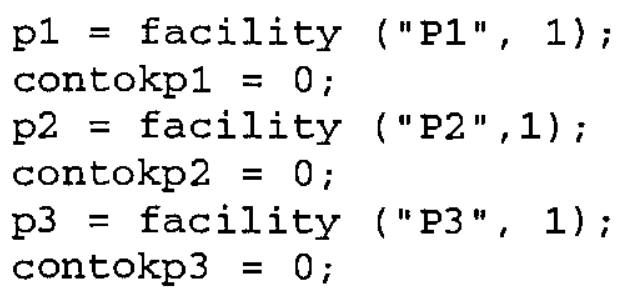

Os comandos de inicialização e finalização serão descritos com maiores detalhes na seção 5.6.

\section{- Estrutura Básica 3:}

Na estrutura básica 3 o token deverá sair do lugar pl e um token deverá ser inserido ou no lugar de saída p2, ou no lugar de saída p3 dependendo de uma condição.

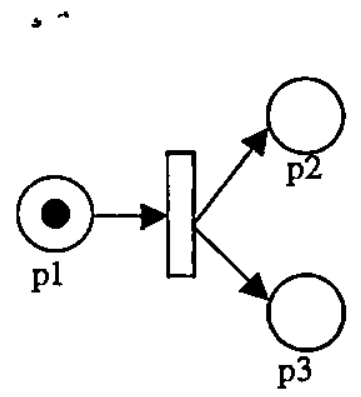

Antes do Disparo

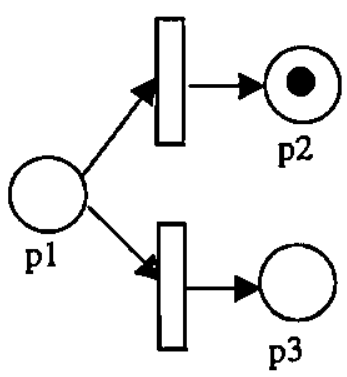

Depois do Disparo

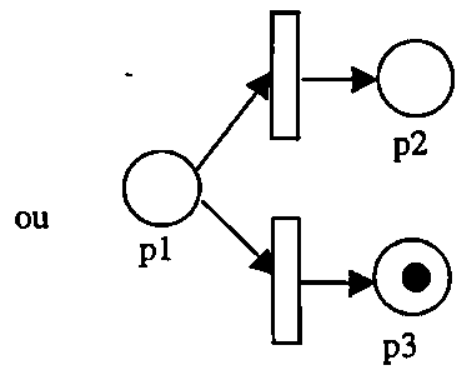

Depois do Disparo

Figura 5.14: Estrutura Básica 3. 
Para exemplificar essa estrutura tem-se o modelo descrito na figura 5.2 que representa o exemplo 1 descrito na seção 5.2 quando ocorre a liberação da CPU Ocupada e a partida do token para umas das filas de um dos recursos de entrada e saída.

Conforme apresentado na figura 5.14 para a simulação dessa estrutura é necessário a utilização de sete eventos em SMPL. A condição que determina qual das transições disparará será representada por uma variável auxiliar como é descrito na figura 5.15.

(1) case $i: /^{*}$ requisição do recurso pl e verificação da variável auxiliar $y * 1$

(5) break;

if (request ( 1, cliente, 1$) !=1$ ) schedule $(i+1,0.0$, cliente); contokp1 ++;

(6) case $i+1:$ /* Iiberação do recurso p1 e escalonamento do próximo recurso no caso da condição ser

(13) break; verdadeira */

(14) case $i+2: /$ * requisição do recurso $\mathrm{p} 2$ */

(15) if (request (p2, cliente, 1) ! = I)

(16) schedule (i+3,0.0, cliente);

(17) contokp2 ++;

(18) break;

(19) case $i+3:$ / Iiberação do recurso p2 */

(20) release (p2, cliente);

(21) contokp2 --;

(22) $\ldots$

(23) break;

(24) case $i+4:$ /* requisição do recurso p3 */

(25) if (request ( 3 , cliente, 1) ! = 1)

(26) schedule ( $i+5$, expntl (texe), cliente);

(27) contokp3 ++;

(28) break;

(29) case $i+5:$ /* Iiberação do recurso p3 */

(30) release (p3, cliente);

(31) contokp3 --;

(32) ...

(33) break;

Figura 5.15: Código referente a Estrutura Básica 3. 
$\mathrm{Na}$ estrutura básica 3 apresentada na figura 5.14 têm-se o recurso pl como lugar de entrada e os recursos p2 e p3 como lugares de saída todos representados como facilities em SMPL. As transiçōes são representadas como eventos e ambas estão habilitadas pelo token presente no lugar pl como descrito na figura 5.15. Os seguintes passos são executados:

$\rightarrow$ requisição do lugar pl (linha (2));

$\rightarrow$ escalonamento do próximo evento (linha(3));

$\rightarrow$ incremento do contador de tokens do lugar pl (linha (4));

$\rightarrow$ liberação do lugar pl e partida do token (linha (7));

$\rightarrow$ decremento do contador de tokens do lugar pl(linha (8));

$\rightarrow$ a verificação da variável auxiliar (linha (9));

$\rightarrow$ escalonamento do evento que requisita o lugar p2 se y for igual a zero (linha(10));

$\rightarrow$ escalonamento do evento que requisita o lugar $\mathrm{p} 3$ se $y$ for diferente de zero (linha(12));

$\rightarrow$ requisição do lugar p2, entrada do token e escalonamento do evento seguinte caso a requisição tenha ocorrido com sucesso (linhas (15) e (16));

$\rightarrow$ incremento do contador de tokens do lugar p2 (linha (17));

$\rightarrow$ liberação do lugar p2 e partida do token (linha (20));

$\rightarrow$ decremento do contador de tokens do Jugar p2(linha (21));

$\rightarrow$ requisição do lugar p3, entrada do token e escalonamento do evento seguinte caso a requisição tenha ocorrido com sucesso (linhas (25) e (26));

$\rightarrow$ incremento do contador de tokens do lugar p3 (linha (27));

$\rightarrow$ liberação do lugar p3 e partida do token (linha (30)).

$\rightarrow$ decremento do contador de tokens do lugar p3(linha (31)); 
A representação desse modelo em SMPL requer ainda a definição das facilities, p1, p2 e p3 além da inicialização dos contadores de tokens de cada lugar com comandos do tipo:

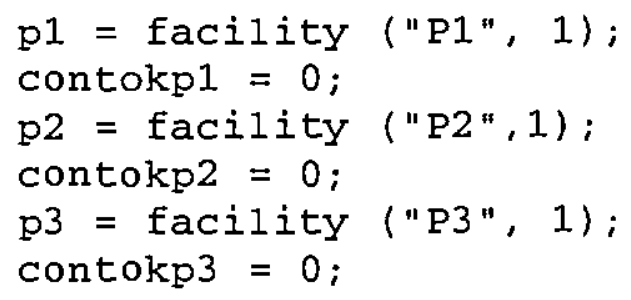

Os comandos de inicialização e finalização serão descritos com maiores detalhes na seção 5.6 .

\section{- Estrutura Básica 4:}

A estrutura básica 4 é mais complexa que as anteriores: nessa estrutura a transição somente pode disparar se houver pelo menos um token em cada um dos lugares de entrada pl e p2. Quando a transição disparar os tokens serão retirados dos lugares p1 e p2 e somente um token será colocado no lugar de saída p3.

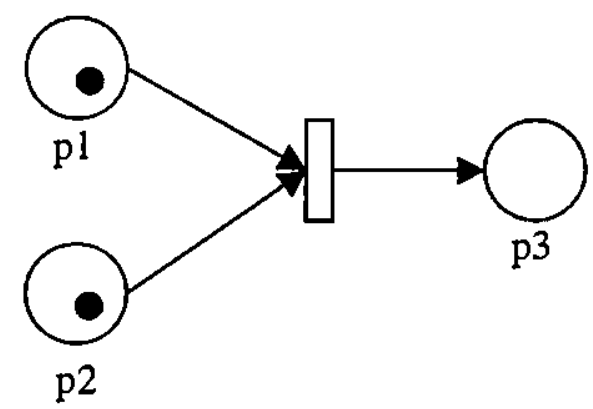

Antes do Disparo

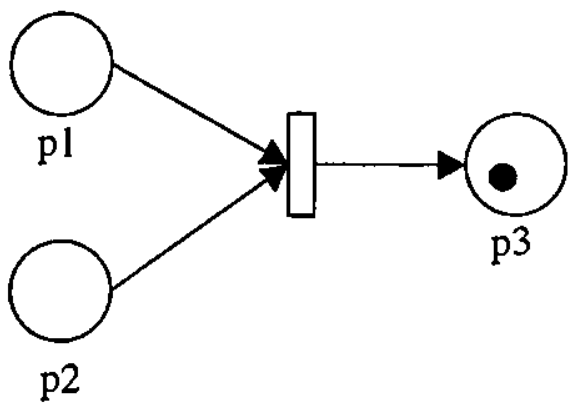

Depois do Disparo

Figura 5.16: Estrutura Básica 4.

Para exemplificar essa estrutura tem-se o modelo descrito na figura 5.4 que representa 0 exemplo 2 descrito na seção 5.2 representando os lugares CPU Livre e Fila.

A estrutura representada na figura 5.16 pode ser simulada em SMPL pelo código descrito na figura 5.17:

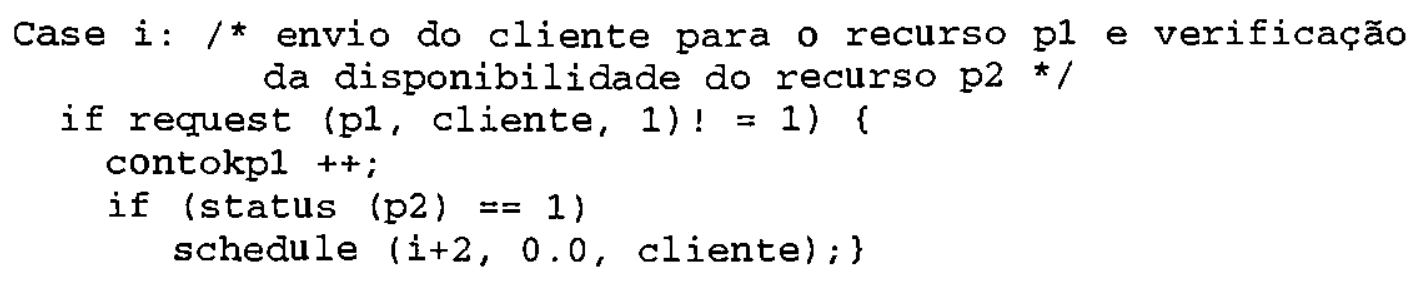


(6) break;

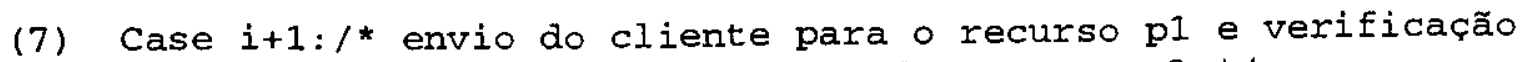
da disponibilidade do recurso $\mathrm{p} 2$ */

(8) if request (p2, cliente, 1)! = 1) (

(9) contokp2 ++;

(10) if (status (p1) $==1$ )

(11) schedule (i+2, 0.0, cliente);)

(12) break;

(13) case i+2: /* liberação dos recursos p1 e p2 */

(14) release ( $\mathrm{p} 1$, cliente);

(15) contokpl --;

(16) release (p2, cliente);

(17) contokp2 --;

(18) schedule ( $i+3,0.0$, cliente);

(19) break;

(20) case $i+3:$ / * requisição do recurso p3 */

(21) if (request (p3, cliente, 1) ! = 1)

(22) schedule ( $i+4$, expntl (texe), cliente);

(23) contokp3 ++ i)

(24) break;

(25) case i+4: /* liberação dos recursos p1 e p2 */

(26) release (p3, cliente);

(27) contokp3 - - ;

(28) $\ldots$

(29) break;

Figura 5.17: Código referente a Estrutura Básica 4.

Na estrutura básica 4 apresentada na figura 5.16 têm-se os recursos pl e p2 como lugares de entrada e o recurso $\mathrm{p} 3$ como lugar de saída todos representados como facilities em SMPL. A transição é representada como evento e está habilitada pelos tokens presentes nos lugares pl e p2 como descrito na figura 5.17. O seguintes passos sāo executados:

$\rightarrow$ requisição do recurso pl(linha (2));

$\rightarrow$ incremento do contador de tokens do recurso pl (linha(3));

$\rightarrow$ verificação do estado do recurso p2 (linha(4));

$\rightarrow$ escalonamento do evento que fará a liberação dos recursos pl e p2 (linha (5));

$\rightarrow$ requisição do recurso p2 (linha $(8)$ );

$\rightarrow$ incremento do contador de tokens do recurso pl (linha(9)); 
$\rightarrow$ verificação do recurso pl (linha (10));

$\rightarrow$ escalonamento do evento que liberará ambos os recursos (linha(11));

$\rightarrow$ liberação dos recursos pl (linha (14));

$\rightarrow$ decremento do contador de tokens do recurso pl(linha (15));

$\rightarrow$ liberação do recurso p2 (linha (16));

$\rightarrow$ decremento do contador de tokens do recurso pl(linha (17));

$\rightarrow$ escalonamento do próximo evento (linha(18));

$\rightarrow$ requisição do recurso p3 (linha (21)); .

$\rightarrow$ escalonamento do próximo evento (linha (22);

$\rightarrow$ incremento do contador de tokens do recurso p3 (linha(23));

$\rightarrow$ liberação do recurso p3 (linha (26));

$\rightarrow$ decremento do contador de tokens do recurso p3 (linha (27)).

Esses procedimentos são necessários para garantir que a transição somente disparará se houver pelo menos um token em cada um dos lugares de entrada.

A representação desse modelo em SMPL requer ainda a definição das facilities, p1, p2 e p3 além da inicialização dos contadores de tokéns de cada lugar com comandos do tipo:

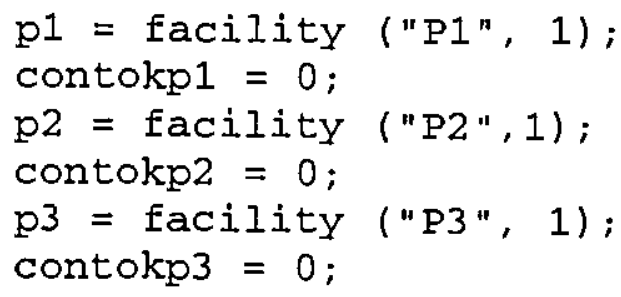

Os comandos de inicialização e finalização serão descritos com maiores detalhes na seção 5.6.

\subsection{Inicializações do SMPL e Suas Facilities}

Para que se possa começar um programa de simulação em SMPL têm-se que primeiramente incluir as bibliotecas e definir as variáveis como é apresentado na figura 5.18:

(1) \#include "smpl.h"

(2) \#include "rand.h"

(3) \#include "coni.o.h" 


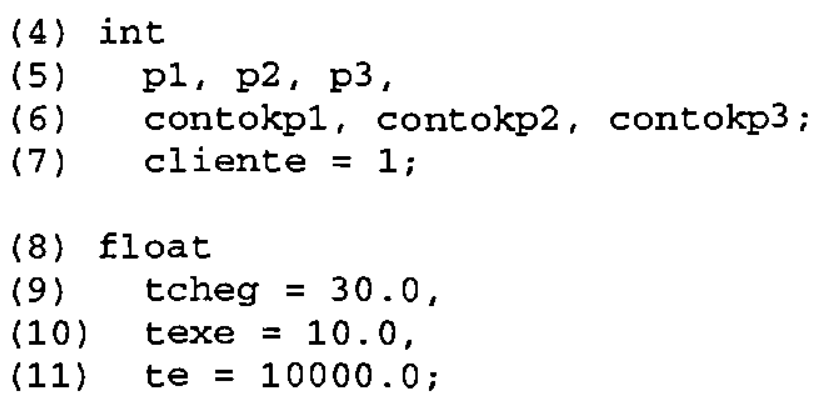

Figura 5.18: Inicialização do Programa e das Variáveis

Na figura 5.18 é apresentado o trecho de código referente ao modelo com três lugares, como o da figura 5.16. As seguintes operações são executadas:

$\rightarrow$ inclusão das bibliotecas smpl.h e rand.h que possuem todas as funções da linguagem SMPL (linhas (1) e (2));

$\rightarrow$ inclusão da biblioteca conio.h que possui as funções de entrada e saída da linguagem C (linha (3));

$\rightarrow$ declaração das variáveis inteiras p1, p2, e p3 que receberão o descritor das respectivas facilities (linha (5)) representando os lugares p1, p2 e p3;

$\rightarrow$ declaração das variáveis inteiras contokpl, contokp2 e contokp3 que representam os contadores de tokens de cada um dos lugares (linha (6));

$\rightarrow$ declaração e inicialização da variável cliente que representa o token (entidade dinâmica que passeia pela rede). A variável é inicializada com o valor 1 por que temse somente um tipo de cliente (linha(7));

$\rightarrow$ declaração e inicialização das variáveis que representam os tempos de chegada de cada cliente (tcheg), de execução em cada recurso (texe) e de execução total da simulação (te). Os valores iniciais de cada uma das variáveis são baseados em dados estatísticos (linhas (9), (10) e (11)).

Além das estruturas básicas descritas na seção 5 é necessário ainda tratar da inicialização das facilities e dos sistemas. Observando-se diversos exemplos de modelos em Redes de Petri é possível verificar que esses podem ser divididos em categorias. As categorias identificadas representam o estado inicial dos sistemas modelados em Redes de Petri. Cada uma dessas 
categorias pode ser automatizada com a utilização da linguagem de simulação SMPL, como será apresentado nos itens a seguir.

\section{- Categoria 1:}

A categoria 1 caracteriza-se pela presença de dois lugares de entrada e um lugar de saída conforme apresentado na figura 5.16. A inicialização das facilities pode ser feita através das funções SMPL apresentadas na figura 5.19:

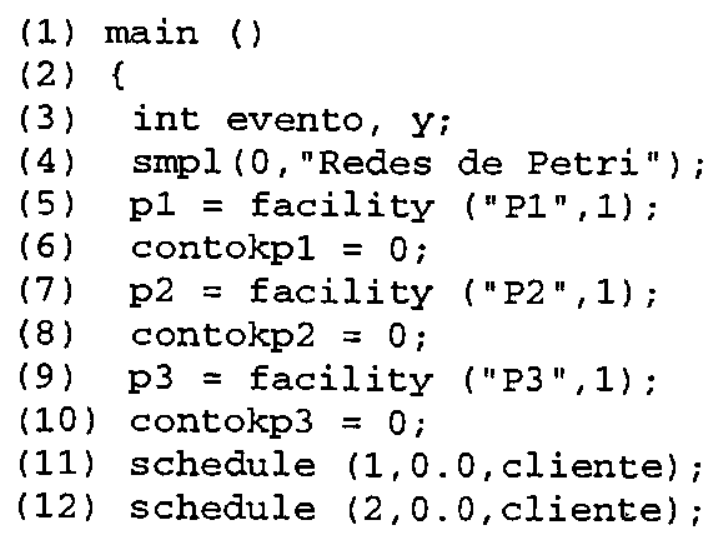

Figura 5.19: Inicialização das facilities em SMPL

Para que se possa inicializar a simulação do sistema é preciso que os Iugares tenham tokens indicando a situação do modelo no início da simulação, para isso devem-se escalonar todos os eventos que representam tais lugares. Assim têm-se na figura 5.19 as seguintes operações:

$\rightarrow$ início do simulação (linha (4));

$\rightarrow$ criação das facilities $\mathrm{pl}, \mathrm{p} 2 \mathrm{e}$ p3 com seus respectivos contadores de tokens (da linha (5) a linha (10));

$\rightarrow$ escalonamento dos eventos 1 e 2 (linhas(11) e (12)).

Devido ao fato desses lugares também representarem a chegada de um novo cliente ao sistema, os mesmos eventos são escalonados novamente com o tempo de chegada, como é apresentado na figura 5.20:

(1) case 1:

(2) schedule $(3,0.0$, cliente): 
(3) schedule (1, expnt1 (tcheg), cliente);

(4) break;

(5) case 2 :

(6) schedule $(4,0.0$, cliente);

(7) schedule (2, expntl (tcheg), c1iente);

(8) break;

Figura 5.20: Eventos Iniciais.

Conforme foi apresentado na figura 5.19, têm-se as seguintes operações para a inicialização do sistema:

$\rightarrow$ escalonamento do evento 3 que fará a requisição do recurso pl (linha(2));

$\rightarrow$ reescalonamento do evento 1 representando a chegada de um novo cliente (linha (3));

$\rightarrow$ escalonamento do evento 4 que fará a requisição do recurso p2 (linha(6));

$\rightarrow$ reescalonamento do evento 2 representando a chegada de um novo cliente (linha (7)).

\section{- Categoria 2:}

A categoria 2 é caracterizada pela presença de dois lugares de entrada e um lugar de saída, mas somente um dos lugares representa a chegada de novos clientes o outro representa o servidor livre, como pode-se visto na figura 5.2! que representa o modelo do exemplo 4 descrito na seção 5.2 .

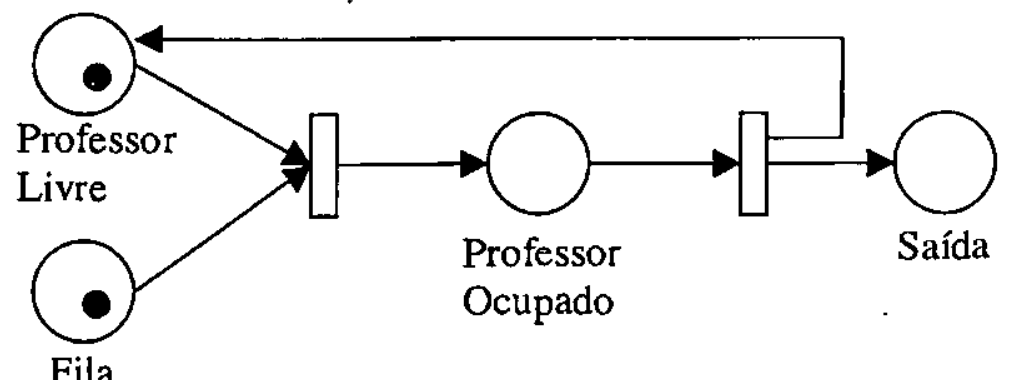

Figura 5.21: Professor em Atendimento aos Alunos. 
A inicialização das facilities pode ser feita através das funções SMPL apresentadas na figura 5.22:

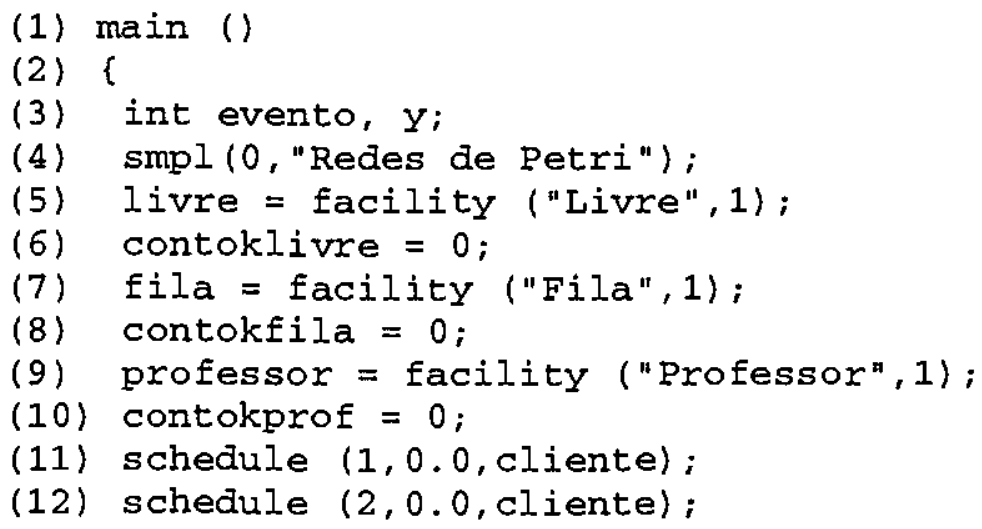

Figura 5.22: Inicialização das facilities em SMPL

Como foi visto no item anterior é preciso que os lugares tenham tokens indicando a situação do modelo no início da simulação, sejam escalonados todos os eventos que representam esses lugares no início do programa para que possa inicializar a simulação. Assim têm-se na figura 5.22 as seguintes operações:

$\rightarrow$ início do simulação (linha (4));

$\rightarrow$ criação das facilities livre, fila e professor com seus respectivos contadores de tokens (da linha (5) a linha (10));

$\rightarrow$ escalonamento dos eventos 1 e 2 (linhas(11) e (12)).

Nesse caso é reescalonado somente o lugar que representa a fila, o que representa o professor livre será reescalonado depois que da liberação do lugar professor livre, como mostra a figura 5.23:

(1) case $1: /$ * chegada dos alunos */

(2) schedule $(3,0.0,1)$;

(3) schedule (1, expntl (tcheg), aluno);

(4) break;

Figura 5.23: Código para a categoria 2. 
Nessa categoria também é necessário escalonar os dois primeiros eventos como na categoria anterior, mas com a diferença de que não é necessário escalonar novamente o evento 2. O evento 2 será escalonado somente quando o recurso se tornar livre.

$\rightarrow$ escalonamento do evento 3 que requisita a fila (linha (2));

$\rightarrow$ reescalonamento do evento 1 que representa a chegada de novos clientes (linha (3));

\subsection{Exemplo}

A simulação de uma arquitetura fluxo de dados apresentada na figura 5.24 representa o cálculo da expressão $e^{(x+y) / y}$. Para a representação desse exemplo têm-se que os lugares filax $\mathrm{e}$ filay representam a chegada de valores para $x$ e para $y$. Essa arquitetura possui um processador para executar a soma $(\mathrm{x}+\mathrm{y})$, um processador para a verificação de $y$, um para a divisäo $((\mathrm{x}+\mathrm{y}) / \mathrm{y})$ e outro para a exponenciação $e^{(x+y) / y}$. Nesse exemplo pode-se observar a presença das estruturas $1,3,4$.

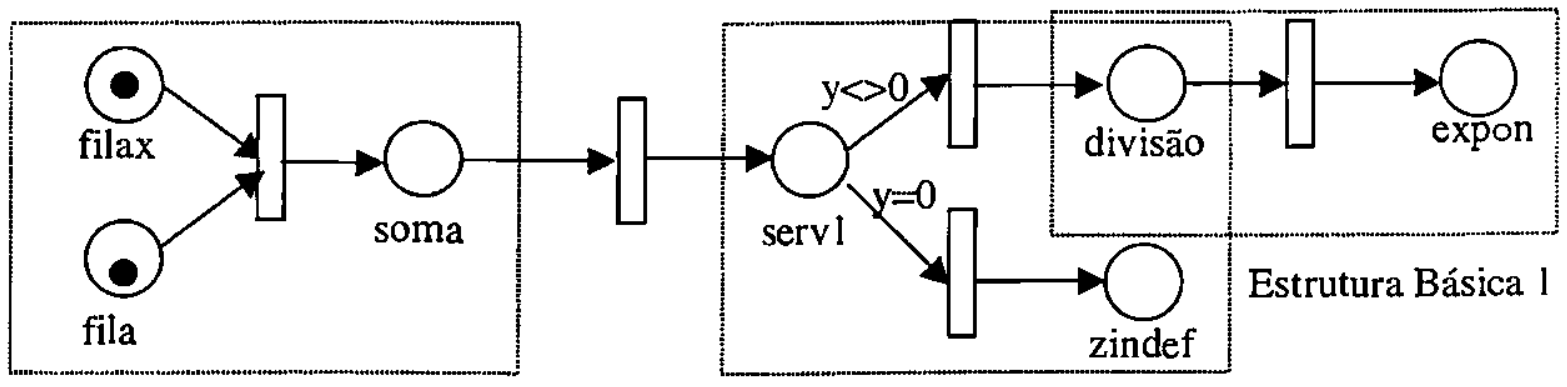

Estrutura Básica 4

Estrutura Básica 3

Figura 5.24: Arquitetura Fluxo de Dados

Simulação em SMPL para esse modelo é apresentado nessa seção. Em cada uma das figuras a seguir (de 5.25 a 5.30) serão explicados todos os passos para a construção do programa em SMPL. A figura 5.25 mostra o trecho de código do início do programa:

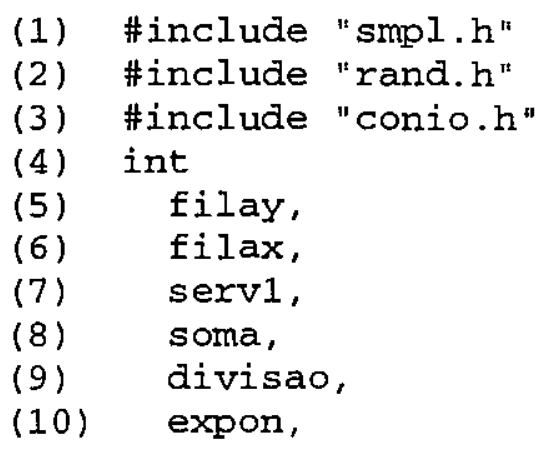




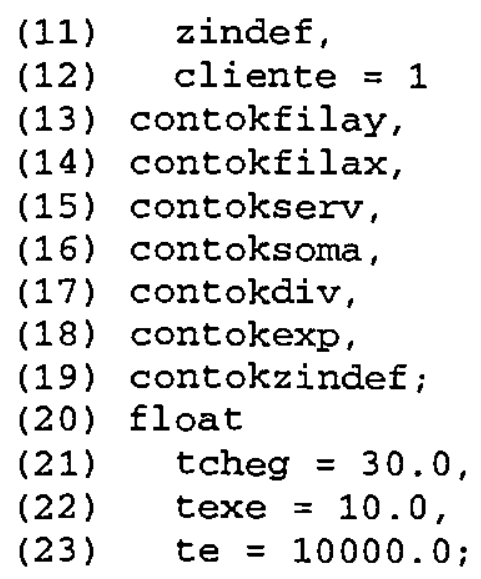

Figura 5.25: Inicialização do Programa e das Variáveis

Conforme apresentado na figura 5.24 são executadas as seguintes operações para a inicialização do programa (observar que os passos das inicializações coincidem com os estipulados na figura 5.18):

$\rightarrow$ inclusão das bibliotecas smpl.h e rand.h que possuem todas as funções da linguagem SMPL (linhas (1) e (2));

$\rightarrow$ inclusão da biblioteca conio.h que possui as funções de entrada e saída da linguagem C (linha (3));

$\rightarrow$ declaração das variáveis inteiras filax, filay, serv1, soma, divisão, expon, zindef, que receberão o descritor das respectivas facilities e representam cada um dos lugares da Rede de Petri (da linha (5) a linha (11));

$\rightarrow$ declaração e inicialização da variável inteira cliente que representa o token (entidade dinâmica que passeia pela rede). A variável é inicializada com o valor 1 por que temse somente um tipo de cliente (linha(12));

$\rightarrow$ declaração das variáveis inteiras contokfilax, contokfillay, contokserv, contoksoma, contokdiv, contokexp, contokzindef que representam os contadores de tokens de cada uma dos respectivos recursos (da linha (13) a linha (19));

$\rightarrow$ declaração e inicialização das variáveis que representam os tempos de chegada de cada cliente (tcheg), de execução em cada recurso (texe) e de execução total da simulação (te). Os valores iniciais de cada uma das variáveis são baseados em dados estatísticos (linhas (21), (22) e (23)). 
$\mathrm{Na}$ figura 5.26 são efetuadas as chamada das funções para iniciar o programa de simulação, criação dos recursos e escalonamento dos dois primeiros eventos, como já foi explicado anteriormente na estrutura 4 (figura 5.16).

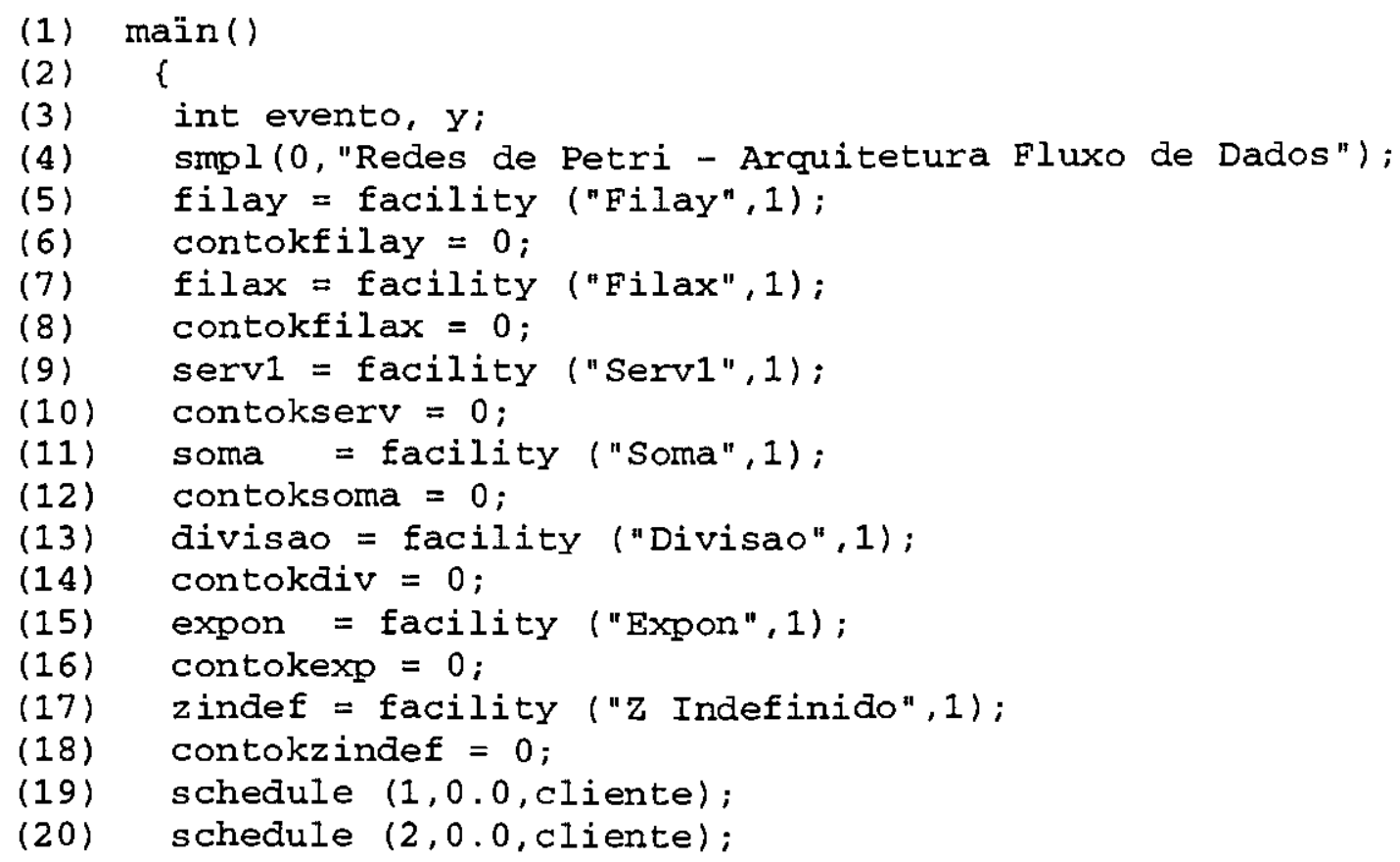

Figura 5.26: Início da função Principal do programa de Simulação.

Conforme visto na figura 5.26 têm-se as seguintes operaçōes para a criação dos recursos filax, filay, servl, soma, divisão, expon e zindef que representam cada um dos nós processadores:

$\rightarrow$ início da função principal do programa de simulação (linha (1));

$\rightarrow$ declaração das variáveis evento e y (linha (3));

$\rightarrow$ início do simulação (linha (4));

$\rightarrow$ criação das facilities filax, filay, serv1, soma, divisão, expon, zindef e seus respectivos contadores de tokens (da linha (5) a linha (18));

$\rightarrow$ escalonamento dos eventos 1 e $2($ linhas(19) e (20)).

Na figura 5.27 é apresentada a estrutura de repetição que é comandada pela variável te e em seguida tem-se o início da geração dos eventos, equivalente ao definido na figura 5.20 
(I) while (time() < te)

(2) $\quad$ i

(3) cause (\&evento, \&cliente);

(4) switch (evento)

\{

case 1: /* geração de $\mathrm{Y} * /$ schedule $(3,0.0$, cliente $)$; schedule ( 1 , expntl (tcheg), cliente); break;

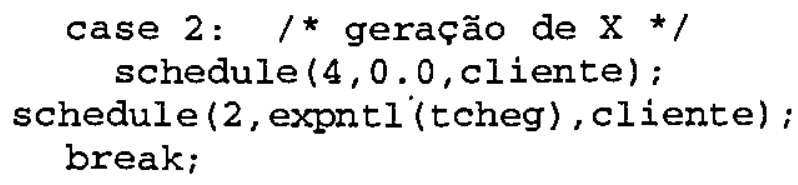

Figura 5.27: Código que representa a geração de $\mathrm{X}$ e $\mathrm{Y}$

Quando um evento é gerado isso significa que foi colocado um evento na lista de eventos futuros, como foi apresentado na figura 5.27 além das seguintes operações:

$\rightarrow$ início da estrutura de repetição while que é controlada pela função time( ) especificada na biblioteca smpl.h - e a variável te que representa o tempo máximo da simulação (linha(1));

$\rightarrow$ função cause que retira os eventos da lista de eventos futuros (linha (3));

$\rightarrow$ comando switch para selecionar o evento (linha(4));

$\rightarrow$ escalonamento do evento 3 para prosseguir a simulação (linha(7));

$\rightarrow$ escalonamento do evento 1 que representa a chegada do elemento $\mathrm{X}$ ao sistema (linha(8));

$\rightarrow$ escalonamento do evento 4 para prosseguir a simulação (linha (11));

$\rightarrow$ escalonamento do evento 2 que representa a chegada do elemento $\mathrm{Y}$ ao sistema $(\operatorname{linha}(12))$;

A figura 5.28 corresponde à parte tracejada da figura 5.24 descrita como estrutura básica 4 que foi explicada na seção 5.5 (figura 5.17):

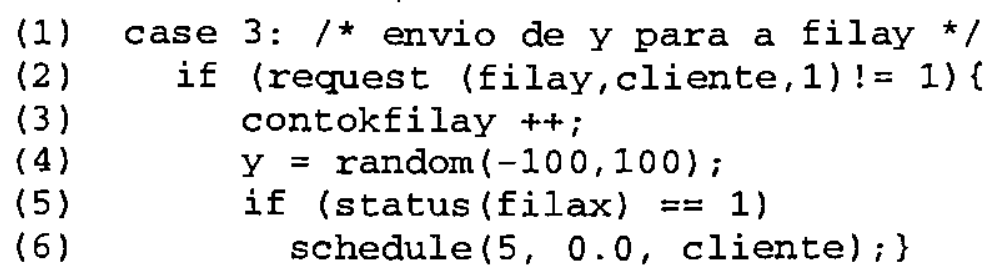




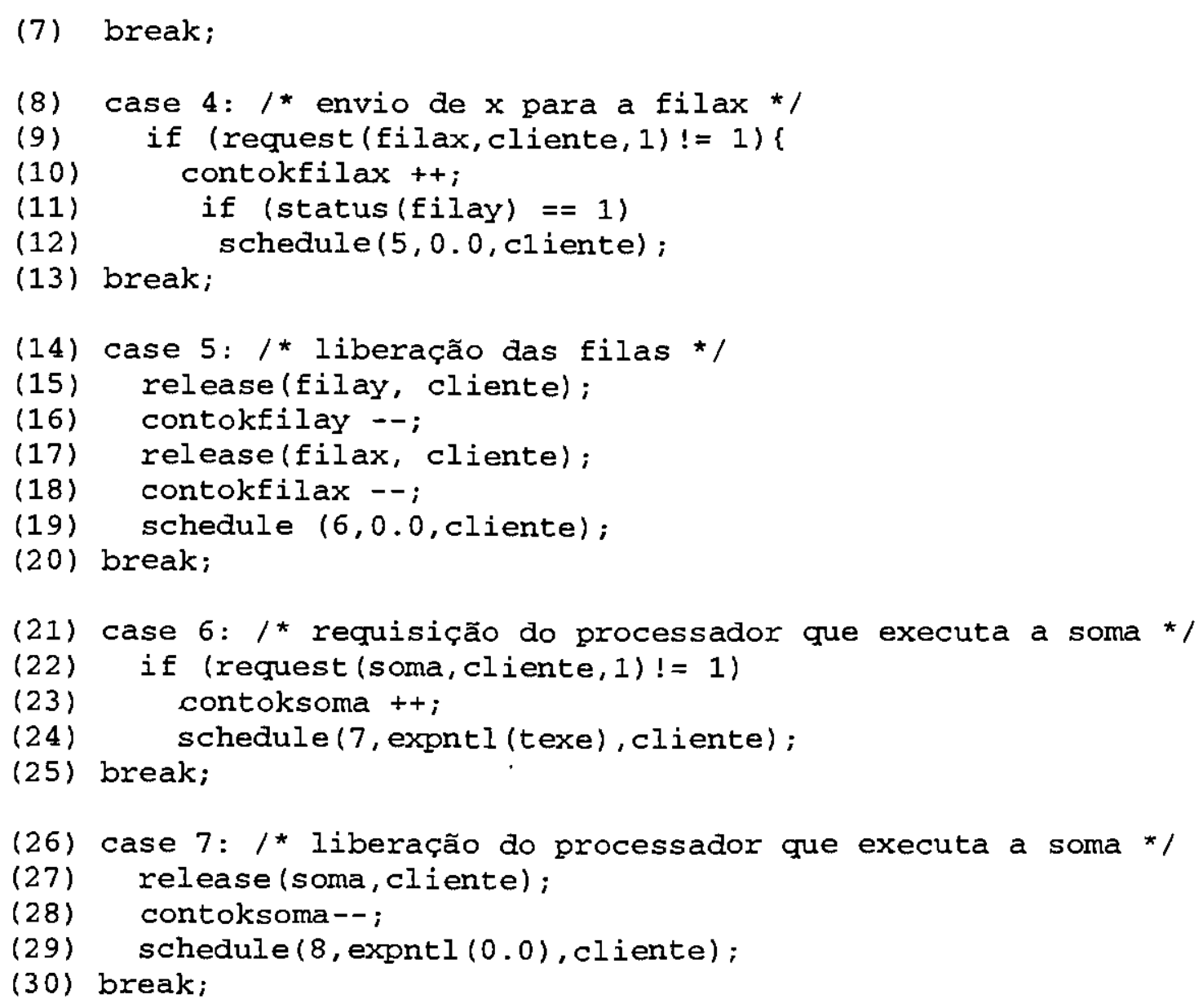

Figura 5.28: Envio de $\mathrm{X}$ e $\mathrm{Y}$ para suas respectivas filas.

O trecho de código descrito na figura 5.28 é explicado em detalhes a seguir:

$\rightarrow$ requisição do recurso filay e entrada do token que representa a presença do o elemento Y no sistema (linha (2));

$\rightarrow$ incremento do contador de tokens do recurso filay (linha (3));

$\rightarrow$ atribuição de um valor aleatório à variável y através da função random( ) que está especificada na biblioteca rand.h (linha (4));

$\rightarrow$ verificação do estado do recurso filax (linha (5));

$\rightarrow$ escalonamento do evento 5 no caso em que o recurso filax esteja ocupado (linha (6));

$\rightarrow$ requisição do recurso filax e entrada do token que representa a presença do o elemento $\mathrm{X}$ no sistema (linha (9));

$\rightarrow$ incremento do contador de tokens do recurso filax (linha (10)); 
$\rightarrow$ verificação do estado do recurso filay (linha (11));

$\rightarrow$ escalonamento do evento 5 no caso em que o recurso filay esteja ocupado (linha (12));

$\rightarrow$ liberação do recurso filax e saída do token (linha (15));

$\rightarrow$ decremento do contador de tokens (linha 16));

$\rightarrow$ liberação do recurso filay e saída do token (linha (17));

$\rightarrow$ decremento do contador de tokens (linha (18));

$\rightarrow$ escalonamento do evento 6 para prosseguir a simulação (linha (19));

$\rightarrow$ requisição do recurso soma que representa a operação matemática $(X+Y)$, entrada do token (linha (22));

$\rightarrow$ incremento do contador de tokens do recurso soma (linha (23));

$\rightarrow$ escalonamento do evento 7 para prosseguir a simulação (linha(24));

$\rightarrow$ liberação do recurso soma saída do token (linha (27));

$\rightarrow$ decremento do contador de tokens (linha (28));

$\rightarrow$ escalonamento do evento 8 para prosseguir a simulação (linha(29)).

Na figura 5.29 é apresentado o trecho do código correspondente à estrutura básica 3 explicada na seção 5.5 , a qual está em destaque na figura 5.24.

(1) case 8: /* requisição do processador que faz a verificação

(2) if (request (serv1, cliente, 1) !=1)

(3) schedule $(9,0.0$, cliente);

(4) contokserv ++;

(5) break;

(6) case 9: /* liberação do processador que faz a verificação de $y$ no caso em que $y$ é igual a zero */

(7) release (servl, cliente);

(8) contokserv --;

(9) if $(y==0)$

(10) schedule (10, expntl (texe), cliente);

(11) else

(12) schedule(12, expntl (texe), cliente);

(13) break;

(14) case 10: /* requisição do lugar que representa $z$ como indefinido * /

(15) if (request (zindef, cliente, 1$) !=1$ ) \{

(16) contokzindef ++; 
(17) schedule $(11,0.0$, cliente);

(18) break;

(19) case 11: /* liberação do lugar e final do programa */

(20) release (zindef, cliente);

(21) contokzindef --;

(22) break;

Figura 5.29 : Código equivalente a Estrutura Básica 3

Conforme visto na figura 5.29 têm-se as seguintes operações melhor explicadas a seguir:

$\rightarrow$ requisição do recurso servl que representa o processador que faz a verificação do valor atribuído a Y, entrada do token (linha(2));

$\rightarrow$ escalonamento do evento 9 (linha (3));

$\rightarrow$ incremento do contador de tokens do recurso servl (linha (4));

$\rightarrow$ liberação do processador servl e saída do token (linha(7));

$\rightarrow$ decremento do contador de tokens (linha (8));

$\rightarrow$ verificação do valor da variável y se esse valor for igual a zero então é executado o escalonamento do evento 10 , caso contrário escalona-se o evento 12 prosseguindo a simulação (da linha (9) a linha (12));

$\rightarrow$ requisição do recurso zindef que representa $\mathrm{Z}$ como um valor indefinido, pois não existe divisão por zero, entrada do token (linha (15));

$\rightarrow$ incremento do contador de tokens do recurso zindef (linha (16));

$\rightarrow$ escalonamento do evento 11 para prosseguir a simulação (linha(17));

$\rightarrow$ liberação do recurso zindef e término do programa de simulação saída do token (linha(20));

$\rightarrow$ decremento do contador de tokens (linha (21));

A figura 5.30 representa o final da estrutura básica 3 e início da estrutura básica 1 tracejadas na figura 5.24 .

(1) case 13:

(2) if (request (divisao, cliente, 1$) !=1)\{$

(3) contokdiv ++;

(4) schedule (14, expntl (texe), cliente); \} 


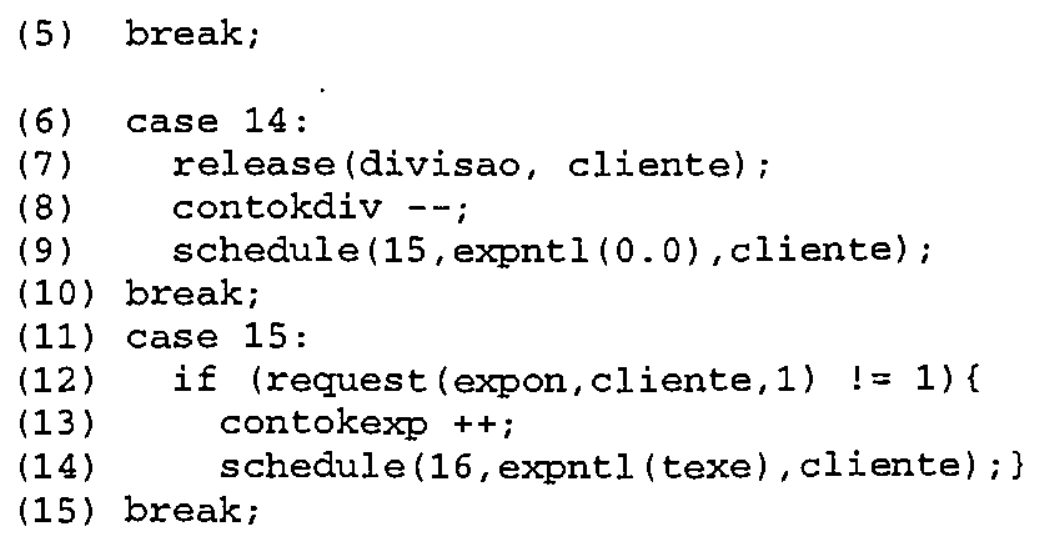

Figura 5.30: Código que faz a divisāo e exponenciação a expressăo.

Na figura 5.30 tem-se que o caso 13 marca o final da estrutura básica 3 e o início da estrutura básica 4 descritas na seção 5.5 e destacadas com linhas tracejadas na figura 5.24. As operações para essa parte do modelo são explicadas a seguir:

$\rightarrow$ requisição do recurso divisão responsável pela operação matemática $((\mathrm{X}+\mathrm{Y}) / \mathrm{Y})$ e entrada do token (linha (2));

$\rightarrow$ incremento do contador de tokens do recurso divisão (linha (3));

$\rightarrow$ escalonamento do evento 14 para prosseguir a simulação (linha (4));

$\rightarrow$ liberação do recurso divisão e saída do token (linha (7));

$\rightarrow$ decremento do contador de tokens (linha (8));

$\rightarrow$ escalonamento do evento 15 para prosseguir a simulação (linha (9));

$\rightarrow$ requisição do recurso expon que representa a exponenciação $(e(x+y) / y)$, entrada do token (linha (12));

$\rightarrow$ incremento do contador de tokens do recurso expon (linha(13));

$\rightarrow$ escalonamento do evento 16 para prosseguir a simulação (linha (14));

Na próxima seção será explicado como devem ser feitas as finalizações de um programa escrito em SMPL. 


\subsection{Finalizações do SMPL}

A finalização de um programa de simulação escrito em SMPL é apresentada na figura 5.31. O caso 16 representa o final da Estrutura Básica 1 e em seguida o final do programa:

(1) case 16: /* liberação do processador que executa a exponenciação */

(2) release(expon, cliente);

(3) contokexp --;

(4) break;

(5) $\}$

(6)\}

(7) report ();

(8)\}

Figura 5.31: Finalização de um Programa em SMPL

Conforme apresentado na figura 5.31 as seguintes operações foram executadas:

$\rightarrow$ liberação do recurso expon, saída do token (linha (2));

$\rightarrow$ decremento do contador de tokens do recurso expon (linha(3));

$\rightarrow$ finalização do comando switch (linha(5));

$\rightarrow$ finalização da estrutura de repetição while (linha(6));

$\rightarrow$ função report responsável pela impressão dos resultados da simulação (linha (7));

$\rightarrow$ final do programa de simulação (linha (8)).

\subsection{Comentários Finais}

Os modelos representados por Redes de Petri apresentam graficamente mais detalhes do que os representados por Redes de Filas. Redes de Petri possibilitam a representação de sistemas paralelos e concorrentes de forma mais clara e objetiva do que Redes de Filas. Portanto, as Redes de Petri mostraram-se mais flexíveis do que as Redes de Filas

Com os exemplos apresentados na seção 5.2 os quais foram representados tanto em Redes de Filas quanto em Redes de Petri, foi possível mostrar que sistemas modelados em Redes de Filas podem ser modelados em Redes de Petri. $O$ mesmo não acontece com no sentido 
oposto, embora alguns sistemas modelados em Redes de Petri podem ser modelados em Redes de Filas, em alguns casos.

Este capítulo mostrou que a extensão funcional SMPL, desenvolvida originalmente para uso com sistemas modelados em Redes de Filas, pode ser utilizada também para simular sistemas modelados em Redes de Petri.

Os exemplos estudados mostram que a simulação pode ser implementada sem a necessidade de qualquer alteração nas funções do SMPL. Isso pode ser válido para um número elevado de situações, mas não se tem uma demonstração final de que seja válido para todos os casos. 


\section{Capítulo 6}

\section{ALTERAÇÕES NECESSÁRIAS NO ASIA}

\subsection{Introdução}

No capítulo 5 foi demonstrada a possibilidade da utilização da linguagem SMPL para a simulação de sistemas modelados em Redes de Petri. Algumas alterações serão necessárias para viabilizar a introdução de Redes de Petri no ASiA. Desta forma, esse capítulo descreve as alterações a serem efetuadas em cada módulo do ASiA: Editor Gráfico, Gerador de Aplicações e Estágio de Saída.

O Editor Gráfico apresenta duas funçōes básicas. A primeira visa oferecer ao usuário uma interface gráfica, através da qual será introduzido o modelo a ser simulado. A seção 6.2 apresenta as alterações a serem efetuadas nesta interface gráfica.

A segunda função do Editor Gráfico é capturar as informações necessárias e organizá-las em arquivos que serão lidos pelo gerador de aplicações. A seção 6.3 apresenta as alterações nesta parte do módulo inicial do ASiA e avalia as alterações necessárias nos arquivos de dados.

O módulo do Gerador de Aplicações deve reconhecer os novos dados do arquivo de comunicação entre o Editor Gráfico e Gerador de Aplicações. A seção 6.4 apresenta as alterações necessárias neste módulo.

Uma vez que o SMPL continuará a ser utilizado, o módulo de saída provavelmente poderá ser integralmente aproveitado.

\subsection{Alterações na Interface Gráfica do Editor Gráfico}

A interface gráfica do Editor Gráfico do ASiA permite aos usuários especificar seu modelos em Redes de Filas como foi descrito no capítulo 4.

Para que os usuários possam especificar seus modelos utilizando Redes de Petri são necessárias algumas alterações na interface gráfica. Assim tem-se:

$\rightarrow$ alterações na barra de menus; 
$\rightarrow$ alterações na barra de ferramentas horizontal;

$\rightarrow$ criação de novos ícones na barra de ferramenta;

$\rightarrow$ alteração na barra de status;

$\rightarrow$ alteração nas caixas de dialogo.

\subsubsection{Criação de Novos Ícones na Barra de Ferramentas}

A Barra de ferramentas do ASiA é a parte do Editor Gráfico que deverá sofrer as maiores alterações.

A criação de novos ícones é necessária pois a representação gráfica de um sistema modelado em Redes de Filas é totalmente diferente da representação em Redes de Petri, conforme explicado no capítulo 5 .

Para uma melhor visualização das alterações necessárias a figura 6.1 apresenta a tela principal do ASiA com o Editor Gráfico para Redes de Filas e a figura 6.2 a tela do Editor Gráfico para Redes de Petri. 


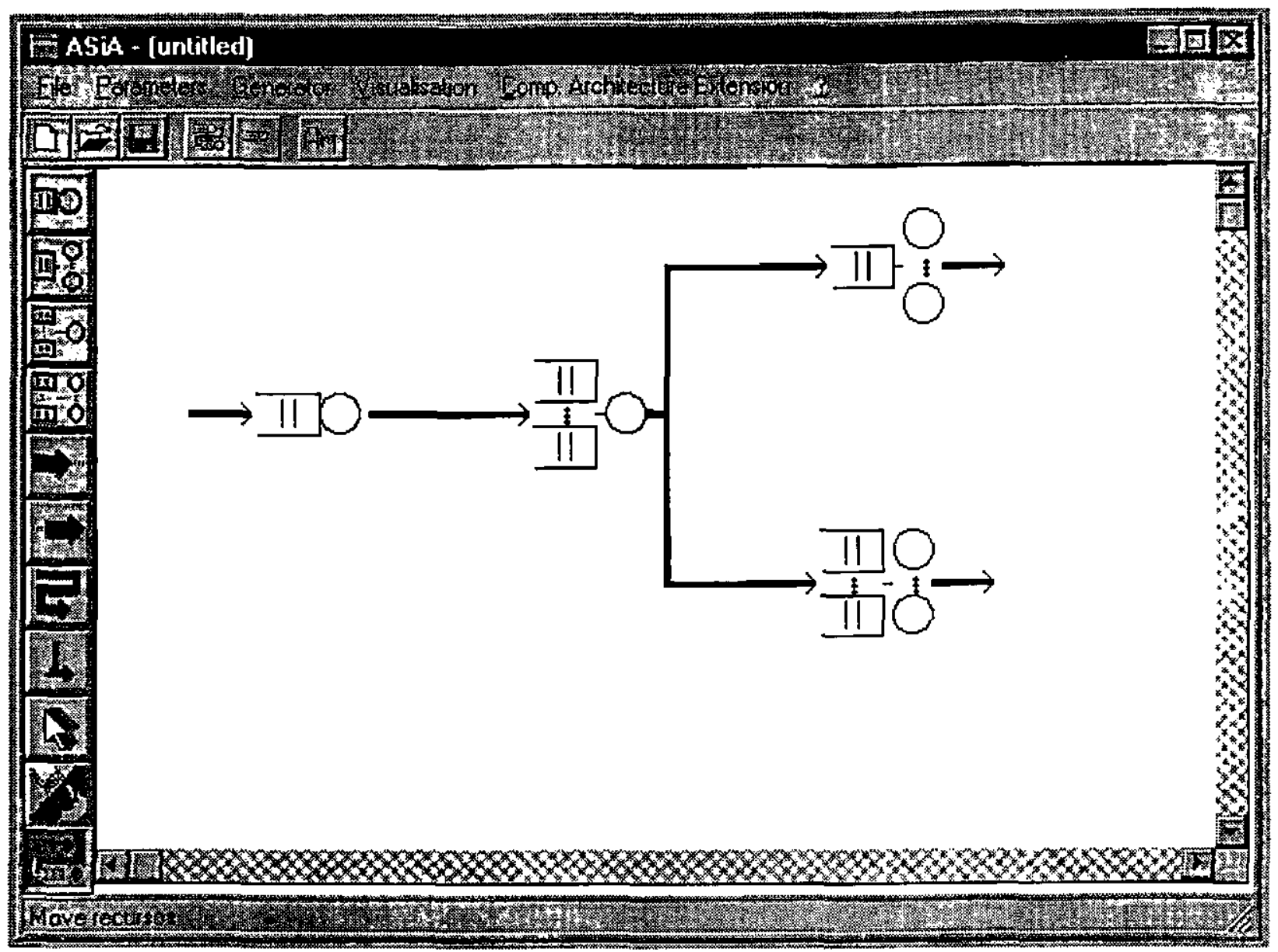

Figura 6.1: Editor Gráfico ASiA - Redes de Filas

Comparando-se a representação gráfica em Redes de Filas e Redes de Petri, observa-se que alguns botões devem ser substituídos. Os botões de centro de serviços com um ou mais servidores, com uma ou mais filas (os quatro primeiros botões da figura 6.1) devem ser substituídos por lugares e transições (dois primeiros botões da figura 6.2).

Os arcos que indicam o fluxo a ser seguido (botões 5 - 8 na figura 6.1) foram substituídos por um único botão (quarto da figura 6.2, que permite representação de ramificações, arcos iniciais, finais e ligações simples). Os botões destinados a apagar ou mover as diferentes figuras foram mantidos, adaptando-se alguns detalhes. 


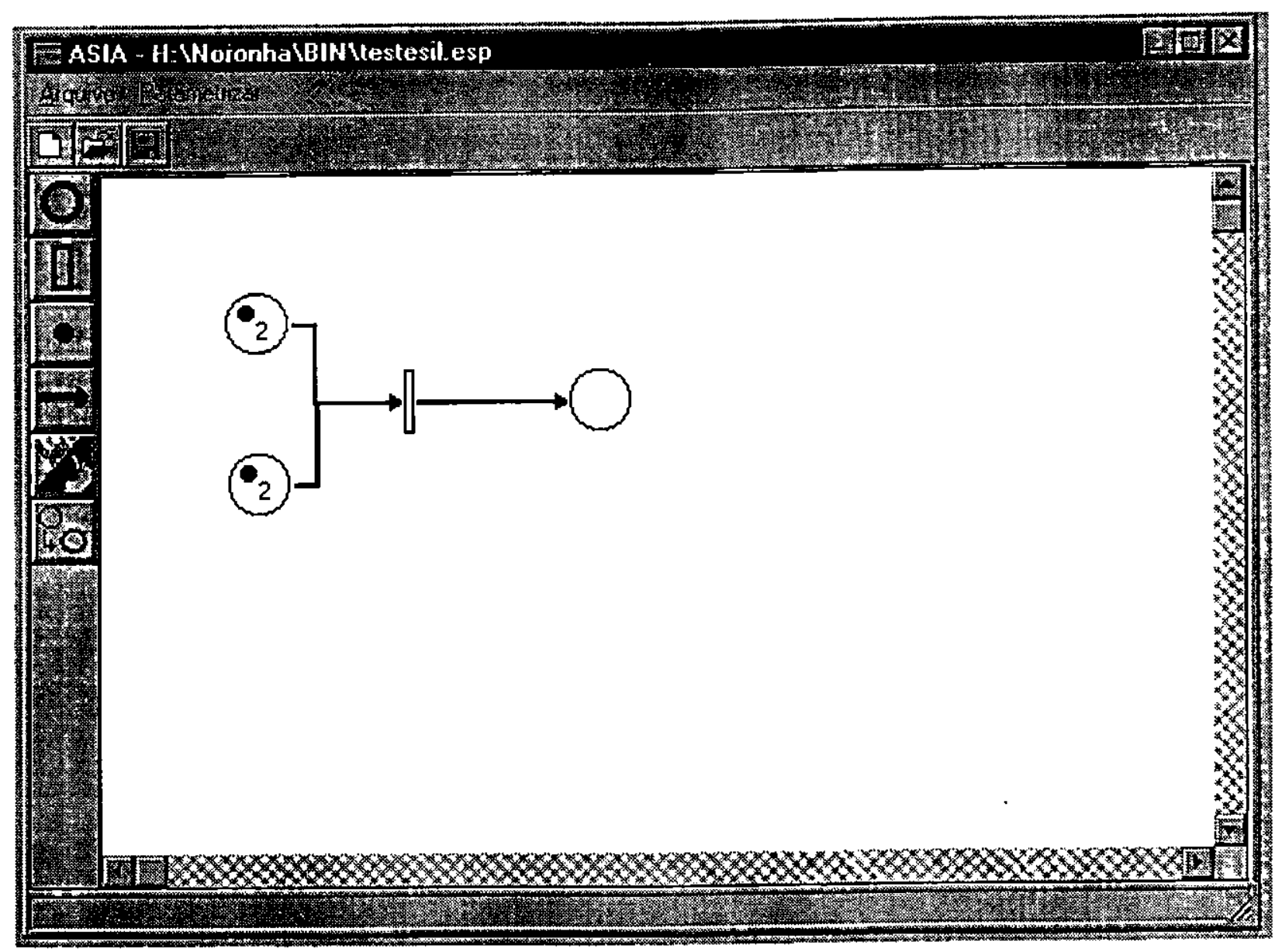

Figura 6.2: Editor Gráfico do ASiA- Redes de Petri.

Dessa forma a Barra de Ferramentas deverá possuir botões para representar:

$\rightarrow$ lugares;

$\rightarrow$ tokens, quando o modelo possuir mais que um token, será desenhado somente um e os demais serão indicados por números;

$\rightarrow$ transições;

$\rightarrow$ arcos;

E botões com as funções:

$\rightarrow$ borracha;

$\rightarrow$ mover os recursos de lugar.

Todas essas funções são consistentes, isto é, o Editor Gráfico não permite um arco ligando dois lugares ou ainda ligando duas transições. Caso aconteça algo desse tipo o usuário é 
informado através de uma mensagem avisando que não é possível ligar recursos de um mesmo tipo.

Utilizando-se o botão borracha para apagar um recurso do tipo lugar ou transição, também serão apagados os arcos que fazem as ligações entre esses recursos.

Também foi implementado o duplo pressionamento do botão esquerdo do mouse para que cada um dos botões da barra de ferramentas possam permanecer ativados até que outro botão seja acionado. Todas essa alterações foram implementadas pelos alunos Leonardo José Pupim e Paulo Robson Alexandre de Noronha do Grupo Pet do ICMC. Essas alterações foram implementadas utilizando a linguagem $\mathrm{C}$, usufruindo de programação API e desenvolvido para plataforma Windows 95.

\subsubsection{Alterações na Barra de Menus}

A estrutura da Barra de Menus do Editor Gráfico para Redes de Petri é apresentada figura 6.2:

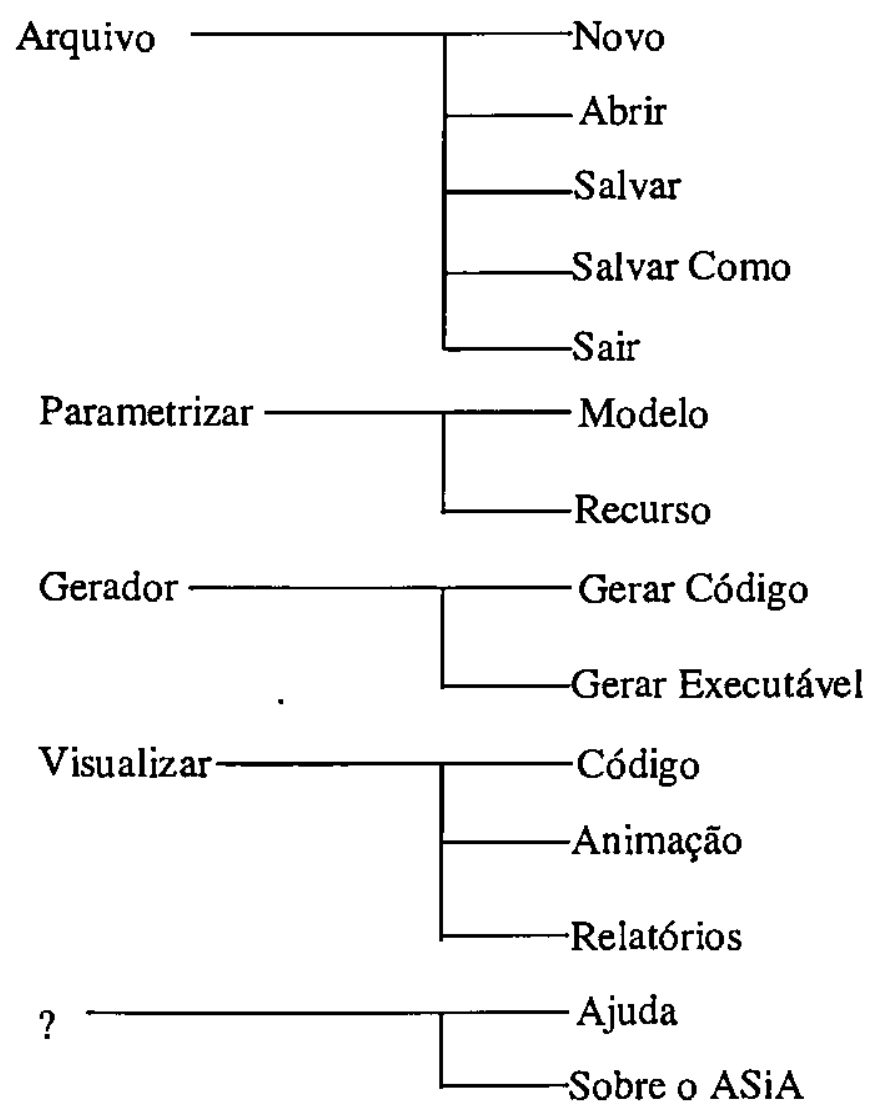

Figura 6.3: Estrutura da nova Barra de Menus do Editor Gráfico 
As funções implementadas pela Barra de Menus relaciona-se a manipulação de arquivos, parametrização dos modelos e recursos e recursos, gerador e visualização e ajuda conforme detalhado a segui:

$\rightarrow$ Funções para utilização de arquivos: criar um novo arquivo $(\mathrm{Ctrl}+\mathrm{N})$, abrir um arquivo já existente $(\mathrm{Ctrl}+\mathrm{A})$, salvar $(\mathrm{Ctrl}+\mathrm{S})$, salvar com outro nome e sair $(\mathrm{Ctrl}+\mathrm{R})$. Essas funções permanecerão inalteradas, uma vez que o conteúdo dos arquivos será alterado e não a sua manipulação;

$\rightarrow$ Parametrização dos recursos selecionados e do modelo. A parametrização de recursos continuará a existir e a ser acionada de forma idêntica. No entanto, a parametrização em si deve ser totalmente reformulada conforme discutido na seção 6.2.5;

$\rightarrow$ Geração do código e do programa executável. Essa função também não sofrerá alterações. Uma vez que o programa continuará a ser gerado em SMPL e continuará a possibilidade de visualizá-lo, modificá-lo e executá-lo a alteração que deverá ocorrer é no gerador de aplicações que será discutido na seção 6.3;

$\rightarrow$ Visualização do código gerado, de animação (ainda não disponível) e dos relatórios. Essa função também não sofrerá alterações. As alterações feitas no gerador de aplicações possibilitará que o programa seja gerado em SMPL e visualizado da mesma forma.

$\rightarrow$ Ajuda on - line. Toda a parte de ajuda relacionada com a edição de gráficos em Redes de Filas deverá ser alterada.

Para disponibilizar o Módulo de Arquitetura, acionado presente na barra de menu serão necessárias algumas alterações. A disponibilidade desse módulo implica na construção dos modelos utilizando Redes de Petri. Esse botão poderá estar disponível com a restrição de só ser utilizado em Redes de Filas.

\subsubsection{Alterações na Barra de Ferramenta Horizontal}

Sendo a barra de ferramenta horizontal um atalho da barra de menus esta sofrerá as mesma alterações da barra de menus, descrita na seção 6.2.2. 


\subsubsection{Alterações na Barra de Status}

A Barra de Status está localizada no final do editor e deverá informar aos usuários o que cada um dos botōes da Barra de Ferramentas representa ainda a função de cada um dos itens da Barra de Menus.

\subsubsection{Alteração nas Caixas de Dialogo}

As informações necessárias para a geração do código e do programa executável do sistema modelado são capturadas pelo Editor Gráfico através da parametrização dos recurso e do modelo. Essa parametrização é feita através das caixas de diálogo.

Como as informaçб̄es obtidas em um sistema modelado em Redes de Fila é diferente de um modelado em Redes de Petri, algumas das caixas de dialogo existentes no Editor Gráfico do ASiA devem ser modificadas para que o programa possa ser gerado de maneira correta obedecendo as regras de cada uma das técnicas de modelagem (Redes de Petri e Redes de Filas).

Os parâmetros dos centro de serviços das Redes de Filas devem ser subdivididos no parâmetros dos lugares e nos das transições.

A definição dos lugares requer os seguintes parâmetros:

$\rightarrow$ nome do lugar;

$\rightarrow$ tipo do lugar - recurso, fila, etc;

$\rightarrow$ distribuições dos tempos de chegada ao lugar - necessário caso as chegadas ao lugar não sejam alimentadas por uma transição;

$\rightarrow$ distribuição do tempo de serviço - caso o lugar represente um servidor;

$\rightarrow$ tio de disciplina da fila (FIFO, LIFO, etc...) - caso o lugar represente uma fila,

$\rightarrow$ quantidade de tokens existentes no recurso.

A definição de uma transição, requer parâmentros distintos dependendo do tipo de estrutura básica (definida na seção 5.5) a que pertence. Dessa forma, tem-se:

$\rightarrow$ Estrutura Básica I - não requer informação adicional;

$\rightarrow$ Estrutura Básica 2 - deve ser definido como será a decisão entre os lugares possíveis;

$\rightarrow$ Estrutura Básica 3 - deve ser definido quando um token no lugar de entrada irá ativar a transição; 
$\rightarrow$ Estrutura Básica 4 - não requer parâmetros adicionais.

É importante salientar que a definição do tipo de estrutura básica a qual a transição pertence, já é um parâmetro a ser definido.

Para definições dos tempos de serviço e de chegada, devem-se definir botões que quando acionados ativam outras caixas de dialogo. Este procedimento é necessário pois todos os tempos são especificados por distribuições estatísticas, a caixa de diálogo para os tempos de chegada e de serviço devem conter campos para definir as seguintes distribuições:

$$
\begin{aligned}
& \rightarrow \text { exponencial; } \\
& \rightarrow \text { hiperexponencial; } \\
& \rightarrow \text { triangular; } \\
& \rightarrow \text { erlang; } \\
& \rightarrow \text { uniforme; } \\
& \rightarrow \text { do usuário; }
\end{aligned}
$$

Estas caixas podem permanecer iguais as existentes no ASiA para Redes de Filas como apresentado respectivamente nas figuras 6.4 e 6.5 :

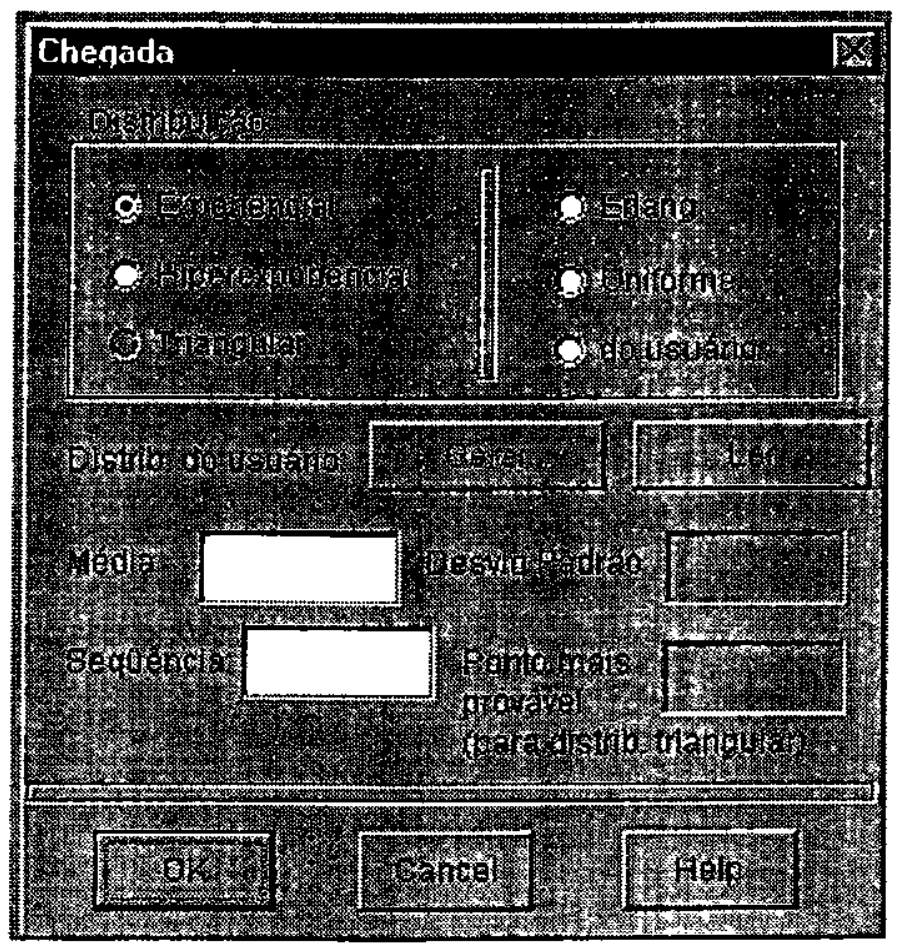

Figura 6.4 : Caixa de Dialogo para parametrização da Chegada do Recurso. 


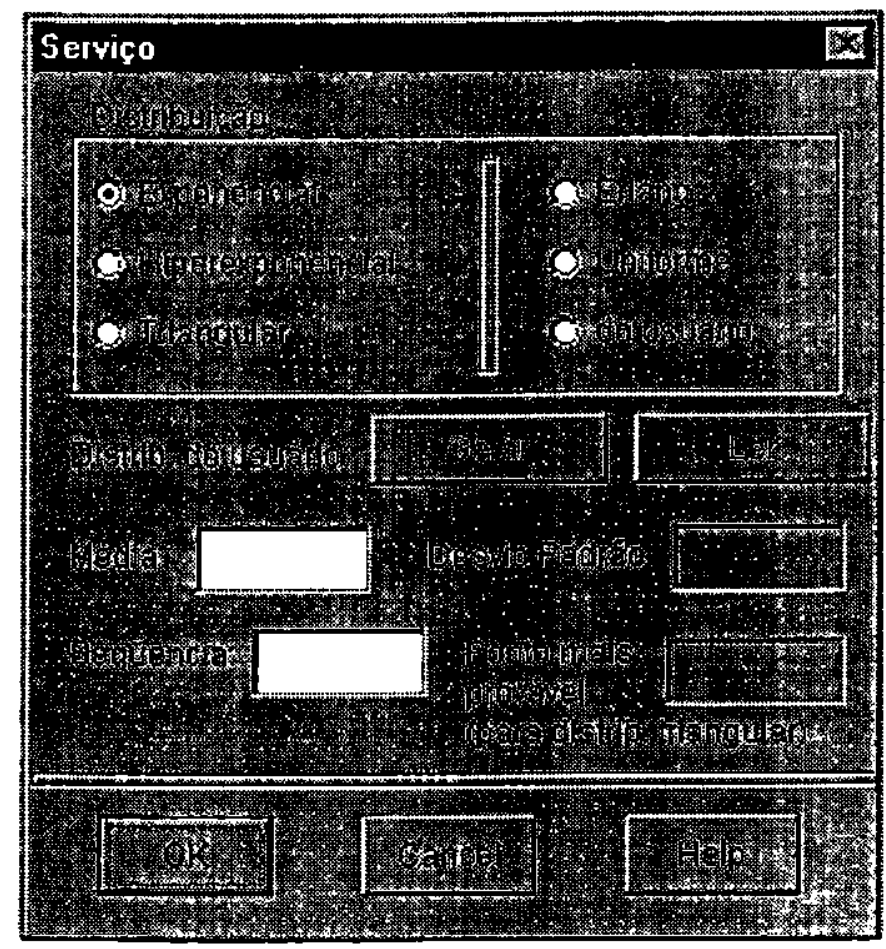

Figura 6.5: Caixa de Dialogo para parametrizaçăo do Tempo de Serviço do Recurso.

Também é preciso uma caixa de diálogo para as transições com campos que identificam os lugares de entrada e saída. Para os lugares de entrada é necessário saber se cada um deles possui pelo menos um token. E para os lugares de saída é necessário saber quantos são para que cada um possa receber um token.

A caixa de diálogo para a parametrização do modelo deve conter os seguintes campos a serem preenchidos pelos usuários:

$\rightarrow$ nome do modelo;

$\rightarrow$ tempo total de execução;

$\rightarrow$ tempo de warmup;

$\rightarrow$ primeira chegada;

$\rightarrow$ um campo para o usuário definir se deseja ou não o relatório final. 


\subsection{Alterações nos Arquivos de Informações para o Gerador de Aplicações.}

Como foi citado anteriormente as informaçōes necessárias para a geração do código e do programa executável no Editor Gráfico para Redes de Filas são primeiramente guardadas na memória em tabelas e depois transferidas a arquivos.

São criados 11 arquivos para cada sistema modelado com as seguintes extensões:

$\rightarrow$.out - para o relatório final;

$\rightarrow$.exe - para o programa executável;

$\rightarrow$.cpp - para o código;

$\rightarrow$.esp - para a especificação gráfica;

$\rightarrow$.lig - para guardar informações referentes as ligações dos recurso;

$\rightarrow$.mod - para guardar informações sobre o modelo;

$\rightarrow$.rec - para as informações de cada um dos recursos;

$\rightarrow$.eve - para informações sobre os eventos - é criado somente quando o modelo possuir looppings;

$\rightarrow$.lop - informações sobre os looppings;

$\rightarrow$.dis - quando utilizar distribuição tabela;

$\rightarrow$.arq - para o módulo de arquitetura.

Dos arquivos acima citados alguns devem permanecer como estão especificados (.out, .exe, .dis) outros deverão ser excluídos (.rec), os demais deverão ser alterados para os modelos em Redes de Petri (.cpp, .esp, .mod, .eve, .lop, .lig) além desses alguns deverão ser criado (.lug, .tra).

Os arquivos que serão criados deverão conter as seguintes informações:

$\rightarrow$.lug - informações sobre os lugares, tais como, nome, tempo de serviço, tempo de chegada;

$\rightarrow$.tra - informações sobre as transições, tais como, quantos lugares de entrada e de saída cada transição possui;

$\rightarrow$.lig - informações referentes as ligações, isto e, quais os lugares que estão sendo ligados por determinada ligação. 


\subsection{Alterações no Gerador de Aplicações}

Como o Gerador de Aplicações gera o programa através das informações contidas nos arquivos, uma vez esses arquivos alterados o gerador também deverá ser alterado.

Os programas são gerados através de um Gabarito que contém o esqueleto de um programa de simulação em SMPL. O código é copiado do gabarito para o programa final, enquanto os comandos precedidos pelo caracter \% determinam quais as primitivas do Gerador que devem ser executadas. Dependendo do identificador que sucede o caracter \%, um grupo de primitivas será considerada. A seqüência de primitivas executadas será definida pela análise dos dados contidos nas tabelas.

O Gabarito atual do ASiA é apresentado na figura 6.3 :

(1) \#include 〈dir.h>

(2) \#include <staio.h>

(3) \#include <conio.h>

(4) \#include "smpl.h"

(5) \#include "rand.h"

(6) \&Idistribuição_tabela

(7) $\operatorname{main}($ ) \{

(8) 80define_tempo_num_max

(9) int Event $=1$, Customer $=1$, Aleatorio;

(10) \&Agera_contadores_loop

(11) \&ldefine_variáveis

(12) \&2define_smpl

(13) \&3define_server

(14) 84 escalona_primeiro_evento

(15) \&Bgera_trace

(16) 85 gera_10op

(17) \{

(18) 8Gwarm_up

(19) $\% 6$ gera_cause

(20) 87 gera_switch

(21) 1

(22) 88 gera_eventos

(23))

(24) \}

(25) 89 gera_relatorio_padrão

(26) \%Cgera_relatorio_estatisticas_max_min

(27) \&Dgera_relatorio_estatistica_fila_vazia

Figura 6.6: Gabarito do ASiA para Redes de Filas

Cada um dos identificadores apresentados na figura 6.3 executa a chamada a uma função especificada no módulo Gerador de Aplicações assim tem-se: 
$\rightarrow$ inicialização do programa com a inclusão das bibliotecas dir.h, stdio.h, conio.h. smpl.h, e rand.h (da linha (1) a linha (5));

$\rightarrow$ verificação se o usuário definiu novas distribuições através da função Distrib_Tabela (linha (6));

$\rightarrow$ início do programa principal (linha(7));

$\rightarrow$ definição do tempo máximo de execução do programa de simulação através da função Define_Tempo_Max (linha(8));

$\rightarrow$ declaração e inicialização das variáveis inteiras Event, Customer e Aleatório (linha(9));

$\rightarrow$ geração de contadores através da função Gera_Contadores (linha(10));

$\rightarrow$ definição das variáveis (linha(11));

$\rightarrow$ execução da função Nome_Parametro que prepara o sistema de simulação e atribui nome ao modelo (linha (12));

$\rightarrow$ cria e atribui nome as facilities através da função Gera_Def_Server (linha(13));

$\rightarrow$ os eventos são escalonados antes do início da simulação através da função Gera_Primeiro_Evento (linha(14));

$\rightarrow$ execução da função Gera_Trace como ferramenta de depuração (linha(15));

$\rightarrow$ execução da função Gera_Loop que define o limite da simulação (linha(16));

$\rightarrow$ implementação de warmup através da função Warmup (linha(18));

$\rightarrow$ os eventos são causados através da execução da função Gera_Cause (linha(19));

$\rightarrow$ executa a função Gera_Switch (linha(20));

$\rightarrow$ os eventos que constituem a simulação são gerados pela função Gera_Eventos (linha(22));

$\rightarrow$ a função Gera_Relatorio_Final é executada para a apresentação dos relatórios finais (linha (25));

$\rightarrow$ o relatório de estatística do tempo máximo de execução é gerado através da função Gera_Relat_Est_Max_Min (linha(26));

$\rightarrow$ o relatório de estatísticas de filas vazias é gerado através da execução da função Gera_Relat_Fila_Vazia (linha (27)). 
O Gabarito do ASiA poderá permanecer o mesmo o que deve ser modificado são algumas das funções ativadas pelo Gerador de Aplicações.

Uma das diferenças entre um programa feito em SMPL para um sistema modelado em Redes de Petri e um sistema modelado em Redes de Filas está na inicialização do programa. Portanto as funções do Gerador de Aplicações que devem ser modificadas são aquelas que tratam da geração do primeiro evento e da declaração das variáveis:

$\rightarrow$ Gera_Primeiro_Evento. A principal modificação que deve ser feita nesta função é para que permita o escalonamento inicial de mais de um evento. Isso é necessário para a implementação das Estruturas Básicas 3 e 4 explicadas no Capítulo 5.

$\rightarrow$ Definição das variáveis. Para possibilitar a declaração das variáveis que representam os contadores de tokens de cada um dos lugares especificados no modelo.

$\rightarrow$ Os contadores de tokens devem ser incrementados no evento que efetua a requisição do recurso e decrementados no evento que efetua a liberação do mesmo recurso. A função do gerador que executará esse procedimento é a Gera_Eventos.

\subsection{Comentários Finais}

Nesse capítulo foram descritas as alterações necessárias no Editor Gráfico do ASiA para que seja possível modelar sistemas em Redes de Petri. Essas alterações no Editor Gráfico foram quase todas já implementadas como foi descrito nas seçōes 6.1 e 6.2.

Além das alterações necessárias no Editor Gráfico também são necessárias algumas alterações nos arquivos que contém as informações dos modelos parametrizados no Editor Gráfico os quais são utilizados pelo Gerador de Aplicações.

Também serão necessárias alterações em algumas funções utilizadas pelo Gerador de Aplicaçōes como foi descrito na seção 6.4 .

Com a implementação dessas alterações e a integralização do Editor Gráfico para Redes de Petri o ASiA poderá oferecer aos seus usuários a possibilidade de modelar e simular seus sistemas tanto em Redes de Petri como em Redes de Filas. 


\section{Capítulo 7}

\section{CONCLUSÕES}

\subsection{Comentários Finais Sobre a Revisão Bibliográfica}

Avaliação de desempenho de sistemas computacionais através de modelagem requer soluções de modelos que podem ser obtidas através de técnicas analíticas ou por simulação. Os modelos analíticos produzem os resultados com menor esforço computacional, porém oferecem pouca flexibilidade à medida que aumenta a complexidade do sistema. Simulação compreende uma ferramenta mais flexível do que técnicas analíticas, porém modelos de simulação são difíceis de validar e em alguns casos o esforço computacional necessário pode se muito grande [SPO94a].

Simulação tem sido usada para comparar e entender sistemas em diversos campos, constituindo uma metodologia para solução de modelos, isto é, constitui uma arte de capturar elementos essenciais e relações para formar modelos úteis, os quais descrevem e manipulam o comportamento do sistema [SWA95].

A formulação de modelos para simulação de sistema discretos é feita através de três abordagens: orientação a processos, a eventos e a atividades. Orientação a eventos é a mais adequada para sistemas de pequeno e médio porte, devido às simplificações que podem levar a uma perda da identidade do sistema modelado. $\mathrm{Na}$ orientação a processos existe uma grande correspondência entre o sistema real e o modelo, tornando essa abordagem adequada para modelos de maior porte [SPO94b].

Modelos podem ser descritos por ferramentas que possibilitam a representação de sistemas computacionais entre elas têm-se Redes de Petri e Redes de Filas. Ambas são ferramentas para a representação gráfica, o que facilita a visuralização do sistema modelado. Os modelos representados por Redes de Petri apresentam graficamente mais detalhes do que os representados por Redes de Filas. Redes de Petri possibilitam a representação de sistemas paralelos e concorrentes de forma mais clara e objetiva que Redes de Filas. 
Uma vez que as características essenciais do sistema a ser simulado estão representadas em um modelo, deve-se passar para uma segunda etapa que é a solução deste modelo através da solução de um conjunto de equações ou de um programa de simulação (que é a ênfase desta dissertação).

Para o desenvolvimento de um programa de simulação pode-se optar pela utilização de diferentes tipos de ferramentas: linguagens para simulação (GPSS, SIMULA, etc), pacote de simulação (Alpha/Sim, SIMPAC) ou extensões funcionais de linguagens de programação de proposito geral (SMPL,GASP, etc).

As extensões funcionais oferecem grande flexibilidade, uma vez que além das facilidades adicionadas pela extensão para simulação, pode-se ainda utilizar todas as ferramentas disponíveis na linguagem de programação utilizada.

Com o intuito de facilitar ainda mais o desenvolvimento de programa de simulação vêm sendo desenvolvidos ambientes de simulação que auxiliam usuários através de interfaces gráficas para definir o modelo a ser simulado e a geração automática do programa.

No grupo de Sistemas Distribuídos e Programação Concorrente vem sendo desenvolvido - ASiA (Ambiente de Simulação Automático) para modelagem e simulação de sistemas utilizando Redes de Filas.

\subsection{Comentários Finais Sobre o Trabalho Desenvolvido}

Conforme definido nos capítulos anteriores, o objetivo deste trabalho é comparar a utilização de Redes de Filas e de Redes de Petri para a representação de modelos para avaliação de sistemas computacionais e estudar a viabilidade de se utilizar Redes de Petri no ASiA.

A comparação entre Redes de Filas e Redes de Petri, para representação de modelos para avaliação de sistemas computacionais através de simulação, foi efetuada através do desenvolvimento de diversos exemplos, utilizando as duas técnicas. Com esses exemplos foi possível mostrar que sistemas modelados em Redes de Filas podem ser modelados em Redes de Petri. O mesmo não acontece no sentido oposto, embora alguns sistemas modelados em Redes de Petri possam ser modelados em Redes de Filas. 
Como as Redes de Petri fornecem uma técnica gráfica para modelagem torna-se mais fácil visualizar um maior número de detalhes do sistema modelado. Outra vantagem é que Redes de Petri foram desenvolvidas para modelar sistemas paralelos e atividades assíncronas.

Desta forma, conclui-se que as Redes de Petri oferecem mais flexibilidade e a possibilidade de representar um número maior de detalhes que as Redes de Filas. Por exemplo, a resolução do problema do jantar dos filósofos descrito na figura 3.16. Esse problema não pode ser resolvido por Redes de Filas pois essa técnica não foi desenvolvida para resolver problemas de deadlock, presente nesse exemplo quando todos os filosofos resolverem pegar os garfos para comer. Utilizando Redes de Petri esse problema é facilmente resolvido.

A vantagem que pode ser observada nas Redes de Filas é a possibilidade de uma representação mais concisa e de fácil entendimento. Ao observar-se um modelo de fila fica mais claro, o fluxo das informações, as filas, etc. Como por exemplo, o sistema modelado na figura 5.3 apresenta um sistema computacional simples que possui uma CPU um Disco e um Floppy. Nesse exemplo pode-se identificar as filas facilmente junto a cada um dos recursos o que não acontece na figura 5.4 onde para cada um dos recursos é necessário um lugar para representar a fila e outro para representar o recurso livre.

Quanto ao estudo da viabilidade de se introduzir a utilização de Redes de Petri no ASiA, alguns pontos devem ser destacados.

A utilização de SMPL para os dois casos (Redes de Filas e Redes de Petri) facilita a adaptação do ASiA. Assim, o primeiro passo foi verificar a viabilidade de se simular um sistema representado através de uma Rede de Petri em SMPL. Neste sentido diversos exemplos representados em Redes de Petri foram implementados utilizando-se SMPL. Assim, mostrou-se, através desses exemplos, que a extensão funcional SMPL, desenvolvida originalmente para uso de sistemas modelados em Redes de Filas, pode ser utilizada também para simular sistemas modelados em Redes de Petri, sem qualquer alteração nas suas funções.

Através dos exemplos implementados em SMPL foi possível ainda identificar as estruturas básicas da representação em Redes de Petri. Essas estruturas básicas possibilitaram definir as funções adicionais para que o Gerador de Aplicações do ASiA possa gerar programas de simulação em SMPL, a partir de uma Rede de Petri. Para que o ASiA possa suportar também sistemas modelados em Redes de Petri são necessárias ainda algumas alterações no Editor Gráfico, nos arquivos que contém as informações da parametrização dos modelos e em algumas funções utilizadas pelo Gerador de Aplicações. 


\subsection{Contribuições}

Baseando-se nos pontos discutidos na seção 7.2, é possível resumir as principais contribuições dessa dissertação como sendo:

$\rightarrow$ Comparação entre a representação de modelos de sistemas computacionais em Redes de Petri e em Redes de Filas, destacando as vantagens e desvantagens de cada um.

$\rightarrow$ Estudo da viabilidade de se simular um sistema representado em Redes de Petri utilizando SMPL.

$\rightarrow$ Definição das alterações a serem efetuadas no ASiA para suportar modelos em Redes de Filas e em Redes de Petri.

\subsection{Trabalhos Futuros}

A continuidade do trabalho desenvolvido nesta dissertação deve-se dar nas seguintes abordagens:

1. Implementação das alterações necessárias para suportar Redes de Filas e Redes de Petri definida neste trabalho. Dentre as alterações vale ressaltar:

$\rightarrow$ Criação de uma nova tela principal do ASiA na qual o usuário poderá escolher qual o tipo de modelagem que ele quer utilizar (Redes de Petri ou Redes de Filas);

$\rightarrow$ Alterar a função Gera_Primeiro_Evento para que essa possa permitir que vários recursos possam representar chegada de clientes;

$\rightarrow$ Alterações no Editor Gráfico para permitir a parametrização dos recursos e dos modelos;

$\rightarrow$ Alteração do Módulo de Arquitetura para suportar modelagem em Redes de Petri;

2. Realização de estudo similar ao apresentado neste trabalho visando a utilização de Statecharts no ASiA.

3. Comparação entre Redes de Filas e Redes de Petri para modelar sistemas que apresentam paralelismo. 


\section{REFERÊNCIAS BIBLIOGRÁFICAS}

[BAR91] BARTHOLOMIEU, BERNARD; DIAZ MICHEL, Modeling and Verification of Time Dependent Systems Using Time Petri Nets, IEEE Transactions on Softwear Engeneering, Março de 1991.

[BRE95] BRENNAN, J. E.; WALENTY, M. E.; MOORE, K. E., Simulating a UNIX Processor Using Petri Nets and ALPHA/SIM, Proceedings of the 1995 Summer Computer Simulation Conference, pp. 63-69, Ottawa, Ontario, Canadá, 24-26 de julho de 1995.

[BRU97] BRUSCHI, SARITA M., Extensão do ASiA para Simulaçāo de Arquiteturas de

Computadores. Dissertação de Mestrado - Instituto de Ciências Matemáticas de São Carlos Universidade de São Paulo, 1997.

[FER92] FERNANDES, M. M., Modelagem Análitica de Desempenho de Sistemas Multiprocessadores: Aplicação do Multiprocessador CPER. Dissertação de Mestrado Universidade Federal de São Carlos, 1992.

[HEU90] HEUSER, C. A., Modelagem Conceitual de Sistemas - Rede de Petri, V EBAI, 1990.

[LAK95] LAKOS, C. A. From Coloured Petri Nets to Object Petri Nets. Procceding fo 16th International Conference on Aplication and Theory of Petri Nets, Lectures Notes in Computer Science 1995.

[MAC87] MACDOUGALL, M. H., Simulating Computing Systems - Techiniques and Tools, The MIT Press, 1987.

[MAC96] MACIEL, P. R. M.; LINS, R. D. ; CUNHA, P. R. F.. Introdução às Redes de Petri e Aplicações. $10^{\mathfrak{a}}$ Escola de Computação- Julho de 1996

[MOL82]MOLLOY, M. K., Performance Analysis Using Stochastic Petri Nets. IEEE Transaction on Computers, Setembro de 1982.

[MO095a] MOORE, K. E.; BRENNAN, J. E, Petri Nets and Simulation: a Tutorial, Proceeding of the 1995 Summer Computer Simulation Conference, pp 45-50, Ottawa, Ontario, Canadá, 24-26 de julho de 1995.

[MOO95b] MOORE, K. E.; BRENNAN, J. E, ALPHA/SIM Simulation SoftwareTutorial, Proceeding of the 1995 Winter Computer Simulation Conference pp.387-394, Crystal City, 3-6 de dezembro de 1995. 
[MUR89] MURATA, T., Petri Nets: Properties, Analysis and Applications, Proceedings of the IEEE 77: 541,580,1989.

[NAI95] NAIK, VIJAY K, Performace of Parallel Benchmark LU on IBM SP Systems- IBM Research Report, 1995.

[NKE96] NKETSA, A., Analysis of Petri Nets With Objects by Means of Conservative Distributed Simulation, Proceding of the 1996 Summer Computer Simulation Conference, Portland, USA, 1996.

[ORL95] ORLANDI, R. C. G. S., Ferramentas para Análise de Desempenho de Sistemas Computacionais Distribuídos. Dissertação de Mestrado - Instituto de Ciências Matemáticas de São Carlos - Universidade de São Paulo, 1995.

[PIE98] PIEKARKI, A.E.T., Uma proposta de Reengenharia para o Ambiente de Simulação Automático (ASiA). Dissertação de Mestrado - Instituto de Ciências Matemáticas e de Computação, Universidade de São Paulo, São Carlos, 1998.

[SAN94] SANTANA, R. H. C.; ORLANDI, R. C. G. S.; SPOLON, R., CALÔNEGO JÚNIOR, N., Técnicas para avaliação de Desempenho de Sistemas Computacionais, Notas Didáticas do ICMSC N 14 , setembro de 1994.

[SAN96] SANTANA, R. H. C., Ambientes de Simulação Automático para modelamento $e$ análise de Sistemas Distribídos, Relatório Parcial do Projeto de Pesquisa CNPq, fevereiro de 1996.

[SAN96a] SANTANA, M. J.; SANTANA, R. H. C.; SPOLON, RENATA; SPOLON, ROBERTA, A Grafical User Interface for na Automatic Simulation System, Proceding of the 1996 Summer Computer Simulation Conference, pp 139-143 Portland, USA, 1996.

[SAN96b] SANTANA, M. J.; SANTANA, R. H. C.; SPOLON, RENATA; SPOLON, ROBERTA, Automatic Generation of Dicrete System Simulation Programs, Proceding of the 1996 Summer Computer Simulation Conference, pp 133-138 Portland, USA, 1996.

[SHA94] SHARP, OLIVER; BACON, F. DAVID, Measure for Measure. Byte, 1994

[SOA92] SOARES, L. F. G., Modelagem e Simulação Discreta de Sistemas, Editora Campus Ltda, 1992. 
[SPO94a] SPOLON, RENATA, Um Editor Gráfico para um Ambịente de Simulaçāo. Automático. Dissertação de Mestrado - Instituto de Ciências Matemáticas de São .Carlos Universidade de São Paulo, 1994.

[SPO94b] SPOLON, ROBERTA, Um Gerador de Aplicação para um Ambiente de Simulaçao Automático. Dissertação de Mestrado - Instituto de Ciências Matemáticas de São Carlos Universidade de São Paulo, 1994.

[SWA95] SWAIN, J. J., Simulation Survey: Tools for Process Undertanding and Improvement, ORMS Today, agosto 1995.

[WWW1] Petri Nets Tools Database, http://www.daimi.aau.dk/PetriNets/tools/quick.html 